Prepared in cooperation with the Bureau of Reclamation Glen Canyon Dam Adaptive Management Program

\title{
Monitoring Riparian Vegetation Composition and Cover Along the Colorado River Downstream of Glen Canyon Dam, Arizona
}

Chapter 14 of

Section A, Biological Science

Book 2, Collection of Environmental Data

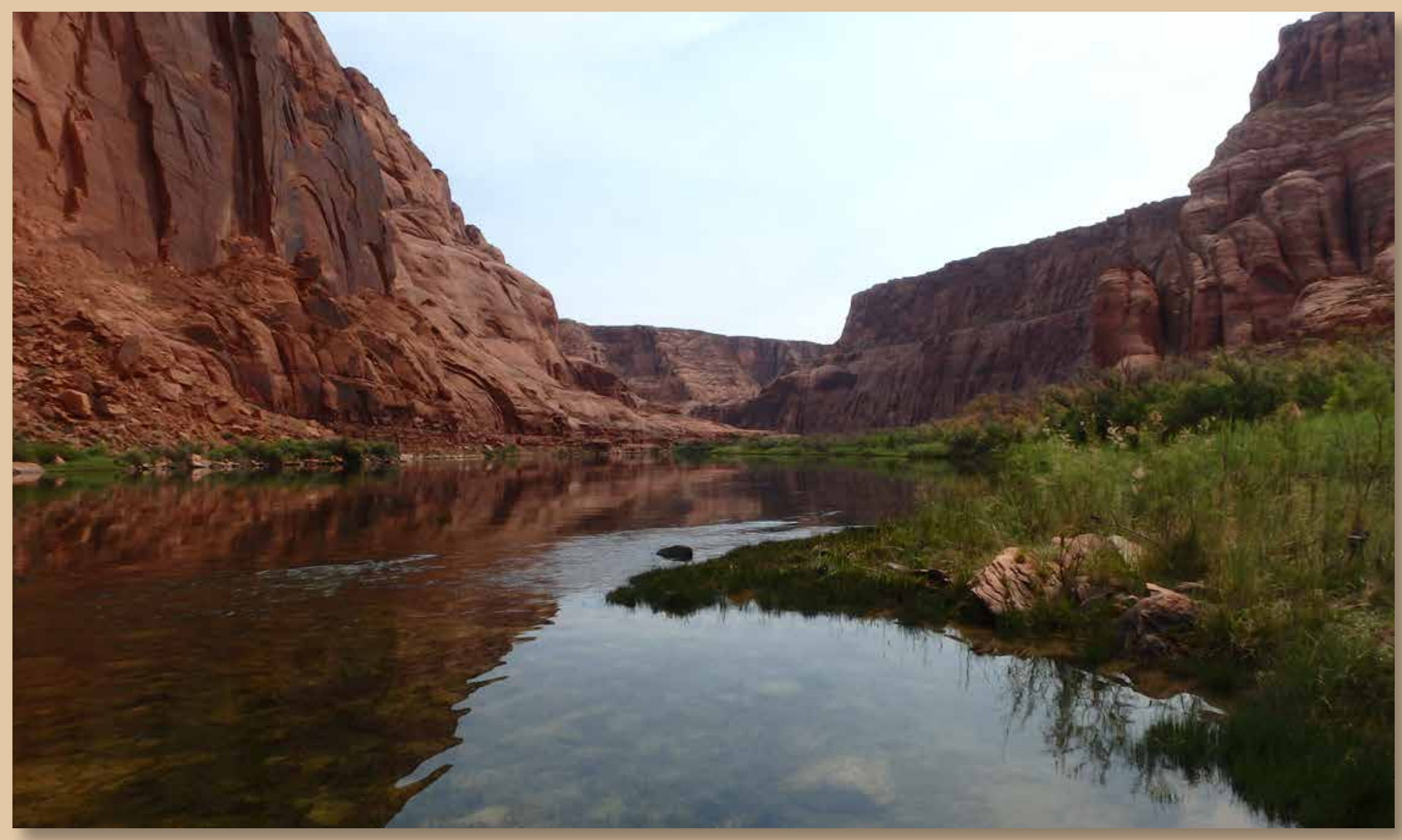

Techniques and Methods 2-A14 
Cover. Riparian vegetation along the Colorado River downstream of Glen Canyon Dam in Glen Canyon National Recreation Area, Arizona. Photograph by Emily Palmquist. 


\section{Monitoring Riparian Vegetation Composition and Cover Along the Colorado River Downstream of Glen Canyon Dam, Arizona}

By Emily C. Palmquist, Barbara E. Ralston, Daniel A. Sarr, and Taylor C. Johnson

Chapter 14 of

Section A, Biological Science

Book 2, Collection of Environmental Data

Prepared in cooperation with the Bureau of Reclamation Glen Canyon Adaptive Management Program

Techniques and Methods 2-A14 


\section{U.S. Department of the Interior RYAN K. ZINKE, Secretary}

\section{U.S. Geological Survey James F. Reilly II, Director}

\section{U.S. Geological Survey, Reston, Virginia: 2018}

For more information on the USGS - the Federal source for science about the Earth, its natural and living resources, natural hazards, and the environment-visit https://www.usgs.gov or call 1-888-ASK-USGS.

For an overview of USGS information products, including maps, imagery, and publications, visit https://store.usgs.gov.

Any use of trade, firm, or product names is for descriptive purposes only and does not imply endorsement by the U.S. Government.

Although this information product, for the most part, is in the public domain, it also may contain copyrighted materials as noted in the text. Permission to reproduce copyrighted items must be secured from the copyright owner.

Suggested citation:

Palmquist, E.C., Ralston, B.E., Sarr, D.A., and Johnson, T.C., 2018, Monitoring riparian-vegetation composition and cover along the Colorado River downstream of Glen Canyon Dam, Arizona: U.S. Geological Survey Techniques and Methods, book 2, chap. A14, 65 p., https://doi.org/10.3133/tm2A14.

ISSN 2328-7055 (online) 


\section{Acknowledgments}

Thank you to the Northern Colorado Plateau Network Inventory and Monitoring Program, particularly Dusty Perkins and Katrina Lund, for assistance and collaboration on methods and data collection. Thanks to Mike Scott, Dave Merritt, Pat Shafroth, Mike Duniway, John Spence, Julian Scott, and Todd Chaudry for input on the sampling methods and data collection.

This work was supported by the Bureau of Reclamation Glen Canyon Dam Adaptive Management Program —Agreement number R15PG00030 — with logistical and managerial support from the U.S. Geological Survey Grand Canyon Monitoring and Research Center.

\section{Contents}

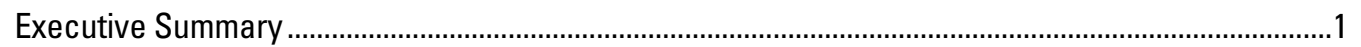

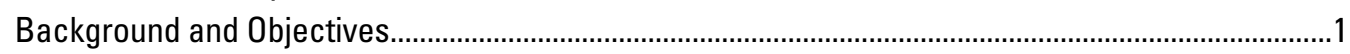

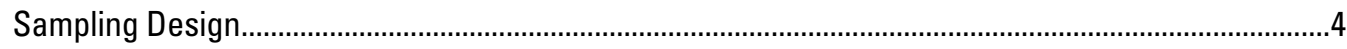

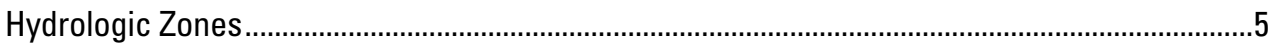

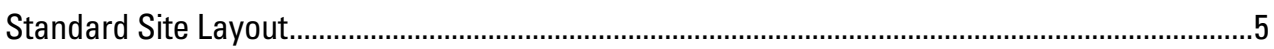

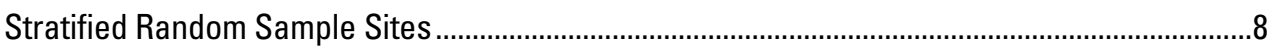

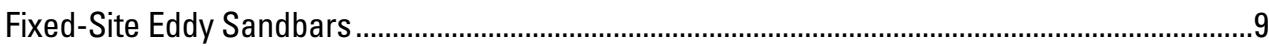

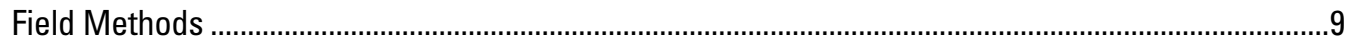

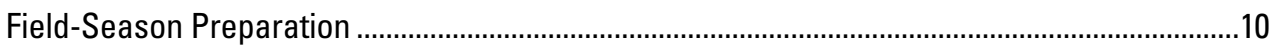

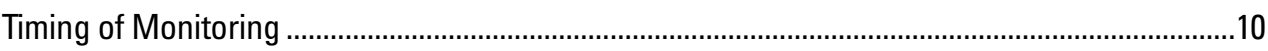

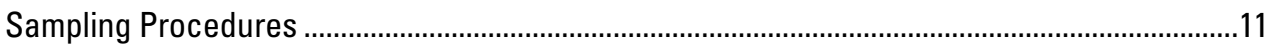

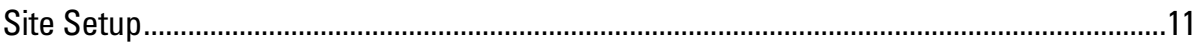

Site Photographs ...............................................................................................................11

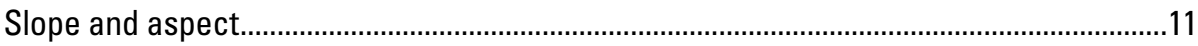

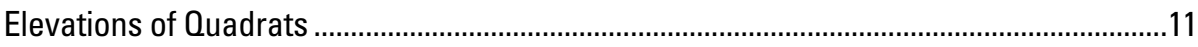

Estimating Species and Ground Cover .........................................................................12

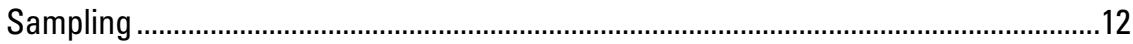

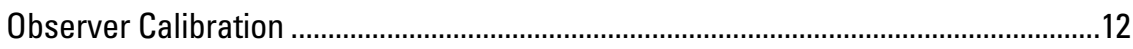

Collecting and Pressing Unknown Species......................................................................12

When Not to Sample a Site ................................................................................................

Data Management, Analysis, and Reporting ...................................................................................

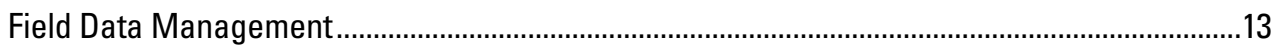

Office Data Management.....................................................................................................

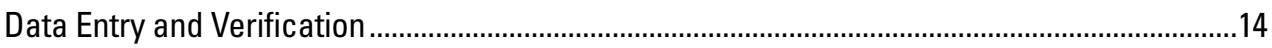

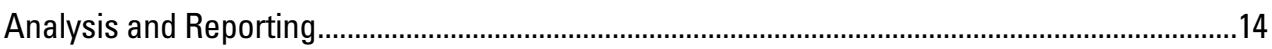

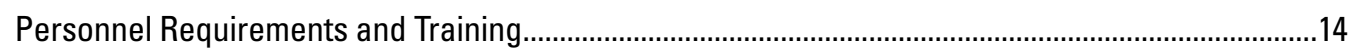

List of Standard Operating Procedures ....................................................................................

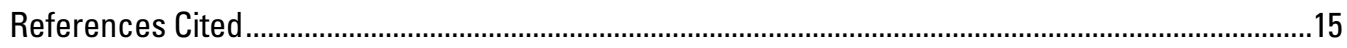

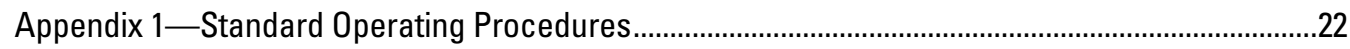

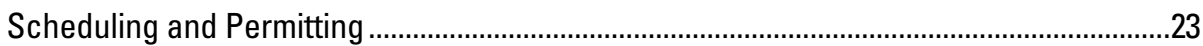

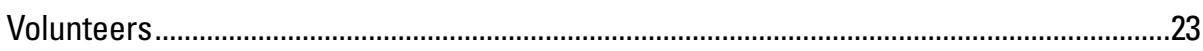

SOP1—Preparations for the Field Season and Equipment Needed ...........................................23 
Random Samples and Random Numbers..........................................................................2

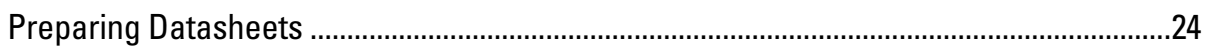

Preparing Reference Materials and Maps .......................................................................24

Preparing Field Equipment ..............................................................................................24

Travel Authorizations and Timesheets ..............................................................................26

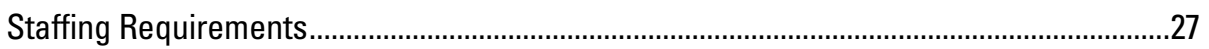

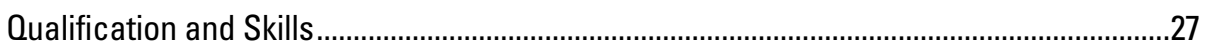

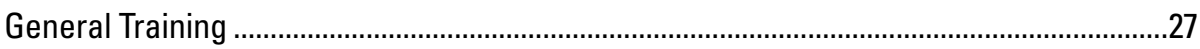

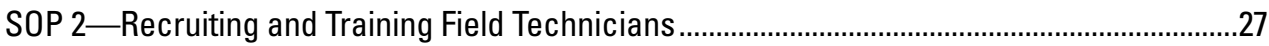

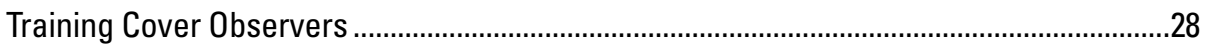

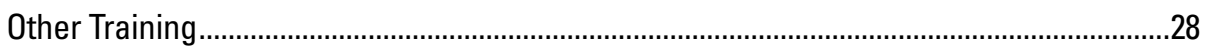

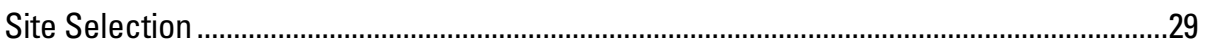

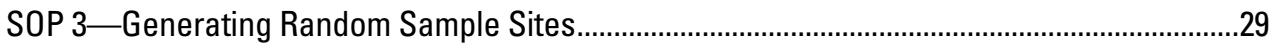

Sampling Site Criteria Attribution ......................................................................................

Standard Layout ..............................................................................................................

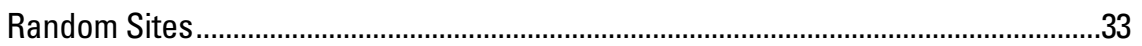

SOP 4-Setting Up the Transects and Quadrats ……………...................................................3

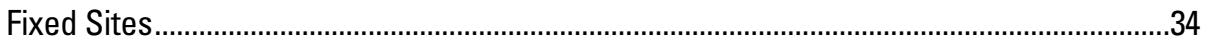

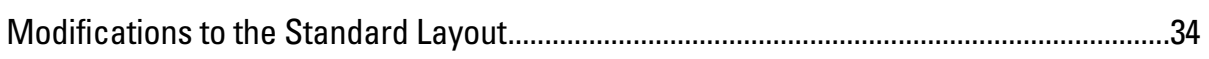

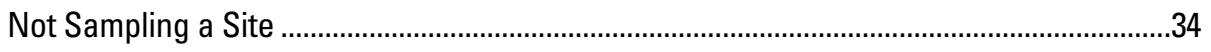

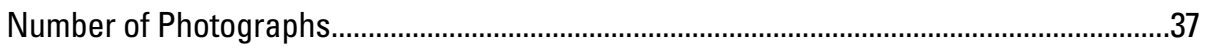

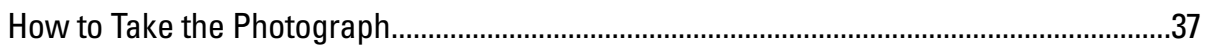

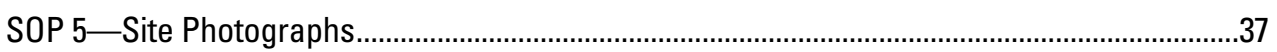

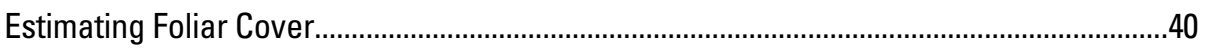

SOP 6 - Vegetation and Ground-Cover Sampling.................................................................4

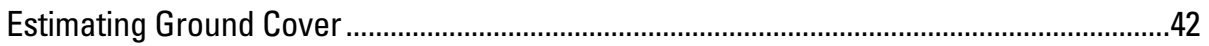

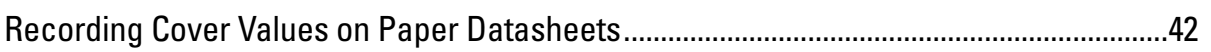

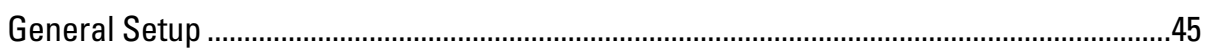

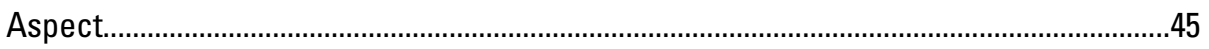

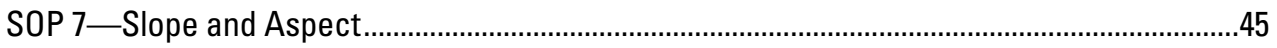

Slope

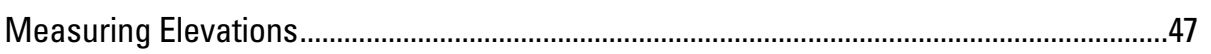

SOP 8-Measuring Quadrat Elevations..................................................................................

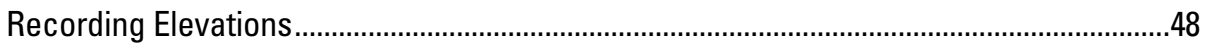

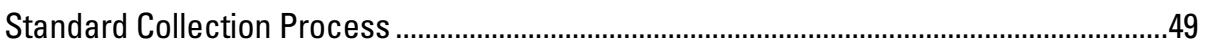

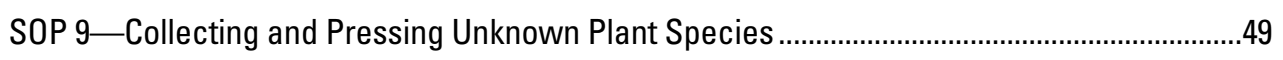

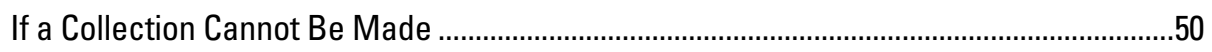

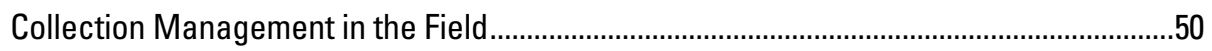

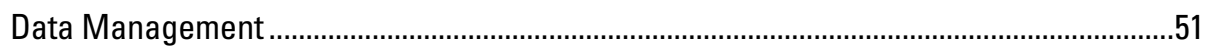

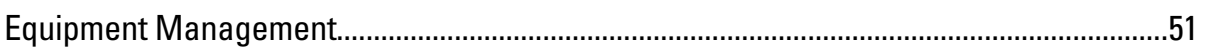

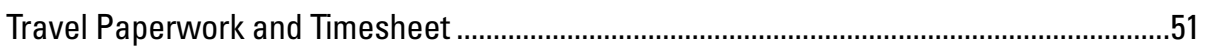

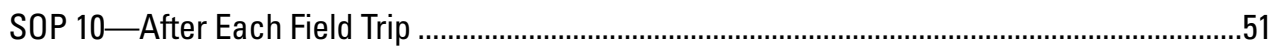

Field Equipment.

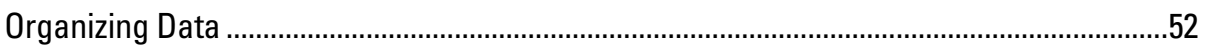

Unknown Plant Collections ..........................................................................................52

SOP 11—After the Field Season............................................................................................. 


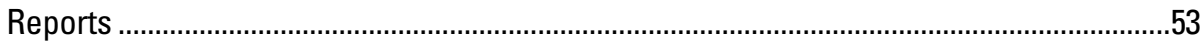

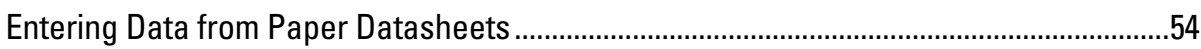

Verifying Data Entered from Paper Datasheets ................................................................54

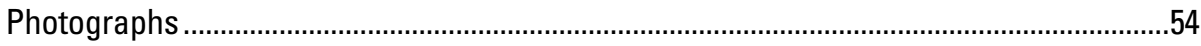

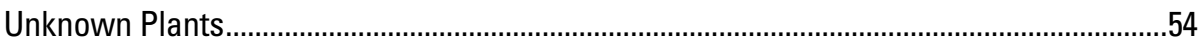

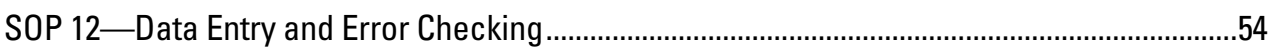

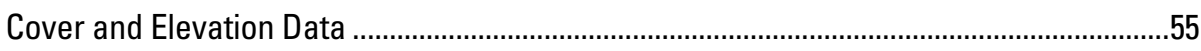

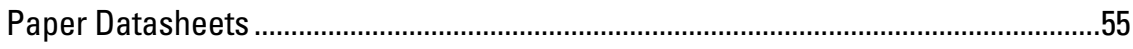

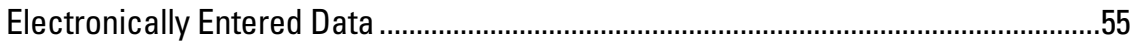

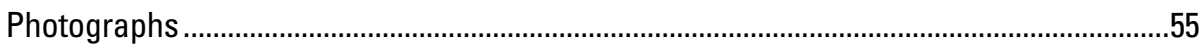

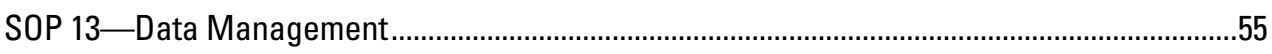

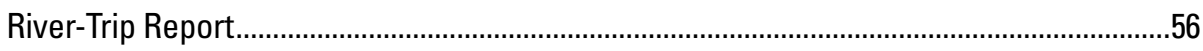

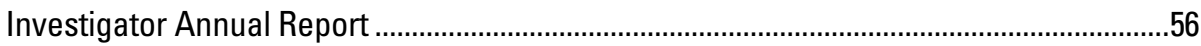

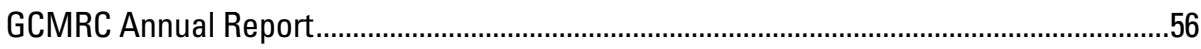

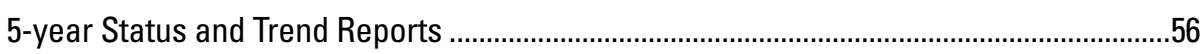

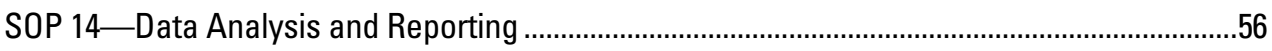

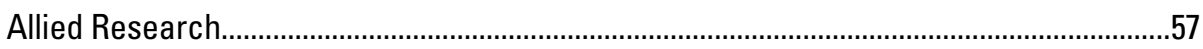

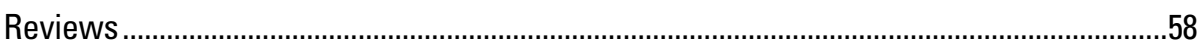

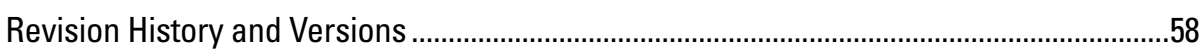

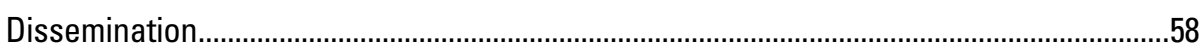

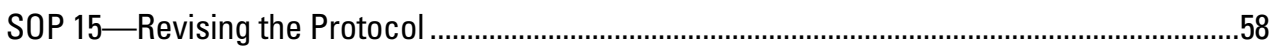

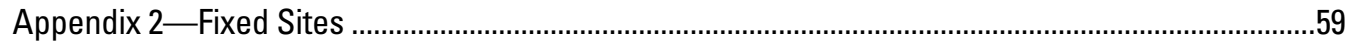

Appendix 3 -Datasheets ..................................................................................................61

Appendix 4-Example Random Sampling Schedule .........................................................................64

\section{Figures}

1. Map of the study area, which includes the riparian area between Glen Canyon Dam and river mile 240

2. Aerial photograph of a riparian-vegetation monitoring site on the Colorado River in Arizona between Glen Canyon Dam and Lake Mead

3. Diagram showing transect placement in a standard site setup for monitoring of riparian vegetation along the Colorado River in Arizona between Glen Canyon Dam and Lake Mead.7

4. Diagram showing quadrat placement in a standard site setup for monitoring of riparian vegetation along the Colorado River in Arizona between Glen Canyon Dam and Lake Mead.7

5. Diagram showing alternative quadrat placement for monitoring of riparian vegetation in a hydrologic zone that is less than 5 meters wide along the Colorado River in Arizona between Glen Canyon Dam and Lake Mead.

6. Aerial image showing an example of the ArcGIS based sampling frame for randomly selected sites for monitoring of riparian vegetation along the Colorado River in Arizona between Glen Canyon Dam and Lake Mead.

S1.1. Example of the random number sheet for selecting random transects at sites for monitoring riparian vegetation along the Colorado River in Arizona between Glen Canyon Dam and Lake Mead.

S3.1. Screenshot of Environment Settings window within the Calculate Field tool in ArcGIS....30

S3.2. Screenshot of the Calculate Field window showing inputs for "Expression," "Expression Type," and "Code Block" in ArcGIS version 10.2. 
S3.3. Screenshot of Saving Data window in ArcGIS version 10.2

S4.1. Aerial photograph showing example transect placement in a standard site setup for monitoring of vegetation composition and cover along the Colorado River in Arizona between Glen Canyon Dam and Lake Mead.

S4.2. Diagram showing quadrat placement in a standard site, where all hydrologic zones are wider than 5 meters, for monitoring of vegetation composition and cover along the Colorado River in Arizona between Glen Canyon Dam and Lake Mead...

S4.3. Diagram showing alternative quadrat placement in a hydrologic zone for monitoring of vegetation composition and cover that is less than 5 meters wide along the Colorado River in Arizona between Glen Canyon Dam and Lake Mead ...

S5.1. Example of a well-taken, downstream photograph for monitoring riparian vegetation along the Colorado River in Arizona between Glen Canyon Dam and Lake Mead .... .37

S5.2. Example of a well-taken downstream photograph for monitoring riparian vegetation along the Colorado River in Arizona between Glen Canyon Dam and Lake Mead ..

S5.3. Example of a poorly taken photograph for monitoring riparian vegetation along the Colorado River in Arizona between Glen Canyon Dam and Lake Mead..

S5.4. Example of a well-taken transect photograph for monitoring riparian vegetation along the Colorado River in Arizona between Glen Canyon Dam and Lake Mead.

S5.5. A series of problematic photographs for monitoring riparian vegetation along the Colorado River in Arizona between Glen Canyon Dam and Lake Mead..

S6.1. Photographs showing examples of estimating cover when plants are sparse rather than dense along the Colorado River in Arizona between Glen Canyon Dam and Lake Mead...

S6.2. Image of the foliar and ground cover datasheet used for monitoring riparian vegetation along the Colorado River in Arizona between Glen Canyon Dam and Lake Mead ..

S7.1. Diagram showing how slope and aspect of a geomorphic feature are measured when monitoring riparian vegetation along the Colorado River in Arizona between Glen Canyon Dam and Lake Mead.

S7.2. Photograph showing an orienteering compass of the type used when monitoring riparian vegetation along the Colorado River in Arizona between Glen Canyon Dam and Lake Mead.

S7.3. Photograph showing the view through the eye piece of a clinometer when measuring the slope of a geomorphic feature when monitoring riparian vegetation along the Colorado River in Arizona between Glen Canyon Dam and Lake Mead..

S8.1. Photograph of crewmembers measuring the height of a quadrat above the water's edge during monitoring riparian vegetation along the Colorado River in Arizona between Glen Canyon Dam and Lake Mead.

S8.2. Image of part of the site sheet datasheet on which the elevations are recorded during monitoring riparian vegetation along the Colorado River in Arizona between Glen Canyon Dam and Lake Mead.

A3.1. Images show front and back of the "site specifics" datasheet for random sites used for riparian-vegetation monitoring along the Colorado River in Arizona between Glen Canyon Dam and Lake Mead.

A3.2. Front image of the "site specifics" datasheet for fixed sites used for riparian-vegetation monitoring along the Colorado River in Arizona between Glen Canyon Dam and Lake Mead

A3.3. Example foliar cover and ground cover datasheet for random sites used for riparianvegetation monitoring along the Colorado River in Arizona between Glen Canyon Dam and Lake Mead 


\section{Tables}

1. Hydrologic zones used to stratify sampling during monitoring of riparian vegetation along the Colorado River in Arizona between Glen Canyon Dam and Lake Mead .5

2. River segments identified to stratify random sampling for monitoring of riparian vegetation along the Colorado River in Arizona between Glen Canyon Dam and Lake Mead.. 9

3. Cover classes for riparian foliar and ground-cover estimates made along the Colorado River in Arizona between Glen Canyon Dam and Lake Mead ................................................... 13

4. Cover types and their definitions used for monitoring of riparian vegetation along the Colorado River in Arizona between Glen Canyon Dam and Lake Mead.

S1.1. The following field equipment is required for sampling of riparian vegetation along the Colorado River in Arizona between Glen Canyon Dam and Lake Mead.

S3.1. River segments identified to stratify random sampling when monitoring riparian vegetation along the Colorado River in Arizona between Glen Canyon Dam and Lake Mead..

S3.2. Graphic information system (GIS) layers used to stratify random sampling for monitoring riparian vegetation along the Colorado River in Arizona between Glen Canyon Dam and Lake Mead.

S6.1. Cover types for estimating foliar cover along the Colorado River in Arizona between Glen Canyon Dam and Lake Mead

S6.2. Cover classes for riparian foliar and ground-cover estimates made along the Colorado River in Arizona between Glen Canyon Dam and Lake Mead

S6.3. Ground-cover elements and their definitions used for monitoring riparian vegetation along the Colorado River in Arizona between Glen Canyon Dam and Lake Mead

S14.1. Time frames and responsibilities for required reports on riparian-vegetation monitoring along the Colorado River in Arizona between Glen Canyon Dam and Lake Mead...

S14.2. Minimum summaries included in each Grand Canyon Monitoring and Research Center annual report on riparian-vegetation monitoring along the Colorado River in Arizona between Glen Canyon Dam and Lake Mead.

A2.1. Table of fixed site eddy sandbars sampled annually for riparian-vegetation monitoring along the Colorado River in Arizona between Glen Canyon Dam and Lake Mead..

A4.1. Example schedule for riparian-vegetation monitoring along the Colorado River in Arizona between Glen Canyon Dam and Lake Mead.

A4.2. Example of final participants list for riparian-vegetation monitoring along the Colorado River in Arizona between Glen Canyon Dam and Lake Mead 


\section{Conversion Factors}

U.S. customary units to International System of Units

\begin{tabular}{lcl}
\hline \multicolumn{1}{c}{ Multiply } & By & \multicolumn{1}{c}{ To obtain } \\
\hline inch (in.) & 25.4 & millimeter $(\mathrm{mm})$ \\
inch (in.) & 2.54 & centimeter $(\mathrm{cm})$ \\
foot (ft) & 0.3048 & meter $(\mathrm{m})$ \\
mile (mi) & 1.609 & kilometer $(\mathrm{km})$ \\
cubic foot per second $\left(\mathrm{ft}^{3} / \mathrm{s}\right)$ & 0.02832 & cubic meter per second $\left(\mathrm{m}^{3} / \mathrm{s}\right)$ \\
acre & 0.4047 & hectare $(\mathrm{ha})$ \\
\hline
\end{tabular}

International System of Units to U.S. customary units

\begin{tabular}{|c|c|c|}
\hline Multiply & By & To obtain \\
\hline millimeter (mm) & 0.03937 & inch (in.) \\
\hline centimeter $(\mathrm{cm})$ & 0.3937 & inch (in.) \\
\hline meter $(\mathrm{m})$ & 3.281 & foot $(\mathrm{ft})$ \\
\hline kilometer (km) & 0.6214 & mile (mi) \\
\hline cubic meter per second $\left(\mathrm{m}^{3} / \mathrm{s}\right)$ & 35.31 & cubic foot per second $\left(\mathrm{ft}^{3} / \mathrm{s}\right)$ \\
\hline hectare (ha) & 2.471 & acre \\
\hline
\end{tabular}

\section{Datum}

Vertical coordinate information is referenced to the National Geodetic Vertical Datum of 1929 (NGVD1929).

Horizontal coordinate information is referenced to the North American Datum of 1983 (NAD83). Altitude, as used in this report, refers to distance above the vertical datum. 


\section{Abbreviations}

$\begin{array}{ll}\text { AC } & \text { active channel } \\ \text { AF } & \text { active floodplain } \\ \text { BSC } & \text { biological soil crust } \\ \text { GCMRC } & \text { USGS Grand Canyon Monitoring and Research Center } \\ \text { GIS } & \text { geographic information system } \\ \text { GLCA } & \text { Glen Canyon National Recreation Area } \\ \text { GRCA } & \text { Grand Canyon National Park } \\ \text { GS } & \text { General Schedule } \\ \text { IAR } & \text { investigator annual report } \\ \text { IF } & \text { inactive floodplain } \\ \text { NAU } & \text { Northern Arizona University } \\ \text { NCPN } & \text { Northern Colorado Plateau Network Inventory and Monitoring program } \\ \text { NPS } & \text { National Park Service } \\ \text { PFD } & \text { personal flotation device } \\ \text { RM } & \text { river mile } \\ \text { SBSC } & \text { USGS Southwest Biological Science Center } \\ \text { SOP } & \text { standard operating procedure } \\ \text { USGS } & \text { U.S. Geological Survey }\end{array}$





\title{
Monitoring Riparian Vegetation Composition and Cover along the Colorado River downstream of Glen Canyon Dam, Arizona
}

\author{
By Emily C. Palmquist, Barbara E. Ralston, Daniel A. Sarr, and Taylor C. Johnson
}

\section{Executive Summary}

Vegetation in the riparian zone (the area immediately adjacent to streams, such as stream banks) along the Colorado River downstream of Glen Canyon Dam, Arizona, supports many ecosystem and societal functions. In both Glen Canyon and Grand Canyon, this ecosystem has changed over time in response to flow alterations, invasive species, and recreational use. Riparianvegetation cover and composition are likely to continue to change as these pressures persist and new ones emerge. Because this system is a valuable resource that is known to change in response to flow regime and other disturbances, a long-term monitoring protocol has been designed with three primary objectives:

1. Annually measure and summarize the status (composition and cover) of native and non-native vascular-plant species within the riparian zone of the Colorado River between Glen Canyon Dam and Lake Mead.

2. At 5-year intervals, assess change in vegetation composition and cover in the riparian zone, as related to geomorphic setting and dam operations, particularly flow regime.

3. Collect data in a manner that can be used by multiple stakeholders, particularly the basinwide monitoring program overseen by the National Park Service's Northern Colorado Plateau Network Inventory and Monitoring program.

A protocol for the long-term monitoring of riparian vegetation is described in detail and standard operating procedures are included herein for all tasks. Visual estimates of foliar and ground covers are collected in conjunction with environmental measurements to assess correlations of foliar cover with abiotic and flow variables. Sample quadrats are stratified by frequency of inundation, geomorphic feature, and by river segment to account for differences in vegetation type. Photographs of sites are also taken to illustrate qualitative characteristics of the site at the time of sampling. Procedures for field preparation, generating random samples, data collection, data management, collecting and managing unknown species collections, and reporting are also described. Although this protocol is intended to be consistent over the long-term, procedures for minor and major revisions to the protocol are also outlined.

\section{Background and Objectives}

The Colorado River system downstream of Glen Canyon Dam, Arizona, including both Glen Canyon and Grand Canyon, is ecologically and culturally important (fig.1). As a large river in a semiarid landscape, this stretch of river greatly increases regional biodiversity (Gregory and others, 1991; Naiman and Decamps, 1997; Sabo and others, 2005), provides key habitat for migratory and resident wildlife (Brown, 1989; Holmes and others, 2005; Ralston, 2005), and harbors culturally important species (Fairley, 2005). Additionally, it offers over 20,000 boaters per year a unique wilderness experience (National Park Service, 2006). The biological and cultural services this system supports are susceptible to changes in the cover and composition of vegetation in the riparian zone (the area immediately adjacent to streams, such as stream banks). Climate change, altered disturbance regimes (for example, regulated flow), invasive plant and animal species, and recreational impacts are all potential sources of vegetation change. Adaptive management of the river for its services depends on resource monitoring that includes a means to track riparian condition over time, using repeatable methods.

The Grand Canyon is known for being particularly botanically rich (Phillips and others, 1987) and the riparian corridor has a similar potential. Gradients in elevation, geology, geomorphology, floristic influence, and disturbance all contribute to creating a highly variable landscape. This area is situated on the edge of the Colorado Plateau where three North American deserts meet - the Great Basin, the Mojave, and the Sonoran (Warren and others, 1982). Thus, all three deserts contribute floristic elements to this landscape, creating unusual species assemblages (Brown, 1982; Phillips and others, 1987; Palmquist and others, 2018). Elevation in this region is a strong driver of vegetation shifts (Phillips and others, 1987; Palmquist and others, 2018), and the river drops approximately 590 meters (m) along its course from Glen Canyon Dam to the western boundary of Grand Canyon National Park (GRCA). Geology and geomorphology also contribute to vegetation distributions. The Grand Canyon is known for its diversity of substrates, and the Colorado River in the canyon has relatively clearly defined geomorphological units, particularly alluvial fans, eddy sandbars, and channel-margin deposits. These geomorphic units have distinctive parent materials, particle sizes, and drainage and moisture holding characteristics, which 


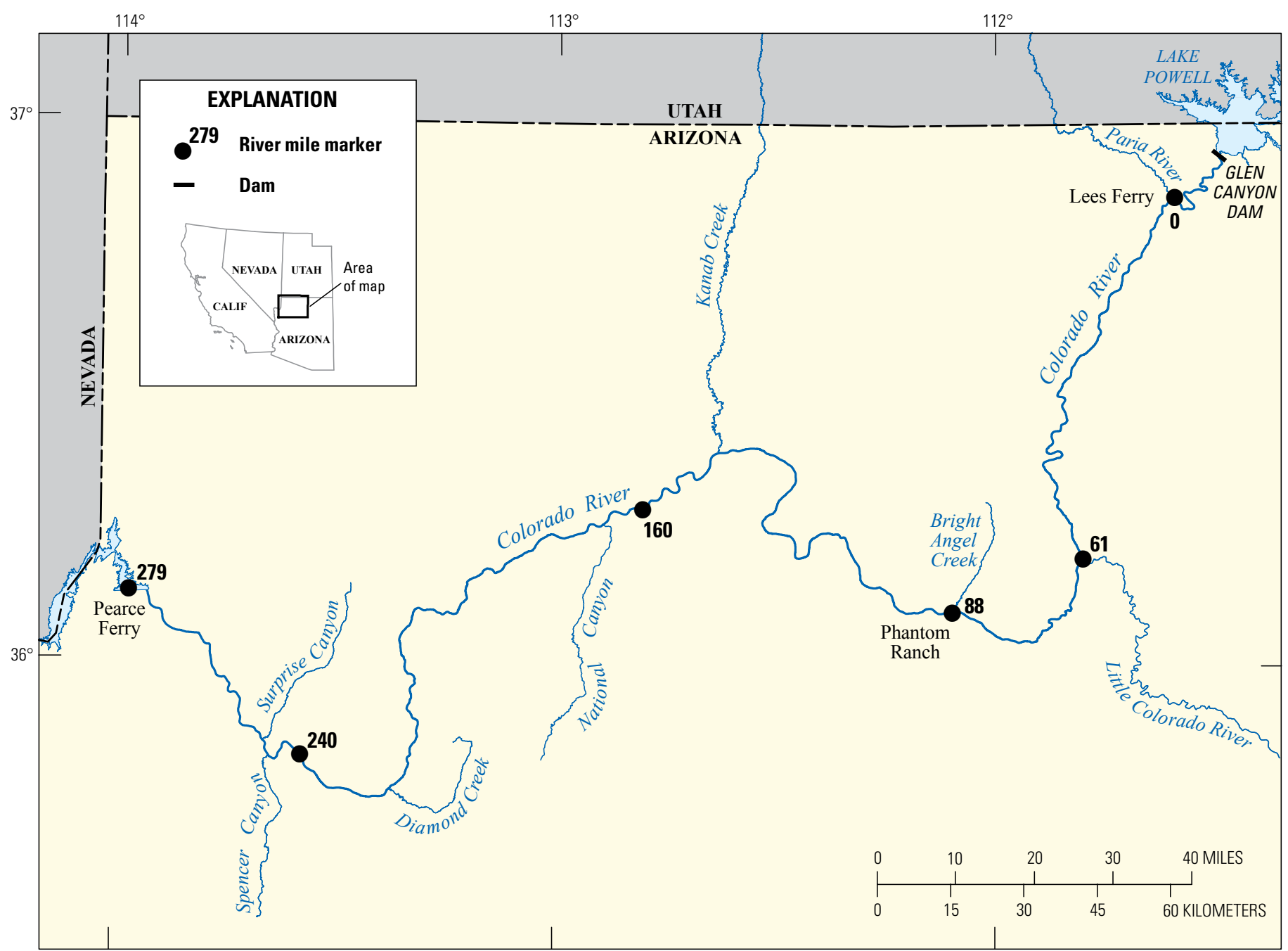

Figure 1. Map of the study area, which includes the riparian area between Glen Canyon Dam and river mile 240. Major tributaries and three other major landmarks (Lees Ferry, Phantom Ranch, and Pearce Ferry) are shown. River miles indicate the distance in miles from Lees Ferry.

affect plant species composition. Time is another dimension for vegetation change along the river, such as alluvial fans exhibiting differences in species composition based on age the of fan development (Bowers and others, 1997). The combination of climatic, geologic, and fluvial disturbance gradients in conjunction with the microclimate forming traits of a large, deep canyon (Stevens, 2012) creates the opportunity for a biologically rich flora.

In a region that has greatly altered riparian systems (Stromberg and others, 2012; Stromberg and others, 2013), this productive riparian ecosystem is valuable for native species dependent on riparian systems (Johnson, 1991; Stevens and others, 1995; Schmidt and others, 1998). The riparian vegetation which has developed along the Colorado River since the closure (beginning of operations) of Glen Canyon Dam in 1963 is a novel and relatively stable habitat that supports a variety of faunal populations, including invertebrates, amphibians, mammals, reptiles, and birds (Carothers and others, 1976; Schmidt and others, 1998; Stevens and others, 2001; Holmes and others, 2005).
The dependence of birds on the riparian habitat through Grand Canyon has been particularly well documented (for example, Brown, 1987; Sogge and others, 1998; Yard and others, 2004; Holmes and others, 2005; Spence, 2006) and indicates that birds rely on this habitat for migrating, nesting, and over-wintering, but require particular vegetation characteristics. Because the composition and structure of riparian vegetation can alter the wildlife associated with it (Farley and others, 1994; Kearsley and Lightfoot, 2006; Merritt and Bateman, 2012), expansion, contraction, and compositional shifts will likely affect wildlife that use this riparian habitat.

The riparian vegetation of Glen and Grand Canyons contains species that are important traditional plant resources for multiple regional tribes, integral to traditional ecological knowledge, and an important component of the greater cultural landscape (Fairley, 2005). For example, Baccharis salicifolia (mule fat) has traditionally been used by the Southern Paiute people for food and construction (Stoffle and others, 1994), and Phragmites australis (common reed) has been used by five regional tribes for a wide 
variety of purposes (Kiviat and Hamilton, 2001). The Kaibab Paiute people used at least 96 species of edible plants, including riparian species, and maintained cultivated fields in the riparian area of the Colorado River (Stoffle and Evans, 1976). Many plants that have been documented as being used by the Navajo are common elements of the Grand Canyon riparian area, for example Equisetum spp. (horsetail), Plantago major (plantain), Juncus arcticus (wire rush), Salix exigua (coyote willow), and Tamarix spp. (salt cedar) (Mayes and Lacy, 1989; Roberts and others, 1995). The Hualapai use riparian plant resources from the Colorado River corridor for food, medicine, construction, and other vital purposes and many of these plants continue to play a central role in maintaining traditional cultural practices (JacksonKelly and Hubbs 2007). The presence and persistence of riparian and marsh habitats in Grand Canyon are regarded as an important goal for the Hopi people, and certain elements of the riparian vegetation are noted as being indicator plants for the health of the ecosystem, particularly cattails (Typha spp.), reeds (Phragmites australis), and willow (Salix spp.) (Huisinga and Yeatts, 2003). Thus, changes in the composition and extent of riparian vegetation can alter the attributes of this landscape that are important to Native American tribes.

For river recreationists, riparian vegetation can be either useful or detrimental depending on the type and location of the vegetation. If it is tall with little understory, it can provide much needed shade (Stewart and others, 2003) and act as a windbreak. If it is shrubby and (or) thorny, it can diminish the camping experience by reducing camping space (Hadley, 2014) and creating an uncomfortable environment. Changes in the health and availability of traditional plants and shifts in species dominance from shade trees to spiny non-natives will impact the cultural services this ecosystem provides.

This diverse and relatively protected ecosystem is also a valuable resource for researching the effects of river regulation on biotic communities. Most of the riparian area is under the management of the National Park Service with limited access other than from the river, so direct impacts from human use are largely limited to use by recreational boaters. Thus, studies on river regulation and climate change have few other humaninduced alterations to take into account. Historical and ongoing scientific studies in this area have created an extensive body of knowledge and highly detailed data on sediment transport, sandbar fluctuations, streamflow, and water quality for this stretch of river, in addition to aerial imagery dating back to 1965 (Dolan and others, 1978; Hazel and others, 2006; Voichick and Wright, 2007). These system-wide studies create the potential to examine broader ecosystem interactions in response to regulation, independent of other intensive human use.

Many factors influence vegetation distribution and change in this ecosystem, but flow release patterns from Glen Canyon Dam have had the greatest and most widespread effects of any human action (Carothers and Brown, 1991; Sankey and others, 2015). The various and dramatic impacts of flow regime alterations are fairly well documented in this system. Periodic vegetation studies in Grand Canyon began in 1944 and, taken together, demonstrate this riparian area is capable of large changes over short periods of time in response to changes in dam operations (Clover and Jotter, 1944; Dolan and others, 1974; Carothers and others, 1976; Turner and Karpiscak, 1980; Stevens and Waring, 1986; Johnson, 1991; Stevens and others, 1995; Waring, 1995; Kearsley and Ayers, 1996; Mortenson and others, 2012; Sankey and others, 2015). The earliest and most notable change was an increase in woody vegetation close to the river (Dolan and others, 1974; Carothers and others, 1976), which has since been corroborated and examined more closely (Waring, 1995; Sankey and others, 2015). Before river regulation, the Grand Canyon was characterized by high volume, sediment- and debris-laden floods in the spring and late summer and very little flow during the fall and winter (Turner and Karpiscak, 1980; Topping and others, 2003). These floods, in combination with a bedrock-confined canyon, presumably prevented vegetation from permanently establishing along the river, resulting in relatively bare shorelines (Dolan and others, 1974; Carothers and others, 1976; Turner and Karpiscak, 1980; Webb, 1996). The increases in summer base flows and elimination of vegetation scouring floods led to an increase in the vegetated riparian area (Carothers and others, 1976; Stevens and others, 1995; Waring, 1995; Sankey and others, 2015). This increase in woody cover has not proceeded at a steady, consistent rate over time or along hydrologic gradients (Stevens and Waring, 1986; Sankey and others, 2015). Unusually large post-dam floods in the early 1980 s removed as much as 50 percent of the riparian vegetation (Stevens and Waring, 1986), which was followed by unrestricted daily increases and decreases in dam releases to follow power demands (hydropeaking) until the early 1990 s, resulting in rapid vegetation growth in areas that were inundated with discharge rates between 708-2,747 cubic meters per second ( $\mathrm{m}^{3} / \mathrm{s}$; Waring, 1995; Sankey and others, 2015). After several years of restricted hydropeaking, short-duration controlled floods, and minor to moderate vegetation increases, vegetation cover expanded rapidly again between 2005 and 2009, but at lower elevations (areas inundated with discharge rates between $226-1,274 \mathrm{~m}^{3} / \mathrm{s}$ ), while vegetation at higher elevations either remained constant or decreased (Sankey and others, 2015). Thus, the timing, patterns, and volume of flow releases alter when and where vegetation will increase or decrease.

The expansion and contraction of woody vegetation has not proceeded in a consistent pattern across species either. In 1976, Carothers and others noted that a suite of woody species had expanded, but indicated that Tamarix spp. (salt cedar) in particular had the potential to form an impenetrable wall along the river if given the opportunity. Subsequently, even though Tamarix spp. remained a dominant part of the vegetation community over succeeding decades, it never achieved the monoculture that was anticipated. In the 1980s, Salix exigua (coyote willow) was found to be colonizing beaches (Brian, 1982), but now it is only a relatively small part of the riparian community and Pluchea sericea (arrowweed) appears to be the more aggressive and successful colonizer. Differing responses of species to flooding or high or low steady flows have the potential to change species composition. Low, steady flows in 2000 were correlated with an increase in Tamarix spp. seedlings, although this was followed by high mortality 
(Porter and Kearsley, 2001; Ralston, 2011). The disturbance and sediment deposition from flood events can favor clonal species over shallow rooted species (Stevens and Waring, 1986; Ralston, 2010). A more subtle change was the large expansion of riverine marshes along the river, which in 1991 were estimated to consist of approximately 1,100 patches covering 25.0 hectares between Lees Ferry (river mile [RM] 0) and Diamond Creek (RM 226) (Stevens and others, 1995). This was followed by a subsequent compositional shift from obligate wetland species toward woody riparian shrubs as these marshes became drier in association with reduced inundation frequency (Kearsley and Ayers, 1996). Changes in the organic components and textures of riparian substrates have also been recorded and could affect vegetation composition (Stevens and Waring, 1986; Kearsley and Ayers, 1996).

Exotic, invasive species can also alter vegetation by changing physical processes (Manners and others, 2014) and (or) habitats; for example, by increasing the prevalence of fire (Richardson and others, 2007; Stromberg and others, 2012). For this reason, the presence and expansion of exotic plant species has been a topic of concern in this system since the first botanical explorations of the canyon (Clover and Jotter, 1944). The river corridor harbors the majority of non-native species in Grand Canyon (Stevens and Ayers, 2002) and the quantity seems to have increased since 1944 (Dolan and others, 1974; Carothers and others, 1976; Johnson, 1991). This is likely caused by a combination of factors. Flow regime alteration, high rates of hydrologic disturbance, and disturbance from visitors provide a setting conducive to the colonization of non-natives (Carothers and others, 1976; Mortenson and Weisberg, 2010; Stromberg and others, 2012; Perkins and others, 2015). Additionally, large rivers often act as dispersal corridors for native and non-native species alike (Johansson and others, 1996; Richardson and others, 2007), making it more probable that non-native species will occur and new non-native species will first colonize in this area. Non-native species in riparian zones also tend to have life history traits that allow them to persist and spread with or without flow regulation, making them more likely to alter the ecosystem over time (Perkins and others, 2015). Although removal efforts for particularly noxious non-native species are ongoing and have had some success (Stevens and others, 2001), many unmanaged nonnative species continue to persist and expand within the riparian ecosystem. It is likely then, that changes to the non-native plant community will play a role in the future of the riparian system below Glen Canyon Dam.

In addition to changes associated with flow alterations and exotic species, riparian vegetation in this area is changing in response to other environmental and human-mediated pressures. Climate change will impact the distribution and composition of plant species over time, particularly in response to changes in precipitation and temperature (Stromberg and others, 2013; Palmquist and others, 2018). Vegetation management programs in Glen Canyon National Recreation Area (GLCA) and in GRCA actively alter the presence or absence of exotic and native species. Visitors to these National Park Service units also inadvertently, and sometimes intentionally, change vegetation patterns due to vegetation destruction (Dolan and others, 1974; Carothers and others, 1976), increased erosion, and facilitating the spread of exotic species.

The Colorado River below Glen Canyon Dam is not the only river exhibiting change in its riparian vegetation. Other large rivers in the arid west have also experienced change in woody and herbaceous vegetation, often to the point of altering the geomorphic and hydrologic processes of the river (Shafroth and others, 2002; Lite and others, 2005; Birkin and Cooper, 2006; Dean and Schmidt, 2011; Manners and others, 2014). Varying degrees of river regulation on western rivers have influenced the manner and amount of vegetation change that has occurred (Merritt and Cooper, 2000; Merritt and Poff, 2010; Mortensen and Weisberg, 2010), making it possible to study how river regulation has influenced vegetation change at large scales and over regional extents. To do such regional analyses, datasets from multiple large rivers with different flow regimes need to be available, have large enough sample sizes, and use comparable methods. As methods for quantifying and monitoring riparian vegetation on large rivers are being developed, it is beneficial to make those monitoring efforts similar enough that the data can be analyzed jointly.

The riparian vegetation below Glen Canyon Dam is a valuable resource that is known to change in response to flow regime and other disturbances within a geomorphic and geographic context. Based on this framework, the following protocol has three primary objectives:

1. Annually measure and summarize the status (composition and cover) of native and non-native vascular plant species within the riparian zone of the Colorado River between Glen Canyon Dam and Lake Mead.

2. At 5-year intervals, assess change in vegetation composition and cover in the riparian zone, as related to geomorphic setting and dam operations, particularly flow regime.

3. Collect data in a manner that can be used by multiple stakeholders and is compatible with the basinwide monitoring program overseen by the National Park Service's Northern Colorado Plateau Network Inventory and Monitoring program.

\section{Sampling Design}

To monitor species composition and cover, and tie those changes to geomorphology, geomorphic change, and dam operations, sampling design is approached in two ways. Each year, sampling is conducted on both a new set of randomly selected sites (sites change each year) and a set of fixed sites that are resampled each year. A stratified, random site-selection design is used to select the new sites, which are used to assess corridor wide changes in vegetation on multiple geomorphic features (see Stratified Random Sample Sites below). Nonrandomly selected, eddy sandbar sites are resampled annually to tie vegetation data to annually collected survey data and legacy datasets. These sample design approaches were chosen such that data collected by the 
U.S. Geological Survey (USGS) Grand Canyon Monitoring and Research Center (GCMRC) are compatible with the Northern Colorado Plateau Network Inventory and Monitoring (NCPN) program's big-river riparian-monitoring protocol (Scott and others, 2012). The NCPN program monitors the large rivers upstream of Glen Canyon Dam - the Green, Yampa, and upper Colorado Rivers. Collecting data in a compatible way will allow us to combine datasets in basinwide analyses.

This protocol will be complemented by periodic assessments of landscape-scale vegetation change using aerial imagery, to gain a broader understanding of changes in woody vegetation over a large spatial scale. Approximately every 5-10 years, the GCMRC collects and rectifies aerial imagery of the entire study area. From this imagery dataset, a woody vegetation classification is created and can be compared to previous years' classifications. Monitoring conducted with aerial imagery complements the ground-based monitoring described in this protocol by providing an assessment of the change in total vegetated area and changes in dominant woody species, which can be compared to trends detected on the ground.

Sampling is designed to be conducted using two primarily nonmotorized (oar boat) trips from Lees Ferry to Pearce Ferry, and one motorized boat trip between Lees Ferry and Glen Canyon Dam. Sampling is conducted between early August and mid-October, when perennial vegetation development is at its maximum. Sampling below Lees Ferry proceeds in a downstream direction and must conform to logistical challenges posed by weather, river flows, the location of potential campsites, steep slopes, and other logistical considerations that accompany remote wilderness areas.

\section{Hydrologic Zones}

The river margin is divided into three spatially explicit hydrologic zones, which are used to stratify samples - the active channel, the active floodplain, and the inactive floodplain (fig. 2, table 1). These zones are related to inundation frequencies and are defined by modeled water-surface elevations and virtual shorelines for specific flow volumes (Magirl and others, 2008). These zones run parallel to the river and can vary in area depending on differing channel characteristics such as width, depth, shape, and slope (Schmidt and Graf, 1990; Magirl and others, 2008; Schmidt and Grams, 2011), with wider reaches tending to have wider hydrologic zones and narrower reaches having narrower zones. These zones are essentially fixed in space and would only change due to improved models or alterations to the canyon morphology. The active channel (AC) borders the river, the active floodplain (AF) is upslope of the active channel, and the inactive floodplain (IF) is upslope of the active floodplain (fig. 2). The AC is the region that can be inundated on a daily basis based on Record of Decision operating criteria for Glen Canyon Dam (U.S. Department of the Interior, 1996) and includes elevations that are inundated with flows as much as $707 \mathrm{~m}^{3} / \mathrm{s}$. The AF is inundated less often than the active channel and includes flows that are between
Table 1. Hydrologic zones used to stratify sampling during monitoring of riparian vegetation along the Colorado River in Arizona between Glen Canyon Dam and Lake Mead.

[Zones are related to inundation frequencies and are defined by modeled water-surface elevations and virtual shorelines for specific flow volumes]

\begin{tabular}{lcl}
\hline Hydrologic zone & $\begin{array}{c}\text { Water discharge, in } \\
\text { cubic meters per second }\end{array}$ & Inundation frequency \\
\hline Active channel & $\leq 707$ & Daily \\
Active floodplain & $707-1,274$ & $\begin{array}{c}\text { Occasionally, primarily } \\
\text { during high-flow } \\
\text { experimental releases } \\
\text { from Glen Canyon }\end{array}$ \\
& $>1,274$ & Dam \\
Inactive floodplain & Extremely rare \\
\hline
\end{tabular}

$707 \mathrm{~m}^{3} / \mathrm{s}$ and $1,274 \mathrm{~m}^{3} / \mathrm{s}$. These flows include the High Flow Experiments and other high flow scenarios (Melis, 2011). The IF is the historical high water zone that is no longer able to be flooded under normal dam operations and experimental releases. This zone was last flooded in the 1980s. Historical flows were as high as $5,946 \mathrm{~m}^{3} / \mathrm{s}$ (Topping and others, 2003), but future flows that high are unlikely.

\section{Standard Site Layout}

The sampling layout at each site consists of three transects that each contain nine 1-square meter $\left(\mathrm{m}^{2}\right)$ sampling quadrats, for a total of 27 sampled quadrats per site (fig. 3, fig. 4). Transects are evenly spaced at each site, and the distance between transects is determined by the length of the feature. The placement of the transects is randomly determined by randomizing the location of the first transect, with subsequent transects placed equidistant downstream of the first (see SOP [standard operating procedure] 4 - Setting Up the Transects and Quadrats; SOPs are given in appendix 1). For fixed sites, the transects are not relocated, but are randomized each year. If relocating transects at fixed sites becomes logistically feasible in the future, this aspect could be altered. Currently, relocating transects at fixed sites requires more time than is available in the given sampling period.

Each transect has three quadrats evenly spaced within each hydrologic zone, so the distance between the quadrats changes depending on the width of the zone (fig. 4). If the width of the zone is less than $5 \mathrm{~m}$, quadrats are placed parallel to the river, $2 \mathrm{~m}$ apart, at the center of the zone (fig. 5). In the IF, the first quadrat is placed $1 \mathrm{~m}$ from the active floodplain/inactive floodplain (AF/IF) boundary and the distance between the quadrats is $2 \mathrm{~m}$ (fig. 4 , fig. 5).

Occasionally, the site setup needs to be modified because of geomorphic limitations, safety, or size of the site. If the IF is not accessible or nonexistent (usually due to the presence of a large cliff), then those quadrats are not sampled and the total number of quadrats is less than 27 . Some of the fixed sites are particularly large $\left(>7,000 \mathrm{~m}^{2}\right)$ and diverse, so these have a fourth transect 


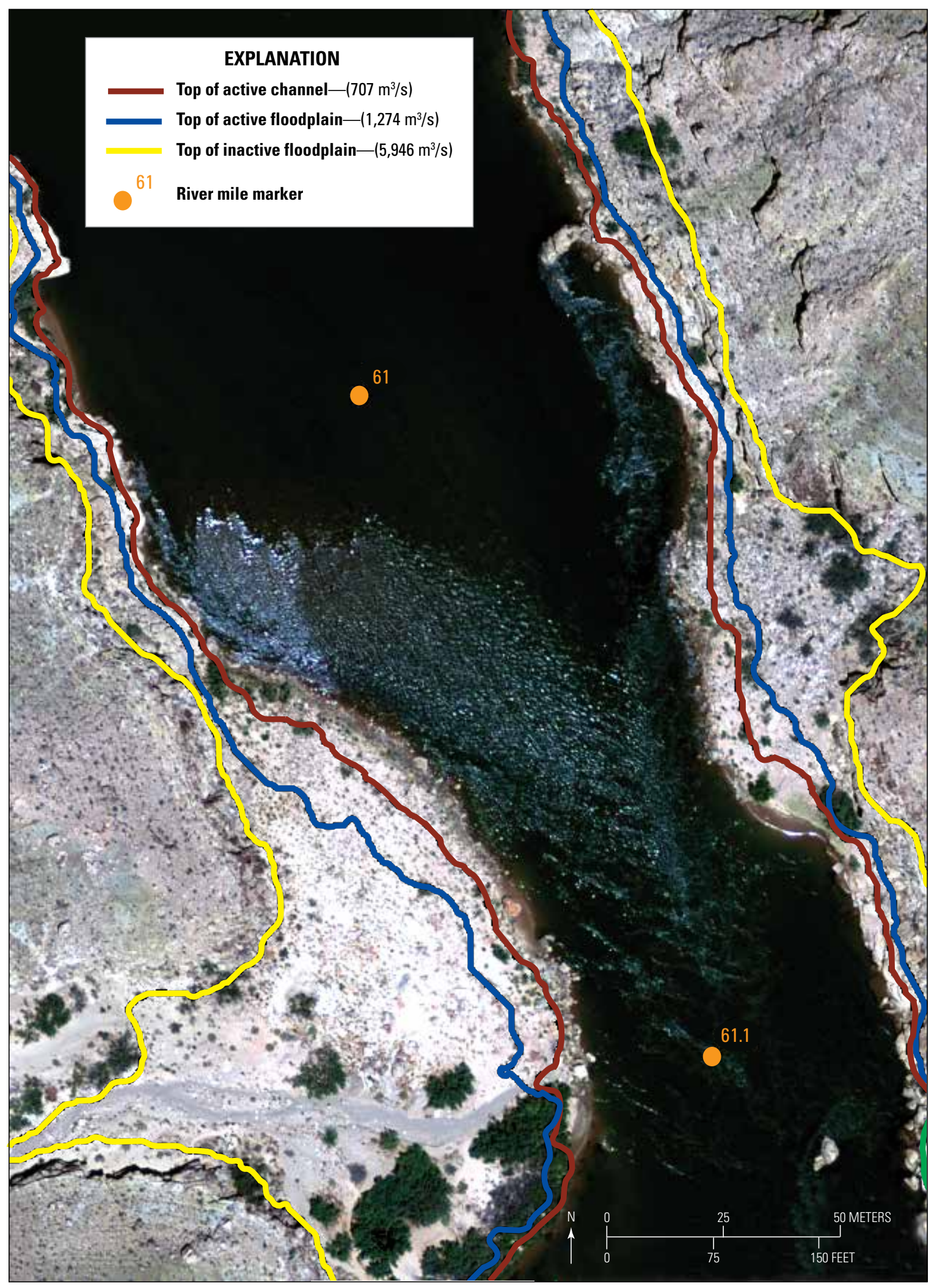

Figure 2. Aerial photograph of a riparian-vegetation monitoring site on the Colorado River in Arizona between Glen Canyon Dam and Lake Mead. Photograph is annotated with modeled flow lines marking the approximate boundaries of the top of the active channel, the top of the active floodplain, and the top of the inactive floodplain. These boundaries are used to stratify sample quadrats at each site. (Modeled flow lines from Magirl and others, 2008). 


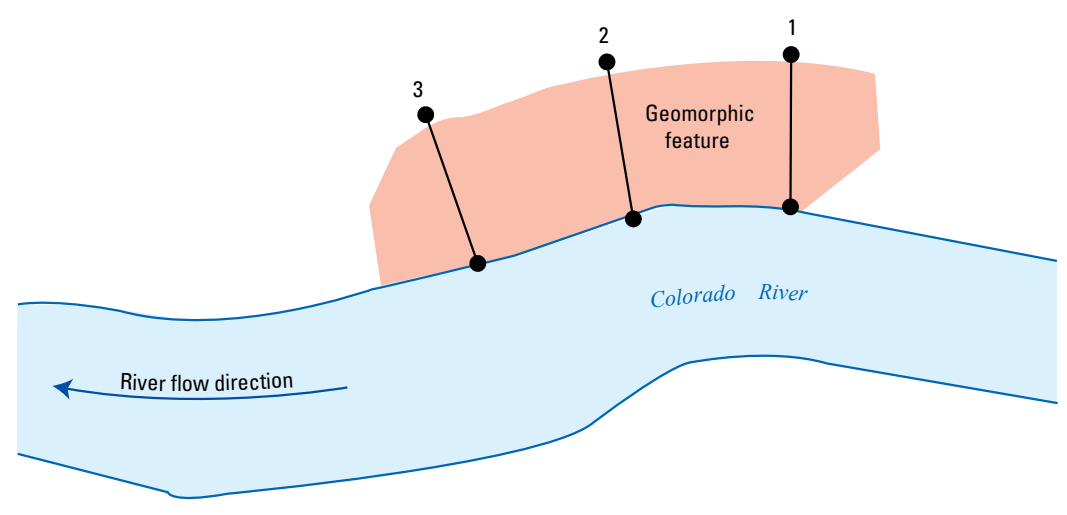

Figure 3. Diagram showing transect placement in a standard site setup for monitoring of riparian vegetation along the Colorado River in Arizona between Glen Canyon Dam and Lake Mead. Each sample site is composed of three transects oriented perpendicular to the river. The distance between transects is variable and based on the length of the feature.
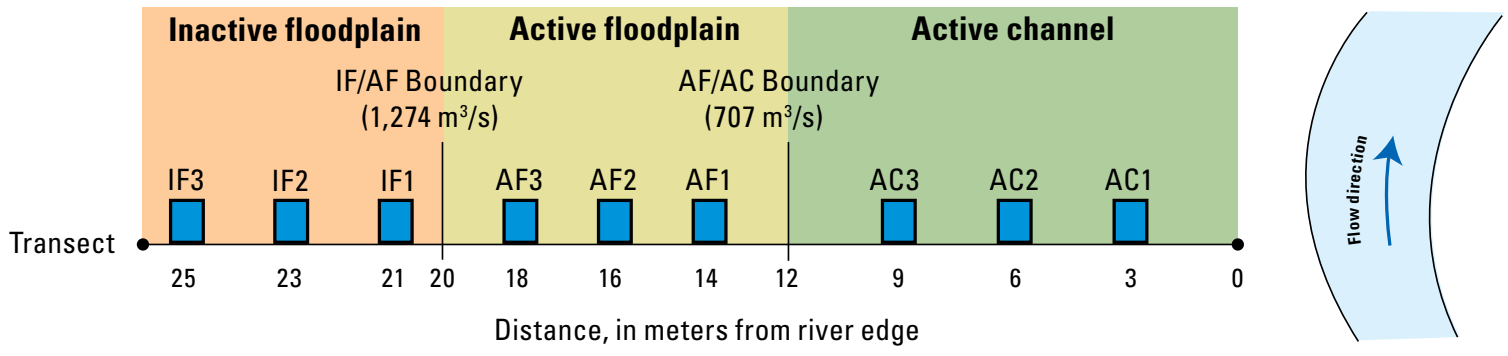

Figure 4. Diagram showing quadrat (blue boxes) placement in a standard site setup for monitoring of riparian vegetation along the Colorado River in Arizona between Glen Canyon Dam and Lake Mead. Each transect has nine quadrats placed on the downstream side. Three quadrats are evenly placed in each hydrologic zone. Active channel (AC) and active floodplain (AF) quadrats are evenly spaced depending on the width of the zone, while inactive floodplain (IF) quadrats are placed 2 meters $(\mathrm{m})$ apart and $1 \mathrm{~m}$ from the active floodplain/inactive floodplain boundary.
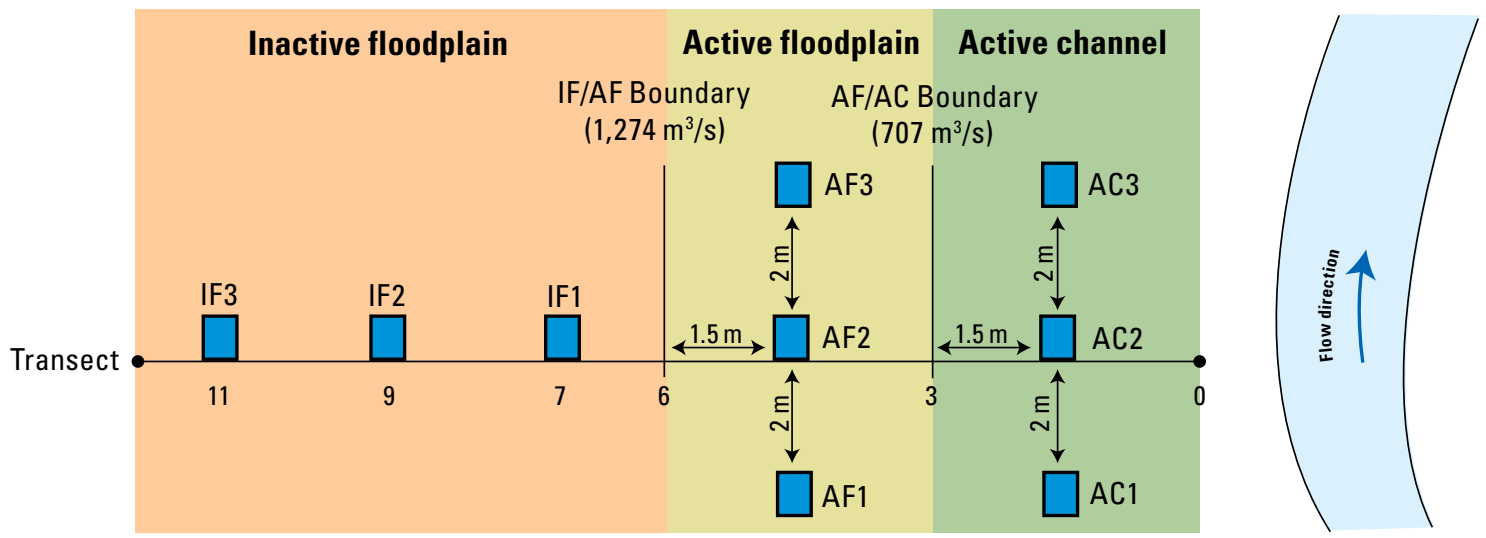

Distance, in meters from river edge

Figure 5. Diagram showing alternative quadrat (blue boxes) placement for monitoring of riparian vegetation in a hydrologic zone that is less than 5 meters $(\mathrm{m}$ ) wide along the Colorado River in Arizona between Glen Canyon Dam and Lake Mead. The quadrats for that zone are placed parallel to the river, $2 \mathrm{~m}$ apart, in the center of the hydrologic zone. Active channel (AC), active floodplain (AF), inactive floodplain (IF). 
of nine quadrats. A few fixed sites are long and narrow, so the transects are rearranged to be four transects with six quadrats each (appendix 2).

\section{Stratified Random Sample Sites}

Stratified random sample sites are generated in ArcGIS (Esri, 2013) between Glen Canyon Dam and RM 240, where the influence of Lake Mead becomes apparent on the shorelines. A new set of sample sites is generated each year; so different sites are visited each year. River miles indicate the distance in miles either upstream (negative values) or downstream (positive values) from Lees Ferry ( 0 mile) along the river centerline. Current navigational convention in Grand Canyon is to use the distance from Lees Ferry in river miles rather than river kilometers, so river miles are used here to facilitate the use of this protocol for logistical planning and field use.

Sites are stratified at three nested scales - river segment, geomorphic feature, and hydrologic zone. The samples encompass differences in vegetation due to geography, geomorphology, and the frequency of inundation. River segments are delineated by floristic groups, as determined in Palmquist and others (2018), and are approximately bounded by three large tributaries - the Paria River, the Little Colorado River, and National Canyon (table 2). The number of sites per segment are generated based on the length of the segment. Longer segments have more sites than shorter segments, but the proportions of sites to the length of the reach are similar. Within each segment, sites are approximately evenly distributed among debris fans, channel margins, and eddy sandbars. Quadrats within each site are divided equally among the three hydrologic zones (table 1). In the standard site layout, nine quadrats are placed in each zone. For further details, see standard site layout.

Random sites are selected within ArcGIS based on a sampling frame consisting of discrete river segments from RM -15.6 to 240 (fig. 6). Sites that are sampled are removed from the available pool of sites until the end of the 5-year monitoring period, which ends with a status and trends report (see SOP 14). The first 5-year monitoring period ends at the end of 2017, so in 2018 all sites are available to sample again. The next time all sites are available to be sampled will be 2023 .

To create the sampling frame, the Colorado River corridor was divided into sampling units on each side of the river centerline for each tenth of a river mile (for a total of 5,114 discrete polygons). A custom program was written in Visual Basic and integrated into Esri's ArcGIS version 10.2. The program uses GCMRC's Colorado River mile system (U.S. Geological Survey, 2002), particularly the centerline and river mile tenths layers, to create perpendicular cross sections for each river mile tenth. The centerline layer consists of a line running along the center of river, whereas the river mile tenth layer consists of points indicating the locations of each river mile tenth in the center of the river. The cross-section lines, centerline, and extent lines (created by buffering $200 \mathrm{~m}$ from the centerline) were geoprocessed (using the Union tool in Esri's ArcGIS version 10.2) to produce discrete

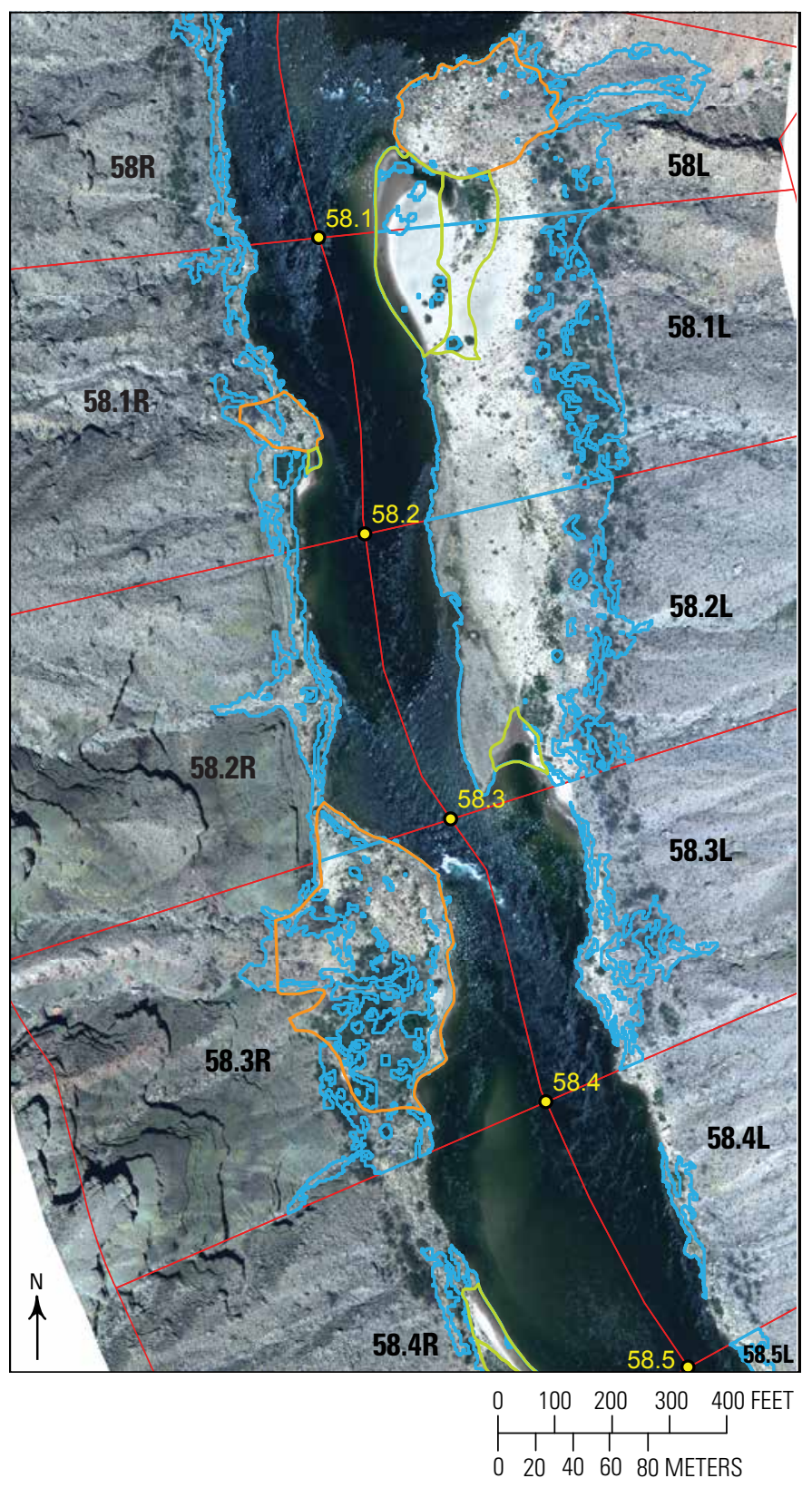

Figure 6. Aerial image showing an example of the ArcGIS based sampling frame for randomly selected sites for monitoring of riparian vegetation along the Colorado River in Arizona between Glen Canyon Dam and Lake Mead. The red-bounded polygons are the query polygons based on river mile and side and are labeled as such. In this example, the red-bounded polygon labeled " $58.3 \mathrm{~L}$ " indicates that the polygon is located at river mile 58.3 and is on river left; $R$, indicates river right. The orange-bounded polygon delineates an area that contains a debris fan. The green-bounded polygons indicate areas that contain sandbars. The blue-bounded polygons indicate areas that have channel margins that are not cliffs. The query polygons (red-bounded polygons) are labeled as either having or not having channel margins, debris fans, and eddy sandbars based on these features. 
Table 2. River segments identified to stratify random sampling for monitoring of riparian vegetation along the Colorado River in Arizona between Glen Canyon Dam and Lake Mead.

[Segments are delineated by floristic groups that occur along the river as delineated by Palmquist and others (2018). River miles follow U.S. Geological Survey (2002). Target number of sites, number of sites that will ideally be sampled each year; km, kilometer]

\begin{tabular}{|c|c|c|c|c|}
\hline Segment name & Upstream boundary & River miles & $\begin{array}{c}\text { Length, in } \\
\text { kilometers (km) }\end{array}$ & $\begin{array}{c}\text { Target number of } \\
\text { sites }\end{array}$ \\
\hline Glen Canyon & Glen Canyon Dam & $-15.6-0$ & 25 & 6 \\
\hline Marble Canyon & Paria River & $0-61$ & 98 & 24 \\
\hline Eastern Grand Canyon & Little Colorado River & $61-160$ & 159 & 39 \\
\hline Western Grand Canyon & Approximately National Canyon & $160-240$ & 129 & 32 \\
\hline
\end{tabular}

query polygons. River mile tenth values and river side were added as attributes to the created query polygons in the final geographic information system (GIS) layer.

Using this sampling frame of query polygons, each potential sampling site (that is, every feature in the query polygons GIS layer) was attributed selection criteria by spatially joining the query polygon layer with ancillary GIS layers based on whether or not they intersect. Two types of attribution were performedexclusionary and inclusionary. Exclusionary attributes remove a polygon from sampling, while inclusionary attributes identify polygons that contain the geomorphic features that are the target of this study. Polygons containing springs, culturally sensitive sites, and long-term monitoring eddy sandbar sites were excluded from sampling by assigning an attribute value of "no" if the query polygon in question intersected any features from the springs layer, the cultural/archeologically significant layer, or the longterm monitoring eddy sandbar sites layer. Polygons were assigned an attribute value of "yes" for channel margins, debris fans, and sandbars independently, so a polygon can contain any combination of those features. If a polygon intersected any features from the debris fan layer or the sandbar layer, it was assigned an attribute value of "yes" for those features. Polygons were assigned as channel margins if they contained at least $50 \mathrm{~m}^{2}$ of contiguous area (and at least $50 \mathrm{~m}$ of length along the river), had a slope of less than 25 percent, and were accessible from the river. Any query polygons that were not excluded, but did not obtain any inclusionary attribution were not considered for the stratified random sample selection. These exclusionary and inclusionary attributes can be recalculated in the future if selection criteria are changed or better spatial layers become available for the current selection criteria.

Each polygon is then assigned a random number each year using Esri's ArcGIS. The random number generator in ArcGIS is parameterized to use ACM599 method (the default method in ArcGIS 10.2) and a set seed number (different each year and recorded) to assign a random number from 0 to 10,000 . Once assigned, the query polygons are sorted in ascending order based on the random number. For each stratum (river segment and geomorphic feature), the first " $n$ " sample sites are selected, where $n$ is the target number of sites plus an additional 20 percent of $n$; these additional sites are selected in case any sites are discarded during field data collection.

\section{Fixed-Site Eddy Sandbars}

Vegetation sampling of fixed sites is conducted annually on 43 eddy sandbars, which are concurrently monitored for geomorphic change (appendix 2). Fixed sites consist only of eddy sandbars, because they are sites that were previously designated for long-term monitoring of geomorphic change through detailed annual surveying. Northern Arizona University (NAU) researchers in collaboration with GCMRC conduct the surveys. Eddy sandbars in Grand Canyon do not shift positionally, as they are linked to fixed tributary confluences or channel restrictions, but do change in volume and area (Schmidt and Grams, 2011), which has repercussions for camping availability (Kaplinski and others, 2005), sediment storage (Wright and others, 2005), and presumably vegetation. Conducting vegetation sampling simultaneously with geomorphic surveying allows vegetation change to be closely linked to changes in geomorphology over time and more closely examine the influences of sediment on vegetation and vice versa.

The eddy sandbars that are surveyed are a mix of popular camping sandbars and infrequently visited sandbars in Marble Canyon, eastern, and western Grand Canyon. Annual sandbar surveying is described in greater detail elsewhere (Beus and others, 1992; Hazel and others, 1999; Kaplinski and others, 2005; Hazel and others, 2010; Schmidt and Grams, 2011). Although some of the fixed sites conform to the standard site layout, some have alterations to the number of transects and the number of quadrats. At fixed sandbar sites that are larger and more complex than other sites, we conduct a more complete site characterization, requiring more intensive sampling. Fixed sandbar sites that are more than $7,000 \mathrm{~m}^{2}$ are sampled using four transects and 36 quadrats. Fixed sites that are long and narrow are sampled using four transects each with six quadrats. See SOP 4 and appendix 2 for details on modifications to fixed site layouts.

\section{Field Methods}

All field work is conducted along the Colorado River between Glen Canyon dam and Lake Mead. Working in this area is remote, difficult to access, and requires months of logistical planning and coordination with over 20 people. At 
all stages of planning and operations, safety, organization, and efficiency are primary considerations.

\section{Field-Season Preparation}

Preparation for the field season starts months before the first data collection trip and requires coordination with the GCMRC logistics and permitting coordinator, the GIS coordinator, the NAU sandbar surveying team, and at least ten volunteers. More details are provided in SOPs 1-3. The following preparations must be made in advance of the field season:

- The monitoring ecologist coordinates with the logistics and permitting coordinator regarding dates of river trips, numbers of boats and boat operators needed, and number of people on the trip. This should be started around the beginning of the calendar year (January) before the first sampling trip.

- Applying for and managing permits is conducted by the principal investigator through the online National Park Service (NPS) online Research and Permitting System, https://irma.nps.gov/rprs/Home. Renewal permits should be submitted in January for GRCA and at least 2 months in advance for GLCA. The logistics and permitting coordinator should be kept up to date about the status of permits to facilitate planning and logistics.

- A list of random samples on debris fans, channel margins, and eddy sandbars should be generated well in advance of the first trip. This should be done in cooperation with the GIS coordinator in ArcGIS. Sites need to be stratified by geomorphic feature and by river reach. This list of sites is used to help develop the river-trip campsites and schedule, so must be available before June.

- Field volunteers need to be recruited, organized, and trained. Collaborators, current USGS employees in a related field, and other people with an invested interest in the work of GCMRC are invited first. If more volunteers are needed, people with local botanical or scientific background are preferred. Information regarding dietary restrictions and pertinent medical conditions of each volunteer are identified as early as possible and passed along to the logistics and permitting coordinator. Information on field schedules, necessary personal gear, data collection protocol, and day of launch instructions need to be sent to volunteers approximately 2 weeks before departure to allow adequate time for personal preparations.

- Tablet computers and data collection software should be prepared and tested well before the trips to ensure that data can be recorded easily and correctly, as well as transferred to the office database. The method for backing up and charging the tablets daily should also be tested.
- Enough paper datasheets need to be prepared to allow for sampling on the entire river trip, in case of electronic failure. These should be printed on waterproof paper and kept organized throughout the field season in waterproof ammo cans or equivalent storage containers.

- Field gear needs to be assessed for completeness and usefulness at least 1 month in advance. There should be enough of each item to support two crews and one replacement for each crew, in case gear fails while in the field. Ordering of new or replacement gear needs to be completed at least 3 weeks before the first trip to allow for shipping and packing time.

- Two informational binders are made, one for each crew, that contain the list of sample sites and their locations, a field schedule, species lists, and species keys. They should also contain enough paper datasheets for four sites, in case of tablet failure.

- All gear must be organized and packed into boat side boxes and (or) "ammo cans" in such a way that the two crews can each work off of two $5.5 \mathrm{~m}$ oar boats (total of four boats for a trip). The gear also needs to be protected from drenching rapids, thunderstorms, and raft upset. Additionally, one ammo can that contains paper datasheets, useful floras for field keying, and backup field gear is shared between both crews and accessed as necessary. Well in advance of their first trip, the monitoring ecologist should meet with the logistics and permitting coordinator to learn the techniques, recommendations, and limitations on field-gear storage on the boats.

- In coordination with the GIS coordinator, four sets of waterproof map books need to be printed, unless maps from previous years are available. These maps of the river corridor contain river miles to the tenth and useful landmarks (for example, camps). Print and bind the map books at least 1 week in advance of the first sampling trip. Each boat will receive one set of map books (see SOP 1 for details).

- Create and print maps of each of the fixed sites and random sites. All maps should include river miles to the tenths, the hydrologic zone boundaries, a scale bar, and the direction of river flow. They should be large enough in scale to identify where transects are located, but still be able to see useful landmarks for finding the site along the river. Fixed sites should also include quadrat points from the previous two years.

\section{Timing of Monitoring}

The Glen Canyon reach, between RM -15.6 and 0, should be sampled approximately 2 weeks before the launch 
of the first river trip. This should be approximately midAugust. Four days of work should be scheduled for training purposes and data collection.

Two 17-day river trips are required for sampling within Grand Canyon. One trip is dedicated to random sampling between RM 0 and 240 and should be timed to start in late August. The second river trip is coordinated with the NAU sandbar geomorphology surveying. This trip focuses on sampling the fixed sites and should be scheduled to start in late September or early October. This maximizes the number of species that can be identified, because most grasses and summer and fall annuals have flowered but still remain on the landscape.

\section{Sampling Procedures}

This section describes the general procedure for data collection. Detailed instructions are included in SOPs 4-9 and should be followed while in the field. Sampling of one site typically takes 1 to 3 hours, depending on the complexity of the site, the level of experience of the crew, and the number of technicians. A four -person crew is the most efficient for sampling the random sites. Two people work on vegetation cover estimates either independently or as an observer/ recorder pair, while the other two people perform the remaining tasks. A two-person crew is sufficient for sampling the fixed sites, but a 3-person crew is more efficient. Two people work on cover estimates, while the third person sets up quadrat locations, takes pictures, and then assists with quadrat assessments. Two crews of four people are needed for the random sampling river trip, while two crews of two to three people are needed for the fixed site sampling.

Until the electronic data collection and database methods are finalized, data will primarily be collected on paper datasheets. Ultimately, data will be entered into a database using a tablet computer in the field. Electronic data will be backed up daily onto multiple external drives that are distributed among the trip boats. In the event of technical problems, paper datasheets will be used to record data.

All data forms should be filled out completely. No space should be left blank. If there is nothing to record, a notation should be made indicating there is no data to record.

\section{Site Setup}

The standard site setup contains three transects oriented perpendicular to the river with nine $1-\mathrm{m}^{2}$ quadrats placed along each transect (fig. 3, fig. 4). Transects are spaced equidistant from a randomly determined starting location. The distance between transects is based on the length of the geomorphic feature.

The boundaries of the hydrologic zones are determined using modeled flowlines on site maps and landscape cues, such as debris piles and sediment deposition. Quadrats are placed along each transect in each of the three hydrologic zones (see Hydrologic Zones for a description of the zones). Three quadrats are equally spaced within each zone and are placed on the downstream side of the transect (fig. 4). If a hydrologic zone is narrower than $5 \mathrm{~m}$, the quadrats are placed parallel to the river at the mid-point of the zone, $2 \mathrm{~m}$ apart (fig. 5). Quadrats in the IF are placed $2 \mathrm{~m}$ apart starting $1 \mathrm{~m}$ from the AF/IF boundary. See SOP 4 for details about setting up the sites.

For some sites, a modification of the standard site set-up is necessary. If a site does not have an IF (due to a sheer cliff, for example), those quadrats are not replaced and not sampled. Also, as mentioned above, fixed sites with areas greater than approximately $7,000 \mathrm{~m}^{2}$ are sampled with an extra transect. Fixed sites that are long and narrow are sampled with four shorter transects.

\section{Site Photographs}

For each sample site, random or fixed, five pictures are taken near the river's edge - upstream, downstream, and photographs of each of the three transects (looking inland from the river edge). The default location for taking the upstream and downstream photographs is the river end of transect 2. In the event that photographs from that location are not informative-for example, covered in dense shrubs - photographs can be taken from either transect 1 or 3 . Note on the datasheet if photographs were taken from a place other than transect 2 .

At fixed sites, these photographs complement the repeat photographs taken as part of the geomorphic monitoring conducted by NAU (available at http://www.gcmrc.gov/sandbar/). Those photographs are automatically taken by stationary field cameras five times daily and include the entire sandbar, but do not show plant species clearly.

Each picture includes a small white board that shows the river mile, side of river, date, and direction the picture is taken. For example, for a picture of transect 3, taken at RM 40.0 on the right side of the river on 28 August 2014, the white board would read, "RM 40.0R, 28 Aug 14, Transect 3."

\section{Slope and aspect}

Slope and aspect are recorded at each random site, but not at the fixed sites. Both measurements are made at the approximate lengthwise middle of the feature. Slope is measured in percent, and aspect measurements are adjusted for magnetic declination. SOP 7-Slope and Aspect describes the methods for these measurements in detail. Accurate measures of slope and aspect for fixed sites can be determined using the survey data, so field measurements are not required.

\section{Elevations of Quadrats}

The elevation of each quadrat is measured for both random and fixed sites, although the methods for each are different. The 
elevation and location of quadrats at fixed sites are recorded as a part of the surveying process. Those data are then processed by the NAU sandbar research team and incorporated into the vegetation dataset. While the quadrats are not relocated each year, this could be reevaluated in the future if surveying techniques become more efficient or logistical constraints can be otherwise alleviated. With current logistical constraints, there is not enough time to both relocate all vegetation sample quadrats and sufficiently survey each sandbar in one river trip.

The elevations of quadrats at random sites are measured from the water's edge and the date and time are recorded. A survey rod is held at the water's edge at the end of the transect, and the height above water is estimated to the nearest decimeter using a stadia level. The observer's height is subtracted from the measured height to get an elevation above water. Using the instantaneous discharge measurements for that date and time, an approximation of the actual elevation of each quadrat is made using 15-minute discharge data (Topping and others, 2003) and modeled watersurface elevations (Magirl and others, 2008).

\section{Estimating Species and Ground Cover}

\section{Sampling}

Within each $1-\mathrm{m}^{2}$ quadrat, each species is identified and its live foliar cover estimated. Only the vertical cover of the species is included in the estimates; spaces within the plant canopy do not count as cover. Thus, a densely packed canopy will have more cover than a loose, open canopy of the same size. The total foliar cover for a species is rounded to the nearest 5 percent with the exception of trace amounts and 1 percent (table 3 ). Cover that is rooted inside the quadrat is estimated separately from cover that is rooted outside the quadrat. Cover that is overhanging the quadrat, but not rooted in the quadrat, is only recorded if it rooted into the same elevation as the species rooted in the plot (that is, within 20 centimeter $[\mathrm{cm}]$ elevation difference). This prevents individuals associated with different inundation frequencies from being associated with the quadrat. Because species level estimates are layered, one estimate of total living plant cover is also made. This represents the actual vertical cover of living plant material over the quadrat and does not include individuals rooted outside the quadrat. Rooted, dead vegetation is estimated separately from live foliar cover and from detached litter. Estimates of ground cover elements are also recorded (table 4). Litter and biological soil crust are estimated independently of mineral components (rock, soil).

\section{Observer Calibration}

All cover observers will calibrate cover estimates at the beginning of the sampling season and if any new observers start collecting data. Initial quadrat assessments are done as a group and how estimations are made are discussed. Observers should work together through as many quadrats as needed to be sufficiently accurate and precise. Observer estimates are considered calibrated when independent estimates of species within the same quadrat are consistently within 5 percent of each other. Observers will also have ready access to reference cards showing what different levels of cover look like, as well as a small card showing the amount of 1 percent cover for a $1-\mathrm{m}^{2}$ frame.

\section{Collecting and Pressing Unknown Species}

Unknown species that occur in quadrats are given a unique code and collected for later identification. Collections of flowers, fruit, leaves, and roots (when useful) are pressed at the site in newspaper, and the unknown code, location, and date are written on the newspaper. Pertinent collection information is written in a collection notebook along with the unknown code. Whenever possible, herbarium-quality collections are made. High-quality collections that are not destroyed while being identified are given to the GLCA herbarium, GRCA herbarium, or the Hualapai Tribe herbarium as appropriate.

\section{When Not to Sample a Site}

The monitoring ecologist or lead crewmember can decide not to sample a site if it is deemed an unsafe location to work, boats cannot safely land or stay anchored, or if time does not allow for both sampling and reaching the destination camping area at a reasonable hour. To ensure that the distribution of sample sites is not skewed to upstream locations, predetermined camp sites should be adhered to and sites with the lowest random sample number given the highest priority. If it does not seem likely all sites between two campsites will get sampled, the sites with the lowest generated sample number (see SOP 3 - Generating Random Sample Sites) should be given priority.

In the event that a random site is rejected, the field lead will confer with the lead boatman to identify a replacement from extra random sample sites generated before the field season. If the field lead determines that sampling goals have been met for the day (that is, the crew is on schedule to meet sampling goals for the day and the river segment), the crew can continue down river without replacing the site.

\section{Data Management, Analysis, and Reporting}

Data management is a crucial component of long-term monitoring and requires specific procedures for collecting, entering, and distributing data. Additional information regarding data management is provided in the publicly available data management plan, "Riparian Vegetation Monitoring downstream of Glen Canyon Dam" available at https://dmptool.org. The monitoring ecologist is primarily responsible for managing the data in each stage of the monitoring protocol.

Reporting is conducted on 1- and 5-year cycles. Yearly reports consist of administrative updates and descriptions of the 
Table 3. Cover classes for riparian foliar and ground-cover estimates made along the Colorado River in Arizona between Glen Canyon Dam and Lake Mead.

\begin{tabular}{cccccc} 
[Cover estimates are rounded to the nearest 5 percent, with the exception of trace $(\mathrm{T})$ and 1 percent] \\
\hline Cover percentage & Cover class & Cover percentage & Cover class & Cover percentage & Cover class \\
\hline$<1$ & $\mathrm{~T}$ & $32.5-37.5$ & 35 & $72.5-77.5$ & 75 \\
$1-2.5$ & 1 & $37.5-42.5$ & 40 & $77.5-82.5$ & 80 \\
$2.5-7.5$ & 5 & $42.5-47.5$ & 45 & $82.5-87.5$ & 85 \\
$7.5-12.5$ & 10 & $47.5-52.5$ & 50 & $87.5-92.5$ & 90 \\
$12.5-17.5$ & 15 & $52.5-57.5$ & 55 & $92.5-97.5$ & 95 \\
$17.5-22.5$ & 20 & $57.5-62.5$ & 60 & $97.5-100$ & 100 \\
$22.5-27.5$ & 25 & $62.5-67.5$ & 65 & -- & -- \\
$27.5-32.5$ & 30 & $67.5-72.5$ & 70 & -- & -- \\
\hline
\end{tabular}

Table 4. Cover types and their definitions used for monitoring of riparian vegetation along the Colorado River in Arizona between Glen Canyon Dam and Lake Mead.

[Foliar cover is recorded separately for cover rooted in the quadrat, cover rooted outside the quadrat, and dead rooted vegetation; mm, millimeter]

\begin{tabular}{ll}
\hline \multicolumn{1}{c}{ Cover type } & \multicolumn{1}{c}{ Definition } \\
\hline $\begin{array}{l}\text { Total foliar cover } \\
\text { Species foliar cover }\end{array}$ & $\begin{array}{l}\text { The total vertical, living plant cover rooted inside a quadrat. } \\
\text { The total vertical, living cover rooted inside a quadrat for one species. }\end{array}$ \\
$\begin{array}{l}\text { Overhanging foliar cover } \\
\text { The total vertical cover for species rooted outside a quadrat with living foliar cover overhanging } \\
\text { the quadrat. The overhanging vegetation comes from an individual that is rooted at the same } \\
\text { elevation as the quadrat. }\end{array}$ \\
$\begin{array}{l}\text { Dead vegetation that is still rooted plus any hanging flood debris (not litter that is lying on } \\
\text { the ground). The species is not recorded; all dead, rooted vegetation is recorded together. } \\
\text { Standing dead includes all standing dead cover that is rooted inside and outside a quadrat. }\end{array}$ \\
$\begin{array}{l}\text { Unrooted, dead plant material, woody or herbaceous. } \\
\text { Bitter }\end{array}$ & $\begin{array}{l}\text { Light gray to black cyanobacteria, moss, lichen. Must be on soil, not on rocks. } \\
\text { Fines (silts, clays) }\end{array}$ \\
$\begin{array}{l}\text { Sediment grains less than } 0.062 \mathrm{~mm} \text { diameter along median axis. } \\
\text { Sand }\end{array}$ & $\begin{array}{l}\text { Sediment grains } 0.062 \text { to } 2 \mathrm{~mm} \text { along median axis. } \\
\text { Rock }\end{array}$ \\
\hline
\end{tabular}

data collected each year. Every 5 years, a status and trends report is created, which assesses change in vegetation over time and may also include allied research.

The following section describes data management and reporting procedures, but more detailed instructions are given in SOPs $10-14$.

\section{Field Data Management}

Paper datasheets (see appendix 3) will be used for data collection until an electronic data collection protocol is developed. These will be checked by the recorder at the end of each transect and with the completion of each site. Before leaving a site, the field crew leader is responsible for ensuring that all data forms have been completed correctly and legibly, organized, and stored properly. Any paper datasheets that are used should be rechecked for species name inconsistencies, illegible handwriting, and missing data. These datasheets are then organized and stored in the "library" ammo can with the empty datasheets, floras, and extra field gear at the end of the day.

Once the electronic data collection methods are implemented, data will be entered directly into the database on field tablet computers, unless problems with the electronic data collection system are encountered, time constraints require the use of paper datasheets in addition to a tablet computer, or there are not enough tablet computers available for use at the time of field sampling. Many of the forms contain quality-assurance/quality-control measures to prevent recording mistakes in the field, but the recorder should check to ensure data was entered properly at the end of each transect. At the end of each day, any tablet computers used to collect data will be backed up on flash drives, one for each boat. 


\section{Office Data Management}

On returning to the office, all datasheets are scanned, the electronic file clearly labeled, and stored in the proper server location. Currently, data is entered into Microsoft Excel files, which are organized in files on the GCMRC server. Excel files are organized by year and type of sample (fixed or random), are clearly labeled, and are stored in the appropriate server location. Development of a vegetation database is underway, which will ultimately house all the cover data, elevation data, and photographs. Hard copies are stored in files indefinitely once the data has been entered and error checked. Any data on tablet computers is merged with the master desktop version of the database. The new, complete database is then put back on the field tablets.

Site photographs, unknown plant photographs, photographs of field crews at work, and related data are saved to the appropriate server locations. File names of site photographs are changed to the appropriate format (see SOP 10), so they can be easily identified.

Collections of unknown species are properly stored and identified. The scientific name of each identified collection is recorded in the collection notebook next to the unknown code and on the newspaper wrapping the collection. Once all the data has been entered and verified, unknown codes in the data can be changed to the correct scientific name. Collections that are not destroyed in the identification process and are of herbarium quality are given to the GLCA, GRCA or Hualapai Tribe herbarium, depending on where it was collected, along with the required collection information.

\section{Data Entry and Verification}

Data recorded on paper datasheets must be entered into Microsoft Excel files, until the database is fully functioning, at which time data will be entered into the database. Data entry should be completed by someone who participated in collecting the data or, at a minimum, is familiar with the project and the data. Care should be taken while entering data to try to make as few mistakes as possible. After entering all the data on paper datasheets into the database, the entered data is verified by comparing each datasheet against the entered data. Any mistakes are corrected as they are found.

Ultimately, data entry will take place in the field on tablet computers, which are merged with the master database in the office. Before merging the field data with the master database, backups of both files will be made. After merging the files, the data will be checked to make sure that all the new data merged properly and that all previous data were retained.

\section{Analysis and Reporting}

The minimum reporting requirements consist of both 1- and 5-year reporting cycles. Annually, a river-trip report, an investigator annual report (IAR), and an annual data update are required. Every 5 years, a status and trends report is published, which analyzes and synthesizes available data and makes statements about status and trends in selected parameters. Guidelines and timelines for these reports are provided in SOP 14.

The river-trip report and IAR are administrative/public interest reports that require minimal statistical analyses. Both summarize the accomplishments of the field season. The rivertrip report focuses more on the success and failures of logistics, personnel, and scheduling, while the IAR focuses on the progress and accomplishments of research and data analysis, which are of particular interest to NPS resource managers.

The annual data update provides basic summaries of the data collected each year, such as a species lists, diversity estimates, richness, and cover of herbaceous and woody vegetation. This report is submitted as a part of the larger GCMRC annual report to stakeholders and is made available in an electronic format.

The 5-year summary report analyzes all available data to assess the status and trends of riparian vegetation, particularly as it relates to hydrologic changes. This report is peer-reviewed and published as a USGS Open-File Report. The topics covered and analyses used in these reports will change over time but will include at a minimum how the riparian vegetation has responded to differing flow regimes over time.

Data collected as a part of this protocol will also be used to answer new, specific research questions over time. Research of this nature will be published in peer-reviewed journals as they are developed and need not be associated with the required reporting.

\section{Personnel Requirements and Training}

As currently designed, this monitoring protocol is to be implemented by three full-time employees - a research ecologist, a monitoring ecologist, and a biological science technician. The majority of field staff consists of volunteers secured for each river trip. The most central person to the successful implementation of this protocol is the monitoring ecologist, ideally a plant ecologist or botanist at the General Schedule-07 (GS-07) grade level or higher, with knowledge of the flora of the southwestern United States, experience and expertise in field sampling, data entry validation, and analysis and reporting. In addition, the monitoring ecologist must have strong organizational and leadership skills to ensure the crew is well outfitted, scheduled, adequately trained, and motivated to do their best work. This individual will serve as the lead for all pre-trip planning, field sampling, specimen and data management, administrative reporting, and yearly analysis and reporting.

For field sampling, one additional crew leader will be needed who has familiarity with the flora, or adequate background to identify unknown plants and make collections, as required. This person can be the research ecologist, biological science technician, NPS cooperator, qualified volunteer, or other qualified individual. The two crews will sample as one team until the monitoring ecologist is confident that the second crew leader and crew can work independently. 
All remaining field crew members, typically volunteers, should be well organized, function well as team members, be comfortable in the field, and work methodically under sometimes difficult conditions. Field crewmembers need to be able to work in the field with other crewmembers for long periods of time, respectfully and with good humor. They must also be willing to work flexible schedules that may include long workdays in inclement weather and a long period away from home.

Because sampling across years and personnel must yield comparable data, training is essential for developing competent observers, both at the initiation of the field season and thereafter. The monitoring ecologist will ensure that training is adequate; and provide a refresher on plant identification, data entry, and other essential skills at the start of the season (SOP 2). The monitoring ecologist will train field crews on all data collection devices and data management methods until mastery is demonstrated. As data are recorded or uploaded, additional training will ensure that data are recorded accurately, errors identified in a timely fashion, and all data are backed up in the most efficient and secure way. The research ecologist, biological science technician, or another returning field crewmember with knowledge of the protocol and logistics of river trips can assist as needed.

After the field season, the monitoring ecologist will be responsible for coordinating with the biological science technician to ensure that all data are complete and error checked. Thereafter, the monitoring ecologist will send notification to the research ecologist that yearly data are available for use.

Every 5 years, the research ecologist (GS-11 or higher) will schedule and take the lead on preparing a status and trends report. This report will be prepared in close consultation with the monitoring ecologist. The research ecologist will also be the lead scientist responsible for framing research questions, conducting more complex and novel statistical analyses, and identifying appropriate venues for publication or presentation, and preparing and publishing peer-reviewed journal articles. The research ecologist will also assist with any power analyses, statistical design adjustments, or other changes to refine or revise the protocol, or to refine statistical analysis and synthesis for any level of reporting. This position will provide overall leadership and scientific guidance for the monitoring program, securing funding, supervising the monitoring ecologist and biological science technician, and ensuring that the riparian monitoring program is well integrated into the operations of GCMRC and the USGS Southwest Biological Science Center (SBSC).

The biological science technician assists with field coordination, organization, and data collection. This position will also complete any necessary data entry and error checking, as well as plant collections management. The biological science technician can help with any other associated work as needed.

\section{List of Standard Operating Procedures}

The SOPs in appendix 1 provide detailed instructions on how to conduct riparian vegetation monitoring riparian-vegetation monitoring along the Colorado River between Glen Canyon Dam and Lake Mead. Copies of all relevant SOPs should be provided to field technicians, paid and volunteer, before sampling. SOPs related to field sampling should be carried into the field as a reference for proper sampling techniques. General methodologies are discussed above in the sections Sampling Design, Field Methods, and Data Handling, Analysis, and Reporting. The SOPs are as follow:
SOP 1—Preparations for the Field Season and Equipment Needed
SOP 2-Recruiting and Training Field Technicians
SOP 3 - Generating Random Sample Sites
SOP 4 - Setting Up the Transects and Quadrats
SOP 5-Site Photos
SOP 6-Vegetation and Ground-Cover Sampling
SOP 7-Slope and Aspect
SOP 8-Measuring Quadrat Elevations
SOP 9 - Collecting and Pressing Unknown Plant Species
SOP 10-After Each Field Trip
SOP 11-After the Field Season
SOP 12-Data Entry and Error Checking
SOP 13-Data Management
SOP 14-Data Analysis and Reporting
SOP 15-Revising the Protocol

\section{References Cited}

Belnap, J., Phillips, S.L., Witwicki, D.L., and Miller, M.E., 2008, Visually assessing the level of development and soil surface stability of cyanobacterially dominated biological soil crusts: Journal of Arid Environments, v. 72, no. 7, p. 12571264, https://doi.org/10.1016/j.jaridenv.2008.02.019.

Beus, S.S., Avery, C.C., Stevens, L.E., Kaplinski, M., Mayes, H., and Cluer, B.L., 1992, The influence of variable discharge regimes on Colorado River sand bars below Glen Canyon Dam, in Beus, S.S., and Avery, C.C., eds., The influence of variable discharge regimes on Colorado River sand bars below Glen Canyon Dam-final report: Flagstaff, Ariz., Northern Arizona University, submitted to Bureau of Reclamation, Glen Canyon Environmental Studies, National Park Service cooperative agreement no. CA 8006-8-0002, 62 p., https://www.gcmrc.gov/library/reports/physical/ Fine_Sed/beus1993.pdf.

Birkin, A.S., and Cooper, D.J., 2006, Processes of Tamarix invasion and floodplain development along the lower Green River, Utah: Ecological Applications, v. 16, no. 3, p. 1103-1120, https://doi.org/10.1890/1051-0761(2006)016[1103:POTIAF]2. $0 . \mathrm{CO} ; 2$.

Bowers, J.E., Webb, R.H., and Pierson, E.A., 1997, Succession of desert plants on debris-flow terraces, Grand Canyon, Arizona, U.S.A.: Journal of Arid Environments, v. 36, no. 1, p. $67-86$. 
Brian, N.J., 1982, A preliminary study of the riparian coyote willow communities along the Colorado River in Grand Canyon National Park, Arizona: Flagstaff, Ariz., Northern Arizona University, M.S. thesis, 84 p.

Brown, B.T., 1987, Monitoring bird population densities along the Colorado River in Grand Canyon: Glen Canyon Environmental Studies, prepared by National Park Service, Cooperative Park Study Unit, Tucson, Ariz., submitted to Bureau of Reclamation, Salt Lake City, Utah, GCEIS/24-87, 26 p., https:/www.gcmrc. gov/library/reports/GCES/Biological/Terrestrial/Brown1987d.pdf.

Brown, B.T., 1989, Breeding ecology of riparian birds along the Colorado River in Grand Canyon, Arizona: Tucson, Ariz., Cooperative National Park Resources Studies Unit, School of Renewable Resources, University of Arizona, technical report no. $25,42 \mathrm{p}$.

Brown, D.E., 1982, Biotic communities of the American southwest-United States and Mexico, v. 4, no. 1-4: Salt Lake City, Utah, University of Utah Press, 342 p.

Carothers, S.W., Aitchison, S.W., Karpiscak, M.M., Rufner, G.A., Sharber, N.J., Shoemaker, P.L., Stevens, L.E., Theroux, M.E., and Tomko, D.S., 1976, An ecological survey of the riparian zone of the Colorado River and its tributaries between Lees Ferry and the Grand Wash Cliffs - final report: Flagstaff, Ariz., Museum of Northern Arizona, Department of Biology, submitted to U.S. Department of the Interior, National Park Service, Grand Canyon National Park, Colorado River Research Series, contribution no. 38, contract no. CX821500007, Colorado River Research technical report no. 10, $251 \mathrm{p}$.

Carothers, S.W., and Brown, B.T., 1991, The Colorado River through Grand Canyon-Natural history and human change: Tucson, Ariz., University of Arizona Press, 235 p.

Clover, E.U., and Jotter, L., 1944, Floristic studies in the canyon of the Colorado and tributaries: American Midland Naturalist, v. 32, no. 3, p. 591-642, https://www.jstor.org/stable/pdfplus/2421241.pdf.

Dean, D.J., and Schmidt, J.C., 2011, The role of feedback mechanisms in historic channel changes of the lower Rio Grande in the Big Bend region: Geomorphology, v. 126, no. 3-4, p. 333-349, https://doi.org/10.1016/j.geomorph.2010.03.009.

Dolan, R., Howard, A., and Gallenson, A., 1974, Man's impact on the Colorado River in the Grand Canyon-The Grand Canyon is being affected both by the vastly changed Colorado River and by the increased presence of man: American Scientist, v. 62 , no. 4, p. 392-401, https://www.jstor.org/stable/27844987.

Dolan, R., Howard, A., and Trimble, D., 1978, Structural control of the rapids and pools of the Colorado River in the Grand Canyon: Science, v. 202, no. 4368, p. 629-631, https://doi. org/10.1126/science.202.4368.629.
Esri, 2013, ArcGIS for Desktop, version 10.2: Redlands, Calif., https://www.esri.com/.

Fairley, H.C., 2005, Cultural resources in the Colorado River corridor, in Gloss, S.P., Lovich, J.E., and Melis, T.S., eds., The state of the Colorado River ecosystem in Grand Canyon-A report of the Grand Canyon Monitoring and Research Center 1991-2004: U.S. Geological Survey Circular 1282, p. 177-192, https://pubs.usgs.gov/circ/1282/.

Farley, G.H., Ellis, L.M., Stuart, J.N., and Scott, N.J., Jr., 1994, Avian species richness in different-aged strands of riparian forest along the middle Rio Grande, New Mexico: Conservation Biology, v. 8, no. 4, p. 1098-1108, https://doi. org/10.1046/j.1523-1739.1994.08041098.x.

Gregory, S.V., Swanson, F.J., McKee, W.A., and Cummins, K.W., 1991, An ecosystem perspective of riparian zones: BioScience, v. 41, no. 8, p. 540-551, https://www.jstor.org/ stable/1311607.

Hadley, D.R., 2014, Geomorphology and vegetation change at Colorado River campsite, Marble and Grand Canyons, AZ: Flagstaff, Ariz., Northern Arizona University, M.S. thesis, 146 p., http://www.gcmrc.gov/library/reports/physical/ Fine_Sed/Hadley_Thesis_Final.pdf.

Hazel, J.E., Jr., Kaplinski, M., Parnell, R., Manone, M., and Dale, A., 1999, Topographic and bathymetric changes at thirty-three long-term study sites, in Webb, R.H., Schmidt, J.C., Marzolf, G.R., and Valdez, R.A., eds., The controlled flood in Grand Canyon: Washington, D.C., American Geophysical Union, Geophysical Monograph Series, v. 110, p. $161-183$.

Hazel, J.E., Jr., Topping, D.J., Schmidt, J.C., and Kaplinski, M., 2006, Influence of a dam on fine-sediment storage in a canyon river: Journal of Geophysical ResearchEarth Surface, v. 111, no. F1, p. 1-16, https://doi. org/10.1029/2004JF000193.

Hazel, J.E., Jr., Grams, P.E., Schmidt, J.C., and Kaplinski, M., 2010, Sandbar response in Marble and Grand Canyons, Arizona, following the 2008 high-flow experiment on the Colorado River: U.S. Geological Survey Scientific Investigations Report 2010-5015, 52 p., https://pubs.usgs.gov/ sir/2010/5015/.

Holmes, J.A., Spence, J.R., and Sogge, M.K., 2005, Birds of the Colorado River in Grand Canyon-A synthesis of status, trends and dam operations effects, in Gloss, S.P., Lovich, J.E., and Melis, T.S., eds., The state of the Colorado River ecosystem in Grand Canyon-A report of the Grand Canyon Monitoring and Research Center 1991-2004: U.S. Geological Survey Circular 1282, p. 123-138, https://pubs. usgs.gov/circ/1282/. 
Huisinga, K., and Yeatts, M., 2003, Soosoy Himu Naanamiwiwyungwa-An analysis of the Grand Canyon Monitoring and Research Center's terrestrial monitoring program and the development of a Hopi long-term plan: Flagstaff, Ariz., Hopi Cultural Preservation Office, submitted to U.S. Geological Survey, Grand Canyon Monitoring and Research Center-final report, cooperative agreement no. 01WRSA0358.

Jackson-Kelly, L., and Hubbs, D., 2007, Traditional Hualapai ecological monitoring knowledge monitoring protocols: Phoenix, Ariz., Hualapai Tribe, Department of Cultural Resources, https://www.usbr.gov/uc/rm/amp/twg/ mtgs/07apr02/Attach_13c.pdf.

Johansson, M.E., Nilsson, C., and Nilsson, E., 1996, Do rivers function as corridors for plant dispersal?: Journal of Vegetation Science, v. 7, no. 4, p. 593-598, https:// doi. org/10.2307/3236309.

Johnson, R.R., 1991, Historic changes in vegetation along the Colorado River in the Grand Canyon, in Marzolf, G.R., and Committee to Review the Glen Canyon Environmental Studies Water Science and Technology Board, eds., Colorado River ecology and dam management, Santa Fe, N. Mex., May 24-25, 1990, Proceedings: National Academy Press, p. 178-206.

Kaplinski, M., Behan, J., Hazel, J.E., Parnell, R.A., and Fairley, H.C., 2005, Recreational values and campsites in the Colorado River ecosystem, in Gloss, S.P., Lovich, J.E., and Melis, T.S., eds., The state of the Colorado River ecosystem in Grand Canyon-A report of the Grand Canyon Monitoring and Research Center 1991-2004: U.S. Geological Survey Circular 1282, p. 193-205, https://pubs. usgs.gov/circ/1282/.

Kearsley, M.J.C., and Ayers, T.J., 1996, The effects of interim flows from Glen Canyon Dam on riparian vegetation in the Colorado River corridor, Grand Canyon National Park, Arizona - final report: Flagstaff, Ariz., Northern Arizona University, submitted to Grand Canyon National Park, Grand Canyon Science Center, cooperative agreement no. 8041-8-0002, 702 p., https:/www.gcmrc.gov/library/reports/ biological/Terrestrial/Kearsley/Kearsley1996b.pdf.

Kearsley, M.J.C., and Lightfoot, D., 2006, Integration and interpretation of vegetation and faunal abundance patterns, in Kearsley, M.J.C., Cobb, N.S., Yard, H.K., Lightfoot, D.C., Brantley, S.L., Carpenter, G.C., and Frey, J.K., eds., Inventory and monitoring of terrestrial riparian resources in the Colorado River corridor of Grand Canyon-An integrative approach — draft final report: submitted to U.S. Geological Survey, Grand Canyon Monitoring and Research Center, 144-159 p., https://www.gcmrc.gov/library/ reports/biological/terrestrial/Kearsley/01_WRAG044/ Kearsley2006.pdf.
Kiviat, E., and Hamilton, E., 2001, Phragmites use by native North Americans: Aquatic Botany, v. 69, no. 2-4, p. 341357, https://doi.org/10.1016/S0304-3770(01)00147-4.

Lite, S.J., Bagstad, K.J., and Stromberg, J.C., 2005, Riparian plant species richness along lateral and longitudinal gradients of water stress and flood disturbance, San Pedro River, Arizona, USA: Journal of Arid Environments, v. 63 , no. 4, p. $785-813$, https://doi.org/10.1016/j. jaridenv.2005.03.026.

Magirl, C.S., Breedlove, M.J., Webb, R.H., and Griffiths, P.G., 2008, Modeling water-surface elevations and virtual shorelines for the Colorado River in Grand Canyon, Arizona: U.S. Geological Survey Scientific Investigations Report 2008-5075, 32 p., https://pubs.usgs.gov/ sir/2008/5075.

Manners, R.B., Schmidt, J.C., and Scott, M.L., 2014, Mechanisms of vegetation-induced channel narrowing of an unregulated canyon river-Results from a natural field-scale experiment: Geomorphology, v. 211, p. 100-115, https:// doi.org/10.1016/j.geomorph.2013.12.033.

Mayes, V.O., and Lacy, B.B., 1989, Nanise', a Navajo herbal-One hundred plants from the Navajo Reservation: Tsaile, Ariz., Navajo Community College Press, 153 p.

Melis, T.S., ed., 2011, Effects of three high-flow experiments on the Colorado River ecosystem downstream from Glen Canyon Dam, Arizona: U.S. Geological Survey Circular 1366, 147 p., https://pubs.usgs.gov/circ/1366/.

Merritt, D.M., and Bateman, H.L., 2012, Linking stream flow and groundwater to avian habitat in a desert riparian system: Ecological Applications, v. 22, no. 7, p. 1973-1988, https:// doi.org/10.1890/12-0303.1.

Merritt, D.M., and Cooper, D.J., 2000, Riparian vegetation and channel change in response to river regulation- $\mathrm{A}$ comparative study of regulated and unregulated streams in the Green River Basin, USA: Regulated Rivers-Research and Management, v. 16, no. 6, p. 543-564, https://doi. org/10.1002/1099-1646(200011/12)16:6<543::AIDRRR590>3.0.CO;2-N.

Merritt, D.M., and Poff, N.L., 2010, Shifting dominance of riparian Populus and Tamarix along gradients of flow alteration in western North American Rivers: Ecological Applications, v. 20, no. 1, p. 135-152, https://doi. org/10.1890/08-2251.1.

Mortenson, S.G., and Weisberg, P.J., 2010, Does river regulation increase the dominance of invasive woody species in riparian landscapes?: Global Ecology and Biogeography, v. 19, no. 4, p. 562-574, https://doi. org/10.1111/j.1466-8238.2010.00533.x. 
Mortenson, S.G., Weisberg, P.J., and Stevens, L.E., 2012, The influence of floods and precipitation on Tamarix establishment in Grand Canyon, Arizona-Consequences for flow regime restoration: Biological Invasions, v. 14, no. 5, p. 1061-1076, https://doi.org/10.1007/s10530-011$0139-\mathrm{z}$

Naiman, R.J., and Decamps, H., 1997, The ecology of interfaces-Riparian zones: Annual Review of Ecology and Systematics, v. 28, p. 621-58, https://www.jstor.org/ stable/2952507.

National Park Service, 2006, Colorado River management plan: U.S. Department of the Interior, National Park Service, Grand Canyon National Park, 35 p., https://www. nps.gov/grca/learn/management/upload/CRMPIF_s.pdf.

Palmquist, E.C., Ralston, B.E., Merritt, D.M., and Shafroth, P.B., 2018, Landscape-scale processes influence riparian plant composition along a regulated river: Journal of Arid Environments, v. 148, p. 54-64, https://doi.org/10.1016/j. jaridenv.2017.10.001.

Perkins, D.W., Scott, M.L., and Naumann, T., 2015, Abundance of invasive, non-native riparian herbs in relation to river regulation: River Research and Applications, v. 32, no. 6, p. 1279-1288, https://doi. org/10.1002/rra.2981.

Phillips, B.G., Phillips, A.M., III, and Schmidt-Bernzott, M.A., 1987, Annotated checklist of vascular plants of Grand Canyon National Park-Monograph no. 7: Grand Canyon, Ariz., Grand Canyon Natural History Association, $79 \mathrm{p}$.

Porter, M.E., and Kearsley, M.J.C., 2001, The response of salt cedar, Tamarix chinensis, to experimental flows in Grand Canyon: Hydrology and Water Resources in Arizona and the Southwest, v. 31, p. 45-50, https://arizona.openrepository. com/arizona/bitstream/10150/296583/1/hwr_31-045-050. pdf.

Ralston, B.E., 2005, Riparian vegetation and associated wildlife, in Gloss, S.P., Lovich, J.E., and Melis, T.S., eds., The state of the Colorado River ecosystem in Grand Canyon-A report of the Grand Canyon Monitoring and Research Center 1991-2004: U.S. Geological Survey Circular 1282, p. 103-121, https://pubs.usgs.gov/ circ $/ 1282 /$.

Ralston, B.E., 2010, Riparian vegetation response to the March 2008 short-duration, high-flow experimentImplications of timing and frequency of flood disturbance on nonnative plant establishment along the Colorado River below Glen Canyon Dam: U.S. Geological Survey Open-File Report 2010-1022, 30 p., https://pubs.usgs.gov/ of/2010/1022/.
Ralston, B.E., 2011, Summary report of responses of key resources to the 2000 low steady summer flow experiment, along the Colorado River downstream from Glen Canyon Dam, Arizona: U.S. Geological Survey Open-File Report 2011-1220, 129 p., https://pubs.usgs.gov/of/2011/1220/of2011-1220.pdf.

Richardson, D.M., Holmes, P.M., Esler, K.J., Galtowitsch, S.M., Stromberg, J.C., Kirkman, S.P., Pysek, P., and Hobbs, R.J., 2007, Riparian vegetation-Degradation, alien plant invasions, and restoration prospects: Diversity and Distributions, v. 13, no. 1, p. 126-139, https://doi.org/10.1111/j.13669516.2006.00314.x.

Roberts, A., Begay, R.M., and Kelley, K.B., 1995, Bits'íís Ninéézi (The river of neverending life)-Navajo history and cultural resources of the Grand Canyon and the Colorado River: Window Rock, Ariz., Navajo Nation Historic Preservation Department, 181 p., https://www.gcmrc.gov/library/reports/cultural/ Navajo/Roberts1995.pdf.

Sabo, J.L., Sponseller, R., Dixon, M., Gade, K., Harms, T., Heffernan, J., Jani, A., Katz, G., Soykan, C., Watts, J., and Welter. J., 2005, Riparian zones increase regional species richness by harboring different, not more, species: Ecology, v. 86, no. 1, p. 56-62, https://www.jstor.org/stable/3450987.

Sankey, J.B., Ralston, B.E., Grams, P.E., Schmidt, J.C., and Cagney, L.E., 2015, Riparian vegetation, Colorado River, and climate - Five decades of spatiotemporal dynamics in the Grand Canyon with river regulation: Journal of Geophysical Research Biogeosciences, v. 120, no. 8, p. 1532-1547, http:// dx.doi.org/10.1002/2015JG002991.

Schmidt, J.C., and Graf, J.B., 1990, Aggradation and degradation of alluvial sand deposits, 1965-1986, Colorado River, Grand Canyon National Park, Arizona: U.S. Geological Survey Professional Paper 1493, 74 p., https://pubs.er.usgs.gov/publication/ pp1493.

Schmidt, J.C., Grams, P.E., and Melis, T.S., 2011, Understanding physical processes of the Colorado River, in Melis, T.S., ed., Effects of three high-flow experiments on the Colorado River ecosystem downstream from Glen Canyon Dam, Arizona: U.S. Geological Survey Circular 1366, p. 17-51, https://pubs.usgs. gov/circ/1366/.

Schmidt, J.C., Webb, R.H., Valdez, R.A., Marzolf, G.R., and Stevens, L.E., 1998, Science and values in river restoration in the Grand Canyon: BioScience, v. 48, no. 9, p. 735-747, https:// www.jstor.org/stable/1313336.

Scott, M.L., Perkins, D.L., and Wheaton, J.M., 2012, Big river protocol development-A prototype warranty project: U.S. Geological Survey-Fort Science Center, Northern Colorado Plateau Network, and Utah State University, Department of Watershed Sciences, 68 p., https://etal.usu.edu/Reports/Big Rivers_Final_Report_2012.pdf. 
Shafroth, P.B., Stromberg, J.C., and Patten, D.T., 2002, Riparian vegetation response to altered disturbance and stress regimes: Ecological Applications, v. 12, no. 1, p. 107-123, https://doi.org/10.1890/1051-0761(2002)012[0107:RVRTA D]2.0.CO;2.

Sogge, M.K., Felley, D., and Wotawa, M., 1998, Riparian bird community ecology in the Grand Canyon-Final report: Flagstaff, Ariz., U.S. Geological Survey, Colorado Plateau Field Station report, cooperative agreement no. 8031-80002, 276 p. plus appendices, https://www.gemrc.gov/ library/reports/biological/terrestrial/Sogge2000b.pdf.

Spence, J.R., 2006, The riparian and aquatic bird communities along the Colorado River from Glen Canyon Dam to Lake Mead, 1996-2000-Final report: Flagstaff, Ariz., National Park Service, Glen Canyon National Recreation Area, submitted to U.S. Geological Survey, Grand Canyon Monitoring and Research Center, 283 p.

Stevens, L.E., 2012, The biogeographic significance of a large, deep canyon - Grand Canyon of the Colorado River, southwestern USA, in Stevens, L.E., ed., Global advances in biogeography: Rijecka, Croatia, InTech, p. 169-208, https:// www.intechopen.com/books/global-advances-inbiogeography/the-biogeographic-significance-of-a-large-deep-canyongrand-canyon-of-the-colorado-river-usa.

Stevens, L.E., and Ayers, T.J., 2002, The biodiversity and distribution of exotic vascular plants and animals in the Grand Canyon region, in Tellman, B., ed., Invasive exotic species in the Sonoran region: Tucson, University of Arizona Press, p. 241-266.

Stevens, L.E., Ayers, T.J., Bennett, J.B., Christensen, K., Kearsley, M.J.C., Meretsky, V.J., Phillips, A.M., III, Parnell, R.A., Spence, J.R., Sogge, M.K., Springer, A.E., and Wegner, D.L., 2001, Planned flooding and Colorado River riparian trade-offs downstream from Glen Canyon Dam, Arizona: Ecological Applications, v. 11, no. 3, p. 701-710, https://doi.org/10.1890/1051-0761(2001)011\%5B0701:PFA CRR\%5D2.0.CO\%3B2.

Stevens, L.E., Schmidt, J.C., Ayers, T.J., and Brown, B.T., 1995, Flow regulation, geomorphology, and Colorado River marsh development in the Grand Canyon, Arizona: Ecological Applications, v. 5, no. 4, p. 1025-1039, https://doi. org/10.2307/2269352.

Stevens, L.E., and Waring, G.L., 1986, Effects of post-dam flooding on riparian substrates, vegetation, and invertebrate populations in the Colorado River corridor in Grand Canyon, Arizona-Terrestrial biology of the Glen Canyon Environmental Studies: Flagstaff, Ariz., Bureau of Reclamation, Glen Canyon Environmental Studies, contract no. IA4-AA-40-01930, GCES 19/87, 175 p., https://www. gcmrc.gov/library/reports/GCES/Stevens1986.pdf.
Stewart, W., Larkin, K., Orland, B., and Anderson, D., 2003, Boater preferences for beach characteristics downstream from Glen Canyon Dam, Arizona: Journal of Environmental Management, v. 69, no. 2, p. 201-211, https://doi. org/10.1016/j.jenvman.2003.08.001.

Stoffle, R.W., and Evans, M.J., 1976, Resource competition and population change-A Kaibab Paiute ethnohistorical case: Ethnohistory, v. 23, no. 2, p. 173-197, https://doi. org/10.2307/481516.

Stoffle, R.W., Halmo, D.B., Evans, M.J., and Austin, D.E., 1994, Piapaza 'Uipi (Big River Canyon)—Southern Paiute ethnographic resources inventory and assessment for Colorado River corridor, Glen Canyon National Recreation Area, Arizona: submitted to Bureau of Reclamation, Glen Canyon Environmental Studies office and National Park Service Rocky Mountain Regional office, project no. GLCA-R92-0011, 369 p.

Stromberg, J.C., Andersen, D.C., and Scott, M.L., 2012, Riparian floodplain wetlands of the arid and semiarid southwest, in Batzer, D.P., and Baldwin, A.H., eds., Wetland habitats of North America-Ecology and conservation concerns: Berkeley, Calif., University of California Press, p. 343-356.

Stromberg, J.C., McCluney, K.E., Dixon, M.D., and Meixner, T., 2013, Dryland riparian ecosystems in the American southwest-Sensitivity and resilience to climatic extremes: Ecosystems, v. 16, no. 3, p. 411-415, https://doi. org/10.1007/s10021-012-9606-3.

Topping, D.J., Schmidt, J.C., and Vierra, L.E., Jr., 2003, Computation and analysis of the instantaneous-discharge record for the Colorado River at Lees Ferry, Arizona-May 8, 1921, through September 30, 2000: U.S. Geological Survey Professional Paper 1677, 118 p.

Turner, R.M., and Karpiscak, M.M., 1980, Recent vegetation changes along the Colorado River between Glen Canyon Dam and Lake Mead, Arizona: U.S. Geological Survey Professional Paper 1132, 125 p., https://pubs.usgs.gov/ pp/1132/report.pdf.

U.S. Department of the Interior, 1996, Record of Decision-Operation of Glen Canyon Dam Final Environmental Impact Statement: Salt Lake City, Utah, U.S. Department of the Interior, Bureau of Reclamation, Glen Canyon Dam Adaptive Management Program, 15 p., http://www.usbr. gov/uc/rm/amp/pdfs/sp_appndxG_ROD.pdf.

U.S. Geological Survey, 2002, Colorado river mile system geospatial database: U.S. Geological Survey Grand Canyon Monitoring and Research Center web page, accessed August, 17, 2017, at https://www.gcmrc.gov/geospatial/ data/. 
Voichick, N., and Wright, S.A., 2007, Water-temperature data for the Colorado River and tributaries between Glen Canyon Dam and Spencer Canyon, northern Arizona, 1988-2005: U.S. Geological Survey Data Survey Series 251, 24 p., https://pubs. usgs.gov/ds/2007/251/.

Waring, G.L., 1995, Current and historical riparian vegetation trends in Grand Canyon, using multitemporal remote sensing analyses of GIS sites: Flagstaff, Ariz., Northern Arizona University, , cooperative agreement no. CA 8000-8-0002, 24 p.

Warren, P.L., Reichhardt, K.L., Mouat, D.A., Brown, B.T., and Johnson, R.R., 1982, Technical report no. 9-Vegetation of Grand Canyon National Park: Tucson, Ariz., Cooperative National Park Resources Studies Unit, University of Arizona and National Park Service, 140 p., accessed http://www.riversimulator.org/Resources/GCMRC/Terrestrial/Warren1982.pdf.
Webb, R.H., 1996, Grand Canyon-A century of changeRephotography of the 1889-1890 Stanton expedition: Tucson, Ariz., University of Arizona Press, 290 p.

Wright, S.A., Melis, T.S., Topping, D.J., and Rubin, D.M., 2005, Influence of Glen Canyon Dam operations on downstream sand resources of the Colorado River in Grand Canyon, in Gloss, S.P., Lovich, J.E., and Melis, T.S., eds., The state of the Colorado River ecosystem in Grand Canyon-A report of the Grand Canyon Monitoring and Research Center 1991-2004: U.S. Geological Survey Circular 1282, p. 17-31, https://pubs.usgs.gov/circ/1282/.

Yard, H.K., van Riper Charles III, Brown, B.T., and Kearsley, M.J., 2004, Diets of insectivorous birds along the Colorado River in Grand Canyon, Arizona: The Condor, v. 106, no. 1, p. 106-115, https://www.jstor.org/stable/1370520. 


\section{Appendix 1-3}




\section{Appendix 1-Standard Operating Procedures}

The 15 SOPs in this appendix provide detailed instructions on how to conduct riparian-vegetation monitoring along the Colorado River in Arizona between Glen Canyon Dam and Lake Mead. Copies of all relevant SOPs should be provided to field technicians, paid and volunteer, before sampling. SOPs related to field sampling should be carried into the field as a reference for proper sampling techniques. General methodologies are discussed in the main text in the sections Sampling Design, Field Methods, and Data Handling, Analysis, and Reporting. 


\section{SOP 1-Preparations for the Field Season and Equipment Needed}

\begin{tabular}{|c|c|c|c|c|c|c|c|}
\hline $\begin{array}{c}\text { Previous version } \\
\text { number }\end{array}$ & $\begin{array}{l}\text { Revision } \\
\text { date }\end{array}$ & Author & $\begin{array}{l}\text { Changes } \\
\text { made }\end{array}$ & $\begin{array}{c}\text { Section and } \\
\text { paragraph }\end{array}$ & Reason & Approved by & $\begin{array}{c}\text { New version } \\
\text { number }\end{array}$ \\
\hline & & & & & & & \\
\hline & & & & & & & \\
\hline & & & & & & & \\
\hline & & & & & & & \\
\hline
\end{tabular}

Only changes in this specific SOP will be logged here. Version numbers increase incrementally by hundredths (for example version $1.01,1.02$ ) for minor changes. Major revisions should be designated with the next whole number (for example version 2.0, 3.0).

This SOP provides detailed instructions on how to prepare for conducting riparian monitoring along the Colorado River in Arizona between Glen Canyon Dam and Lake Mead. Use of this SOP should begin at least 8 months before conducting field operations.

\section{Scheduling and Permitting}

Scheduling of field data collection should start by the beginning of the calendar year and is conducted in conjunction with the GCMRC logistics and permitting coordinator. Sampling the Glen Canyon reach should be scheduled for approximately mid-August; about 2 weeks before the launch date for the first GRCA sampling trip. Four days are required for training and sampling this segment. Two 17-day river trips for sampling in GRCA should be scheduled to begin in late August and late September/early October. Because the second sampling trip is conducted in conjunction with the NAU sandbar monitoring group, coordination with that group is necessary to schedule dates. The logistics and permitting coordinator will decide the exact launch and take-out dates for each trip.

Early in the calendar year, the approximate number of boats needed, the approximate number of people involved, and approximate dates should be sent to the logistics and permitting coordinator. Fifty days before the launch date, the number of people, the total number of boats, and an approximate schedule need to be submitted. The finalized personnel list and finalized schedule should be provided as soon as possible before the launch date.

A river-trip schedule indicating the likely camping sites and sample locations needs to be created for each river trip. The schedule should carefully consider the locations of the sample sites and reasonable distances to row for each day. A schedule for the random-sample trip is made by the monitoring ecologist. This schedule should carefully assess where logical camping sites are located given the randomly selected locations. Some days have more rowing and less sampling, whereas other days may consist of much more sampling and fewer rowing miles. The Phantom Ranch personnel exchange should occur approximately half way through the sampling trip, and the Diamond Creek motorboat for oar boats exchange should occur about 2 days before the Pearce
Ferry take out day. The schedule for the NAU sandbar monitoring trip is determined by the lead principal investigator of that trip.

In the 2 months before the launch date, names of participants, dietary requirements, and Phantom Ranch/Diamond Creek exchange specifics are provided to the logistics and permitting coordinator to complete scheduling (see appendix 4).

Permitting for GLCA and GRCA is managed on the NPS Research Permit and Reporting System website (https://irma.nps. gov/rprs/Home). Applications for permit renewals should be sent in January before sampling for GRCA and at least 2 months before sampling for GLCA.

\section{Volunteers}

Once dates for the sampling trips are set, field volunteers need to be recruited and scheduled (see SOP 2 for more details). This can start at any time of the year, but scheduling of volunteers should start at least 3 months in advance of the sampling dates, approximately in May. Collaborators, current USGS employees in a related field, and other people with an invested interest in the work of GCMRC are invited first. If more volunteers are needed, people with a regional botanical or transferrable scientific background are preferred.

Volunteers can participate in the entire 17-day sampling trip or half of that trip. Exchanges can be made at Phantom Ranch approximately half way through the sampling trip.

Information on field schedules, what to pack and what not to pack, data collection protocol, and day of launch instructions need to be sent to volunteers at least 2 weeks before launching to allow adequate time for personal preparations.

Check with the logistics and permitting coordinator regarding what kinds of gear are available to be loaned to volunteers. Typically, personal flotation devices (PFD) and one large dry bag are available. Depending on availability, cots and tents can also be loaned out. PFDs, tents, and cots can be shared among participants on the upper and lower half of trips - for example, if volunteer 1 hikes out at Phantom Ranch, volunteer 2 who hikes in at Phantom Ranch can use the tent, PFD, and cot of volunteer 1. This reduces the amount of gear transported on the river. Details on gear volunteers will need to borrow from GCMRC should be finalized as soon as possible and at least 2 weeks in advance. 
All volunteers will be required to complete safety training before launching. Coordinate with safety personnel, the logistics and permitting coordinator, and administrative staff regarding current required training and required documentation.

Volunteers will need to fill out volunteer paperwork before the launch day. Coordinate with administrative staff about the number and professional association of the volunteers at least 2 weeks before the launch day.

If funding is available, volunteers can receive standard per diem rates for fieldwork. Volunteers who work for other government agencies (for example, National Park Service) will need to have an Interagency Travel Agreement in place to receive per diem from GCMRC. Coordinate with the GCMRC budget analyst to establish Interagency Travel Agreements for volunteers from other agencies. Per diem can be voluntarily waived by the participant.

\section{Random Samples and Random Numbers}

The locations of random sample sites are generated each year using the current version of ArcGIS. Samples are generated for each river segment independently, and a random sample of debris fans, channel margins, and eddy sandbars are generated for each. Specific guidance is given in SOP 3.

Random numbers for transect starting points for the random and fixed sites need to be generated before launching. The length of the feature is estimated from a map or in ArcGIS and then divided by the number of transects required for that site (random sites are always divided by 3 ). The resulting number is the distance between transects and the maximum value for random starting distances. For random sites, estimation of the feature size can be done in the office or in the field. One page of random numbers for each crew is generated using a random number function, printed out, and carried in the field-sampling box. The random number sheet contains columns for the length of the feature by $5-\mathrm{m}$ increments and rows are random numbers between 1 and the feature length divided by 3 (fig. S1.1). Random numbers are crossed out as they are used. For fixed sites, a random number for the distance of transect 1 from the upstream survey boundary needs to be generated. This is conducted for each fixed site separately and is done every year. The approximate length of each fixed site is listed in appendix 2 .

\section{Preparing Datasheets}

Prepare enough paper datasheets to allow for sampling on the entire river trip. Print one site- specifics datasheet and two, two-sided vegetation-sampling datasheets for each site (see appendix 3). Make enough sets of datasheets to cover the maximum number of sites that could be sampled plus extras in case of loss or mistakes.

If funding allows, datasheets should be printed on waterproof paper. At minimum, 30 percent of the datasheets should be on waterproof paper, in case of inclement weather.
Datasheets should be kept organized throughout the field season.

\section{Preparing Reference Materials and Maps}

Make two informational binders, one for each crew that contain the list of sample sites and their locations, a field schedule, species lists, and species keys. They should also contain enough paper datasheets for four sites, in case of the failure of a tablet computer.

Review species lists for the river corridor and fixed sites. If new species were recorded the year before, add them to the species lists. Make a short list of commonly encountered species with their six letter codes to be used by volunteers as a reference.

Coordinate with the GIS coordinator to make waterproof map books of the river corridor that will be used for navigation. They should contain the most recent imagery, river miles to the tenth, and useful landmarks (for example, camps and tributary names). These books will include more than 500 pages, so should be divided into sections. Logical breaks are at Lees Ferry (Glen Canyon reach), river mile 61.5 (Marble Canyon), Kanab Creek, Diamond Creek, and Pearce Ferry. Only one or two copies of books with maps for the Glen Canyon reach are necessary. Four copies of books with maps for the other reaches should be made, so that each boat has a full set of maps. Print and bind the map books at least 2 weeks in advance of the first sampling trip. If maps from previous years are still up to date, they can be reused.

Make and print large-scale maps (approximate scale of 1:1,000) for the fixed and random sites; also use waterproof paper. They should be large enough in scale to identify where transects are located, but still be able to see useful landmarks for finding the site along the river. Maps of both fixed sites and random sites should include the most recent available imagery, name and location of sites, a scale bar, direction of river flow, river mile to the tenth, and the modeled hydrologic zone boundaries (Magirl and others, 2008). Maps for fixed sites should also include the previous year's quadrat points and survey boundaries.

\section{Preparing Field Equipment}

Assess field gear and replace broken gear as necessary. Have enough of each item to support two crews and have replacements in the event of gear failure while in the field. See table 1 for specific gear and amounts. This should be completed at least one month before the first trip to allow for purchasing and shipping time.

Pack field equipment, datasheets, and reference resources (regional floras, vegetation binders) in waterproof ammo cans and (or) side boxes at least 1 week before the launch. Label these boxes with their general contents, for example, field equipment, library, electronics. Field equipment should be packed so that two crews can work independently. 
Table S1.1. The following field equipment is required for sampling of riparian vegetation along the Colorado River in Arizona between Glen Canyon Dam and Lake Mead.

[PVC, polyvinyl chloride; $\mathrm{m}$, meter; $\mathrm{m}^{2}$, square meter; in., inch]

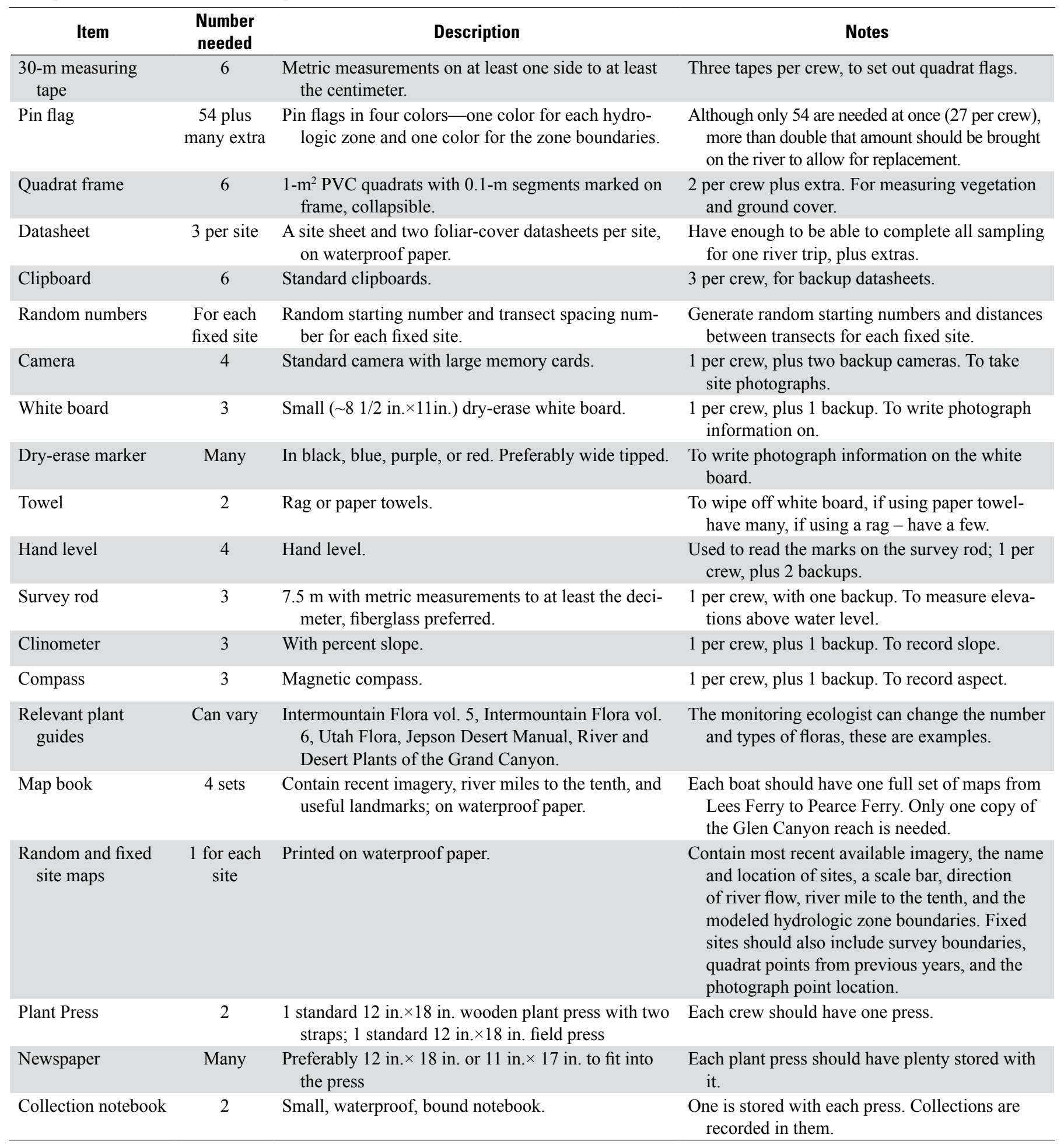




\section{Travel Authorizations and Timesheets}

Coordinate with administrative personnel to learn current procedures for travel authorizations and vouchers. Before each field trip, set up travel authorizations for all employees and volunteers, as necessary.
All employees should complete timesheets before going into the field, unless they will return before the timesheet due date.

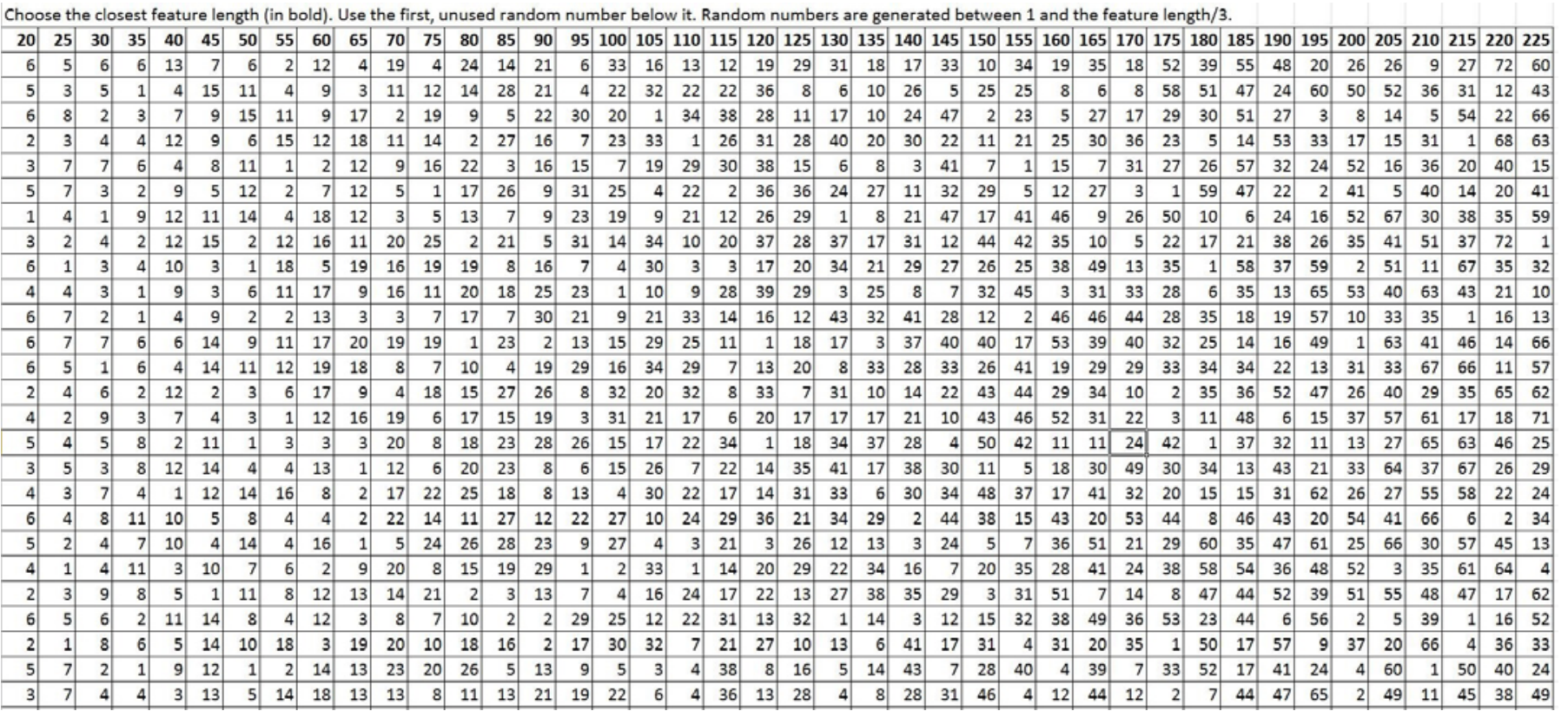

Figure S1.1. Example of the random number sheet for selecting random transects at sites for monitoring riparian vegetation along the Colorado River in Arizona between Glen Canyon Dam and Lake Mead. The approximate length of the feature is selected from the bold numbers in the top row, and the random start for transect 1 is the first unused number below. Random numbers are generated using a random number formula. Random numbers are generated between 1 and the feature length divided by 3. 


\section{SOP 2-Recruiting and Training Field Technicians}

Version 1.00: Revision History Log

\begin{tabular}{|l|l|l|l|l|l|l|}
\hline $\begin{array}{c}\text { Previous version } \\
\text { number }\end{array}$ & $\begin{array}{c}\text { Revision } \\
\text { date }\end{array}$ & Author & $\begin{array}{c}\text { Changes } \\
\text { made }\end{array}$ & $\begin{array}{c}\text { Section and } \\
\text { paragraph }\end{array}$ & $\begin{array}{c}\text { Reason } \\
\text { Approved by }\end{array}$ & $\begin{array}{c}\text { New version } \\
\text { number }\end{array}$ \\
\hline & & & & & & \\
\hline & & & & & & \\
\hline
\end{tabular}

Only changes in this specific SOP will be logged here. Version numbers increase incrementally by hundredths (for example version 1.01 , 1.02) for minor changes. Major revisions should be designated with the next whole number (for example version 2.0, 3.0).

This SOP describes procedures for recruiting and training paid and volunteer field technicians for riparian-vegetation monitoring along the Colorado River in Arizona between Glen Canyon Dam and Lake Mead. Experienced, qualified botanists and detail-oriented, organized technicians are crucial to obtaining reliable, high-quality data. Whenever possible, it is best to conduct training before launching. This is typically not feasible, so most technicians will be trained in the field. Training is conducted at the beginning of the sampling trip and anytime new crewmembers join the sampling trip during an exchange. Technicians should be provided with the sampling SOPs (4-9) before launching.

\section{Staffing Requirements}

A permanent or term monitoring ecologist at the GS-07 level or higher is needed to lead the field crews, plan daily sampling goals in coordination with the lead boatman, and maintain organization of the data and gear in the field. The composition and number of the sampling crews differ between the Glen Canyon reach sampling, the random sites sampling, and the fixed site sampling. Crewmembers can be seasonal GCMRC hires, volunteers, interns, or cooperators, depending on funding and availability.

Glen Canyon sampling requires three technicians in addition to the monitoring ecologist. Preferably, two of those crewmembers are trained botanists. These crewmembers and the botanists will form one four-person crew.

The Grand Canyon random site sampling requires seven crewmembers in addition to the monitoring ecologist. Three of those crewmembers need to be trained botanists, preferably with prior experience estimating foliar cover. These crewmembers and the monitoring ecologist will form two crews of four people each. Each crew should have two botanists and two other crewmembers.

The Grand Canyon fixed site sampling requires three technicians in addition to the monitoring ecologist. At least one of the technicians, in addition to the monitoring ecologist, needs to be a trained botanist. These technicians and the monitoring ecologist will form two two-person crews, each with one botanist. Using three-person crews for this sampling is more efficient, because the third person sets up quadrats, takes pictures, and then assists with quadrat assessments.

\section{Qualification and Skills}

To collect high-quality, reliable vegetation data, data collectors and recorders need to be detail-oriented, conscientious, competent, organized, and tolerant of repetitive, simple tasks. They also need to be tolerant of physically uncomfortable working conditions, such as heat, cold, uneven and steep terrain, large rapids, sun exposure, wind exposure, and bailing-out boats. Technicians should be in good physical condition with the ability to maneuver within and around slippery boats all day and swim in swift current in an emergency. All of these skills and abilities need to be covered with the applicant or volunteer during the interview process, and the potential crewmember needs to give examples of how they meet those criteria.

In addition to the attributes listed above, technicians conducting foliar and ground-cover estimates need to be well trained and experienced in vegetation data collection. For vegetation data to be credible and reliable over time and for trends to be noticeable and real, species identification and cover estimations need to be consistent over time. Thus, technicians conducting cover estimates should be trained botanists with experience estimating cover, preferably with experience working in the Grand Canyon region. Ideally, the same botanists will conduct foliar and ground-cover estimates for an entire sampling trip and return to conduct the same sampling for multiple years to increase consistency.

\section{General Training}

All technicians and boat operators can be trained to setup transects and quadrats, record data, take photographs, and collect slope, aspect, and elevation data (no technician is exempt from training):

- Before training, all technicians should read the relevant SOPs. Copies of these protocols should be provided at the training as well, so that technicians can make notes and refer back to the written protocol at any time during sampling.

- Safety during work and off-work hours needs to be emphasized. Continue to discuss emergency procedures while working, boating, and camping. General safety 
issues are covered in the required volunteer safety training and during the pre-launch boating meeting conducted by the lead boat operator.

- The SOPs describing procedures for site setup, recording slope and aspect, taking site photographs, and assessing and recording elevations should be covered in detail. All technicians should have a chance to practice both observing and recording for all these tasks.

- Each person should be trained on geomorphic and depositional cues for recognizing hydrologic-zone boundaries.

\section{Training Cover Observers}

As stated above, only trained botanists should conduct foliar and ground-cover estimates. Training needs to emphasize calibrating cover estimates among observers, difficult plant identifications, and details on how cover is assessed (no data collector is exempt from training):

- In addition to general training, cover observers will also be trained in species identification and foliar and groundcover estimation.

- Before the sampling trip, send species lists to cover observers. If possible, organize and conduct plant review training at an herbarium before sampling. This would primarily cover commonly encountered species and commonly misidentified species.

- Review dominant and easily misidentified plant species in the field. Species that are commonly mistaken for another species need to be emphasized to reduce mistakes.
Because many new species occur for the first time downstream from Lees Ferry, this training is continuous throughout the sampling trip.

- Inform observers of the various resources available to them for identifying plant species in the field, such as keys and species lists.

- Carefully review and discuss the procedures in SOP 6 covering foliar and ground-cover estimation.

- All cover observers need to practice foliar estimation and species identification by assessing multiple quadrats simultaneously and discussing how estimations were made. Observers should work together through as many quadrats as needed to be sufficiently accurate and precise. Observers are considered calibrated when independent estimates of species within the same quadrat are consistently within 5 percent of each other.

\section{Other Training}

Before launching at Lees Ferry, the lead boatman conducts a safety and procedural training for all people participating in the sampling trip. This training is conducted again after the exchange at Phantom Ranch. It covers boater safety, safety on land, emergency procedures, camping rules and regulations, and river etiquette.

USGS employees who work regularly in remote, backcountry situations are required to receive at least a wilderness first aid level of training and heat stress training. The monitoring ecologist should maintain at least a wilderness first responder level certification, as well as a basic swiftwater rescue certification. Check with safety and administration staff for current required trainings. 


\section{SOP 3-Generating Random Sample Sites}

Version 1.00: Revision History Log

\begin{tabular}{|l|l|l|l|l|l|l|l|}
\hline $\begin{array}{c}\text { Previous version } \\
\text { number }\end{array}$ & $\begin{array}{c}\text { Revision } \\
\text { date }\end{array}$ & Author & $\begin{array}{c}\text { Changes } \\
\text { made }\end{array}$ & $\begin{array}{c}\text { Section and } \\
\text { paragraph }\end{array}$ & Reason & Approved by & $\begin{array}{c}\text { New version } \\
\text { number }\end{array}$ \\
\hline & & & & & & & \\
\hline & & & & & & & \\
\hline & & & & & & & \\
\hline & & & & & & & \\
\hline
\end{tabular}

Only changes in this specific SOP will be logged here. Version numbers increase incrementally by hundredths (for example version 1.01 , 1.02) for minor changes. Major revisions should be designated with the next whole number (for example version 2.0, 3.0).

This SOP provides a detailed description of how to randomly select sites on channel margins, debris fans, and eddy sandbars for riparian-vegetation monitoring along the Colorado River in Arizona between Glen Canyon Dam and Lake Mead. Random sites are generated between river miles -15.6 and 240, and are stratified by geomorphic feature and river segment (table S3.1). Springs, repeat sandbar sites (which are sampled separately), cliffs, and protected archeological and sacred sites are excluded from the sampling area. The target number of sites per river segment (table S3.1) is based on a sampling rate of approximately one site for every 2.5 river miles. This is an optimistic sampling rate and is expected to be the greatest number of sites able to be sampled if weather conditions, technician skills, and logistical considerations are optimal. More sites than can be sampled within the sampling time frame should be generated to allow some sites to be rejected due to inaccessibility, safety, or other concerns.

Sites that are sampled are removed from the pool of available sites for each 5-year sampling period, which is ended with a 5-year status and trends report. At the beginning of the next 5-year increment, all sites are available for selection. If a site is on the list of possible sample sites, but not actually sampled, it remains in the pool of available sites. The end of the first 5-year sampling increment is at the end of 2017, so all sites are available for sampling in 2018, 2023, 2028, and so forth.

The protocol uses a GIS approach to defining the sampling frame and the specific sites to eventually be selected. GIS uses a number of geospatial data layers and a sampling protocol based on a combination of those data layers to randomly select sites along the Colorado River on either river left bank or river right bank between RM - 15.6 and RM 240. The GIS data layers and associated information are listed below in table S3.2.

\section{Site Selection}

The site selection process for riparian-vegetation monitoring along the Colorado River in Arizona between Glen Canyon Dam and Lake Mead is based on a sampling frame, the query polygon layer and exclusionary and inclusionary layers (table S3.2). Exclusionary layers are used to remove areas that should not be sampled (springs, archeological sites, and long-term monitoring eddy sandbars) and inclusionary layers identify geomorphic feature locations. If there are any additions or deletions to the inclusionary or exclusionary layers, the Boolean values (presence/ absence) for the query polygons must be updated for the affected layers (the method for updating these values is discussed below in Sampling Site Criteria Attribution):

- Open the ArcGIS map document, "RandomSample generate." This file contains all the layers necessary for site selection.

- Assign a random number to each query polygon by calculating values for the "RanNum" attribute in the attribute table. This is performed using the "Calculate Field" tool in ArcToolbox (one of the built-in tools within ArcGIS version 10.2). Toolbox $>$ Data Management Tools $>$ Fields $>$ Calculate Fields. In the Environment

Table S3.1. River segments identified to stratify random sampling when monitoring riparian vegetation along the Colorado River in Arizona between Glen Canyon Dam and Lake Mead.

[Segments are delineated by floristic groups identified in Palmquist and others (2018). River miles follow (U.S. Geological Survey, 2002). Target no. sites, maximum number of sites that will be sampled each year; km, kilometer]

\begin{tabular}{|c|c|c|c|c|c|}
\hline Segment & Upstream boundary & River miles & $\begin{array}{c}\text { Length } \\
\text { (km) }\end{array}$ & $\begin{array}{l}\text { Target no. } \\
\text { sites }\end{array}$ & Sites to generate \\
\hline Glen Canyon & Glen Canyon Dam & $-15.6-0$ & 25 & 6 & 8 \\
\hline Eastern Grand Canyon & Little Colorado River & $61-160$ & 159 & 39 & 47 \\
\hline Western Grand Canyon & Approximately National Canyon & $160-240$ & 129 & 32 & 38 \\
\hline
\end{tabular}


settings, under Random Numbers, select the seed value (an integer), and the random generator type (ACM599 is the default) (fig. S3.1). Each year's sampling should use a different seed integer value. Use the same seed value to generate the exact same random number values. In the document listing the selected sites, record the seed value used. These samples can then be recreated in the future if necessary.

- Complete the "Calculate Field" tool form inputs (fig. S3.2). "Input Table" should be the query polygon layer (RiverMile_Tenths_QueryPolygons_Strata). 'Field
Name' should be the field or attribute that will contain the random number. The code block contains a Python function, which returns a random number between 0 and 10,000 for each query polygon in the layer:

- def getRandomNumber():

- return(arcgis.rand('Integer 0 10000’))

- Export the query polygon layer's attribute table as a text file: Right click on the query polygon layer (RiverMile_Tenths_QueryPolygons_Strata) $>$ Open

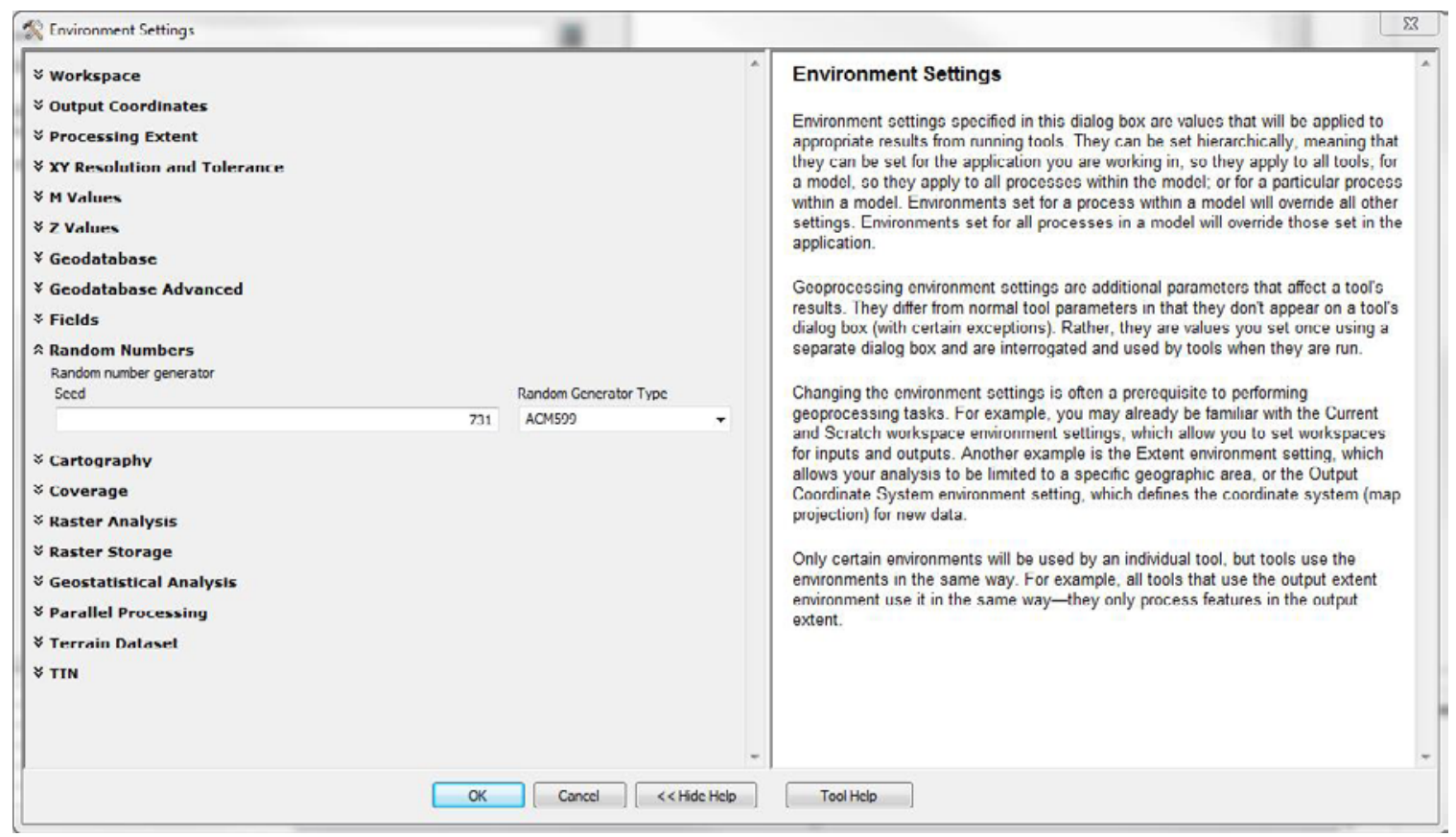

Figure S3.1. Screenshot of Environment Settings window within the Calculate Field tool in ArcGIS version 10.2.

Figure S3.2. Screenshot of the Calculate Field window showing inputs for "Expression," "Expression Type, " and "Code Block" in ArcGIS version 10.2.

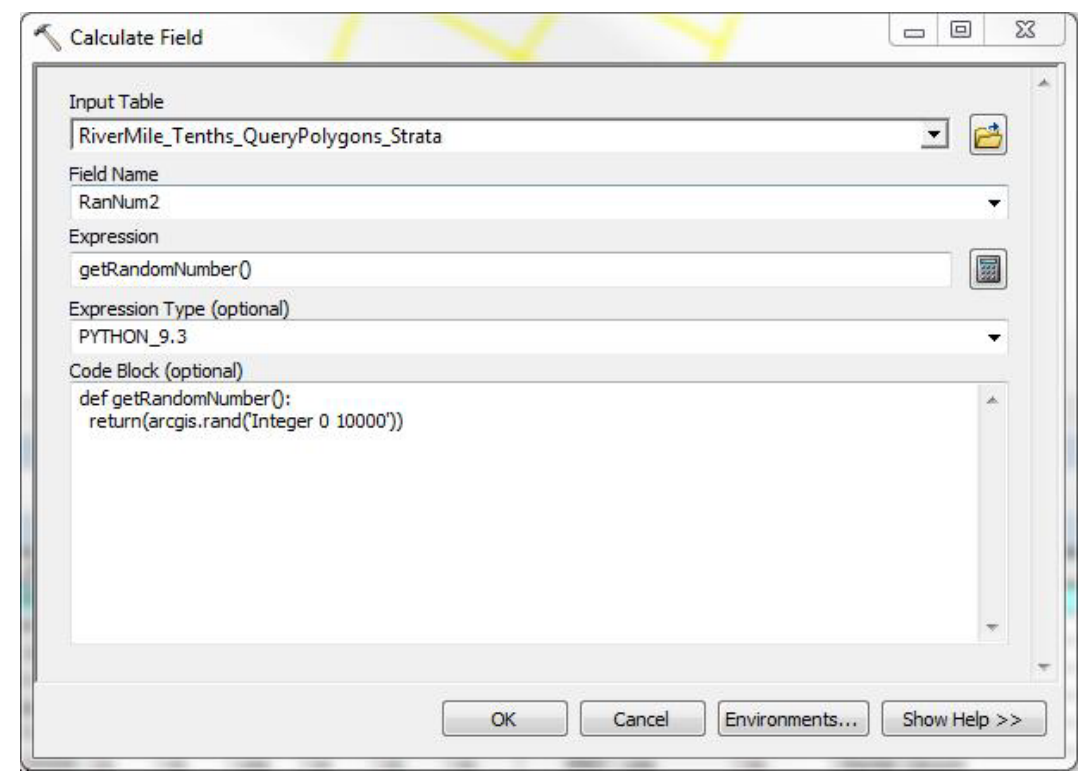


Attribute Table. From the attribute table's menu bar drop down list, select "Export." Designate the file folder to put it in, the name of the file, and change the file type to "Text File" (fig. S3.3).

- Open the text file using a spreadsheet (for example, Microsoft Excel). Sort the spreadsheet based on the river segment, each feature independently (descending), and then random number attribute (ascending).

- The final number of sites selected from the total number of available sites is the target number of sites (table S3.1) plus 20 percent. For example, for Marble Canyon, which has 24 sites as the target, 29 sites should be selected $(24+(24 \times 0.20))$.

- For each river segment, the total target number of sampling sites is divided roughly between eddy sandbars, channel margin, and debris fans. Each record in the spreadsheet is selected in the random number order for each category until the total number of samples for that reach equals the target number. For example, if the target number of sites for a given reach is 30 , then the first 10 query polygons attributed as sandbar, the first 10 query polygons attributed as channel margin, and the first 10 query polygons attributed as debris fans would be selected.
- The monitoring ecologist should review the random selections to ensure that all sites will be accessible. If necessary, the next query polygon record (based on the ordered random number value) would be selected as a replacement.

\section{Sampling Site Criteria Attribution}

If any changes are made to the inclusionary and exclusionary layers, the Boolean value (presence/absence) for the affected layers must be updated: channel margin, debris fans, eddy sandbars, springs, archaeological/culturally significant sites, and long-term sandbar monitoring sites.

The Archeological/Cultural Significant Sites layer is not stored in the random sample map document, because it contains sensitive information. If this layer is needed, it can be requested from the GIS Coordinator or the remote-sensing research geologist.

- For the affected layer, perform a "Select by Location" (under "Selection" in the top menu bar) against the query polygons.

- If any of the exclusionary layers have features present in the query polygon layer, it is assigned an attribute "Approved" value of "no." An "Approved" value of "yes" needs to be assigned when any of the three inclusionary layers indicate features present.

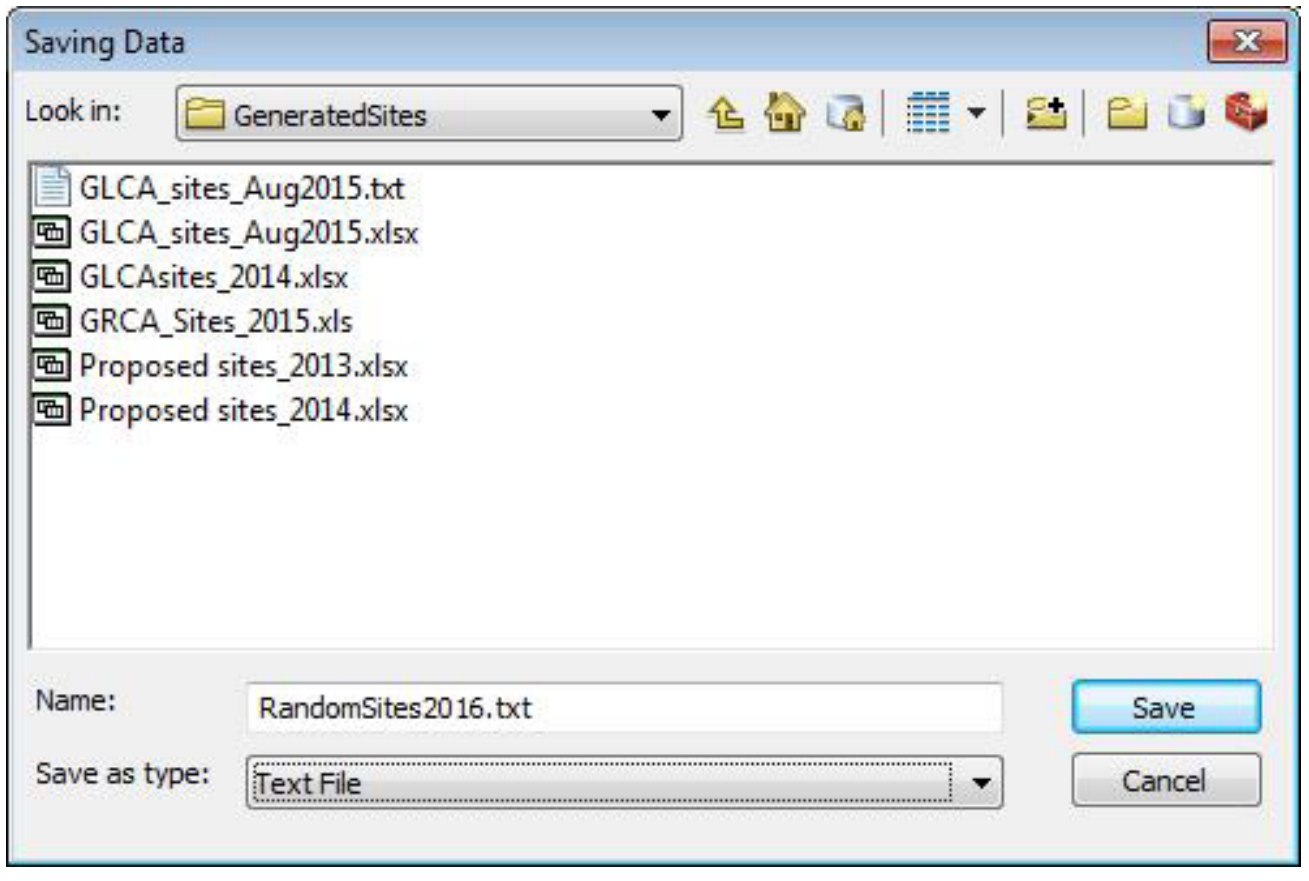

Figure S3.3. Screenshot of Saving Data window in ArcGIS version 10.2. Once the location for the exported attribute table file is chosen, give it a logical name and change the file type to "Text File." 
Table S3.2. Graphic information system (GIS) layers used to stratify random sampling for monitoring riparian vegetation along the Colorado River in Arizona between Glen Canyon Dam and Lake Mead.

[m, meter; NAU, Northern Arizona University, GCMRC, U.S. Geological Survey Grand Canyon Monitoring and Research Center; NPS, National Park Service]

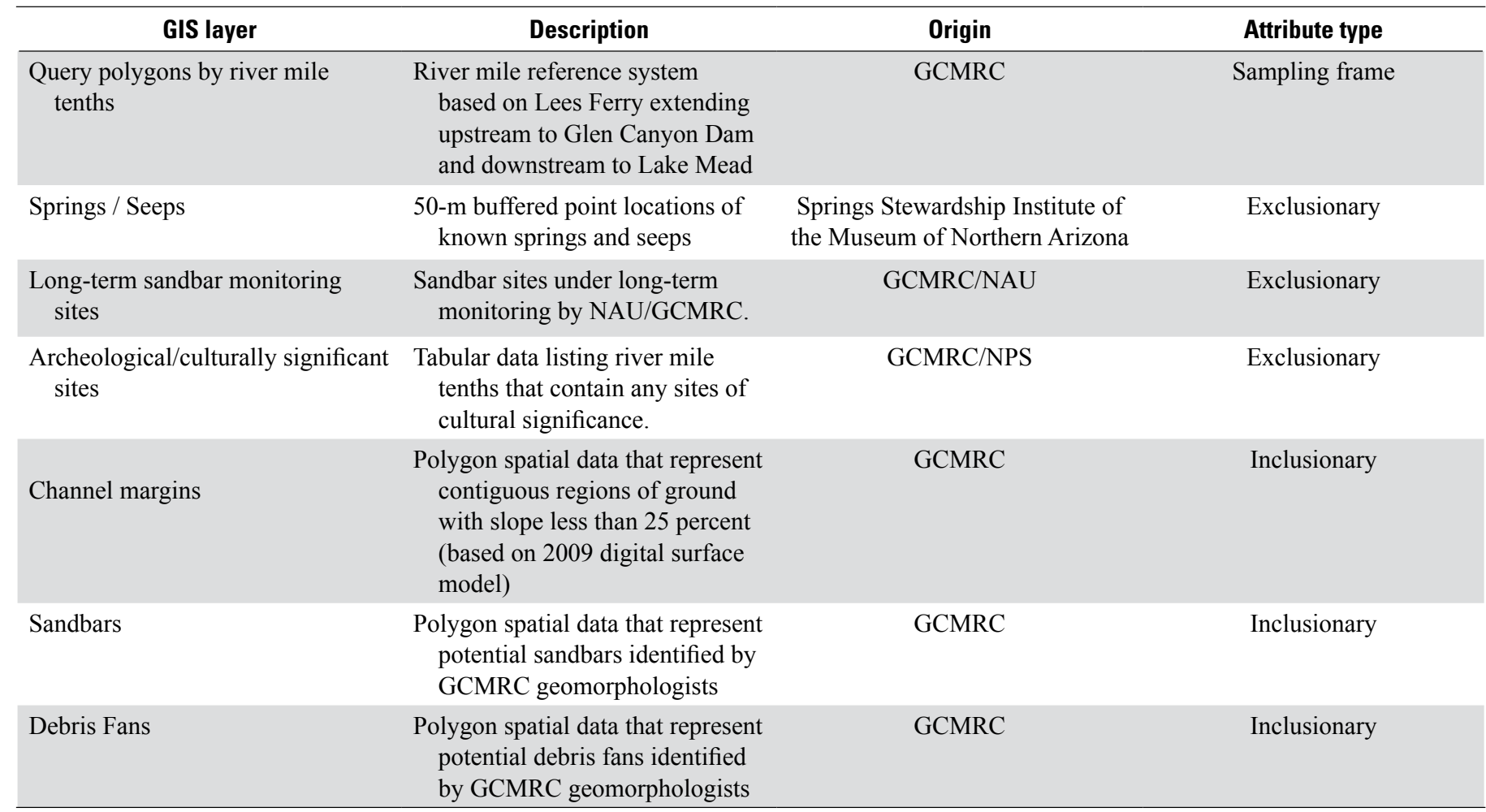




\section{SOP 4-Setting Up the Transects and Quadrats}

Version 1.00: Revision History Log

\begin{tabular}{|c|c|c|c|c|c|c|c|}
\hline $\begin{array}{c}\text { Previous version } \\
\text { number }\end{array}$ & $\begin{array}{l}\text { Revision } \\
\text { date }\end{array}$ & Author & $\begin{array}{c}\text { Changes } \\
\text { made }\end{array}$ & $\begin{array}{c}\text { Section and } \\
\text { paragraph }\end{array}$ & Reason & Approved by & $\begin{array}{l}\text { New version } \\
\text { number }\end{array}$ \\
\hline & & & & & & & \\
\hline & & & & & & & \\
\hline & & & & & & & \\
\hline
\end{tabular}

Only changes in this specific SOP will be logged here. Version numbers increase incrementally by hundredths (for example version $1.01,1.02$ ) for minor changes. Major revisions should be designated with the next whole number (for example version 2.0, 3.0).

This SOP describes the methodology for setting up the sampling quadrats at a site in the standard layout, as well as when and how to modify that layout for riparian-vegetation monitoring along the Colorado River in Arizona between Glen Canyon Dam and Lake Mead. Throughout this SOP, we will refer to the length of a geomorphic feature as the dimension parallel to river flow and width as the distance along transects perpendicular to the river. Fixed sites and random sites are set up somewhat differently.

Once pin flags mark the locations of quadrats, the elevations of those locations are measured and recorded by a survey team. If the survey team has recorded a pin flag, it cannot be moved until vegetation data has been collected for that quadrat. If the quadrat is moved between the time it is surveyed and the time the vegetation data has been collected, the wrong elevation has been recorded for that quadrat and the vegetation cannot be linked to the recorded elevation.

\section{Standard Layout}

\section{Random Sites}

Setup three transects oriented perpendicular to the river using 30-m measuring tapes (fig. 1). The transects are numbered as follows: 1 , furthest upstream; 2 , middle; and 3, furthest downstream (fig. S4.1). The distance between transects is dependent on the length of the geomorphic feature, with the exception of channel margins. The distance between transects on channel margins is always $20 \mathrm{~m}$, given the indeterminate length of the channel margin. The distance between transects for debris fans and sandbars is the length of the feature divided by three.

On arriving at a debris fan or sandbar, the geomorphic feature length is determined either using maps with recent aerial imagery or paced following the shape of the shoreline to obtain an approximate length of the area to be sampled. This can also be done in the office before sampling (using ArcGIS or maps), but may need to be adjusted in the field for water levels, erosion, deposition, etc. The length of the feature is divided by 3 to determine the distance between transects. A random starting point between 0 and the maximum distance between transects is selected to determine the distance between the upstream end of the feature and the first transect. The selected random number is measured along the water's edge starting at the upstream end of the feature to determine the starting point of the first transect. The water's edge end of the other two transects are placed the maximum distance between transects (feature length/3) downstream, also following the water's edge. For example, if a sandbar that is $200 \mathrm{~m}$ long is to be sampled, the number 200 would be divided by three, with the result being $66 \mathrm{~m}$. A random number between 0 and 66 is generated, which is the distance between the upstream end of the feature and beginning of the first transect. That number is measured following the shoreline. For this example, the random number is 26 . Starting from the upstream end of the sandbar, a distance of $26 \mathrm{~m}$ would be measured along the shoreline and the beginning of transect 1 placed at that location. The beginning of transect 2 would be placed $66 \mathrm{~m}$ downstream from transect 1 and transect 3 placed $66 \mathrm{~m}$ downstream of transect 2 . All transects start at the water's edge and are placed in a straight line perpendicular to the river (fig. S4.1).

On arriving at a channel margin, the downstream edge of the first boat to land is used as a starting point. The water's edge end of transect 2 is placed $3 \mathrm{~m}$ downstream of the first boat to land. Transect 1 and 3 are placed $20 \mathrm{~m}$ upstream and downstream of transect 2, respectively. If this placement of transects would require unsafe working conditions (for example, cut-bank into swift current), this set-up can be shifted to accommodate those conditions. For example, if having a transect upstream and downstream of the first boat to land results in transect 1 being dangerous to work on, all the transects can be shifted downstream, such that transect 1 is placed $3 \mathrm{~m}$ downstream of the first boat to land, transect 2 is placed $20 \mathrm{~m}$ downstream from there, and transect 3 is placed $20 \mathrm{~m}$ downstream of transect 2 .

Determine the boundaries of the three hydrologic zones for each transect and mark them with one color pin flagactive channel (AC), active floodplain (AF), and inactive floodplain (IF). This requires practice but will become straightforward after the first few days. The modeled flow lines on the site maps should be used in conjunction with landscape cues, such as debris piles and sediment deposition, to estimate the boundaries. The AC includes the river's edge and comprises the area that can be inundated daily. The upper boundary of the $\mathrm{AC}$ should be marked just upslope from the 
accumulated drift piles and (or) cutbanks associated with daily fluctuations. The AF includes the area that is flooded during high flow events. The AF should be marked just upslope of the accumulated drift piles and (or) sand deposition of the last high flow event. The IF is the area that was flooded annually before river regulation. The IF is upslope of the upper boundary of the AF.

Establish the locations of the quadrats along each transect and place a pin flag at each position. Use pin flags of a different color than those used for the hydrologic boundaries. Each hydrologic zone should contain 3 evenly spaced quadrats, for a total of nine $1-\mathrm{m}^{2}$ quadrats per transect. To determine the quadrat spacing for the $\mathrm{AC}$ and $\mathrm{AF}$, measure the linear distance between hydrologic zone boundaries for each transect. If the distance is $5 \mathrm{~m}$ or greater, divide the linear distance into four equal sections and place the quadrats on the three points between the lower and upper boundary of the zone. For example, if the $\mathrm{AC}$ was $12 \mathrm{~m}$ wide, the quadrats would be placed at $3 \mathrm{~m}, 6 \mathrm{~m}$, and $9 \mathrm{~m}$, counting up from $0 \mathrm{~m}$ at the river's edge (fig. S4.2). If the distance is $<5 \mathrm{~m}$, place one quadrat at the center of the zone, and the other two $2 \mathrm{~m}$ upstream and downstream of that quadrat, such that they run parallel to the river (fig. S4.3). For the IF quadrats, place the first quadrat $1 \mathrm{~m}$ from the AF/IF boundary, and the other two quadrats $2 \mathrm{~m}$ from the previous quadrat (fig. S4.2). The quadrat is placed on the downstream side of the transect with the center of one side at the flagged point. For example, in figure S4.2 the quadrat labeled AC1 would span from $2.5 \mathrm{~m}$ to $3.5 \mathrm{~m}$. Quadrats are labeled using the hydrologic zone it occurs in and the numbers 1 and 3, with 1 being close to the river and 3 being far from the river. Thus, you should have the following quadrats on each transect: AC1, AC2, AC3, $\mathrm{AF} 1, \mathrm{AF} 2, \mathrm{AF} 3$, IF1, IF2, and IF3.

\section{Fixed Sites}

Setup for a fixed site is similar to the setup for random sites. Differences lie in the number of transects and quadrats, the placement of transects, and the pin flag setup.

Some of the fixed sites are larger ( $>$ approximately $7,000 \mathrm{~m}^{2}$ ) and more diverse than the random sample features, so require more intensive sampling. At these sites, more transects and more quadrats are sampled. These sites contain 4 transects and 36 quadrats. The number of transects and quadrats per fixed site are listed in appendix 2.

Some of the fixed sites are very long and narrow. These sites are sampled using four transects, each with six quadrats. See appendix 2 for the number of transects and quadrats per site.

Transect 1 is the most upstream transect, whereas transect 3 or 4 (depending on the number of transects) is the furthest downstream. Use the pre-generated random starting point and distance between transects to setup transects. From the upstream boundary of the survey area, measure the distance of the random starting number along the shoreline and place the beginning of transect 1 at that location. Then measure or pace the distance between transects along the shoreline to determine the starting point of the remaining transects. If pacing is used instead of measuring, each person's pace must be measured before pacing. It is common to pace less than one meter. All transects start at the water's edge and are placed in a straight line perpendicular to the water's current.

Determine the boundaries of the three hydrologic zones for each transect using the site maps and the landscape cues described above. These boundaries do not need to be marked with pin flags. This can be done simultaneously with establishing the locations of the quadrats.

Quadrats are placed in the same manner as random samples and their locations marked with pin flags. Quadrats are equally spaced within each hydrologic zone on each transect. All pin flags are the same color. Pink is the most visible. The pin flags are numbered and set-up in order starting with pin flag \#1 at the river end of transect 1 and pin flag $\# 9$ as the highest elevation quadrat of transect 1. Pin flag \#10 is then the first flag next to the river's edge on transect 2 and so forth. These numbers are used by the geomorphic survey team to label the points associated with the quadrats.

\section{Modifications to the Standard Layout}

For random sites, if a site is missing a hydrologic zone (usually IF), for example, a sheer cliff backs a debris fan, those quadrats are not sampled and not replaced. The total number of quadrats sampled is fewer than 27.

The IF zone is not sampled on all the fixed sites. In these cases, the survey boundary does not extend to the IF. Appendix 1 indicates whether or not quadrats are sampled in the IF for each fixed site.

\section{Not Sampling a Site}

Occasionally, a randomly generated site will not be sampled due to safety reasons. The lead crewmember decides if a site is safe to sample and takes input from the rest of the crew. If the crew lead and most of the crew feel comfortable working at a site, the site should be sampled. If a site is deemed unsafe to work on, often due to a dangerously steep or unstable channel margin, that site is not sampled. Because crewmembers will have differing abilities and comfort levels, all crewmembers have the right to not work in a situation that seems unsafe for them, even if the rest of the crew feels safe. Crew members who do not feel safe working at a site may elect to, without any pressure to do otherwise, refrain from sampling that site or to only conduct aspects of sampling that do seem safe for their abilities.

If the boats cannot safely land and remain securely anchored at or near the sample site, the boat operators can decide that a site will not be sampled. A site may be skipped if sampling is taking longer than expected and the camping destination must be reached. Continuing downriver is necessary for the timing of the take-out. 


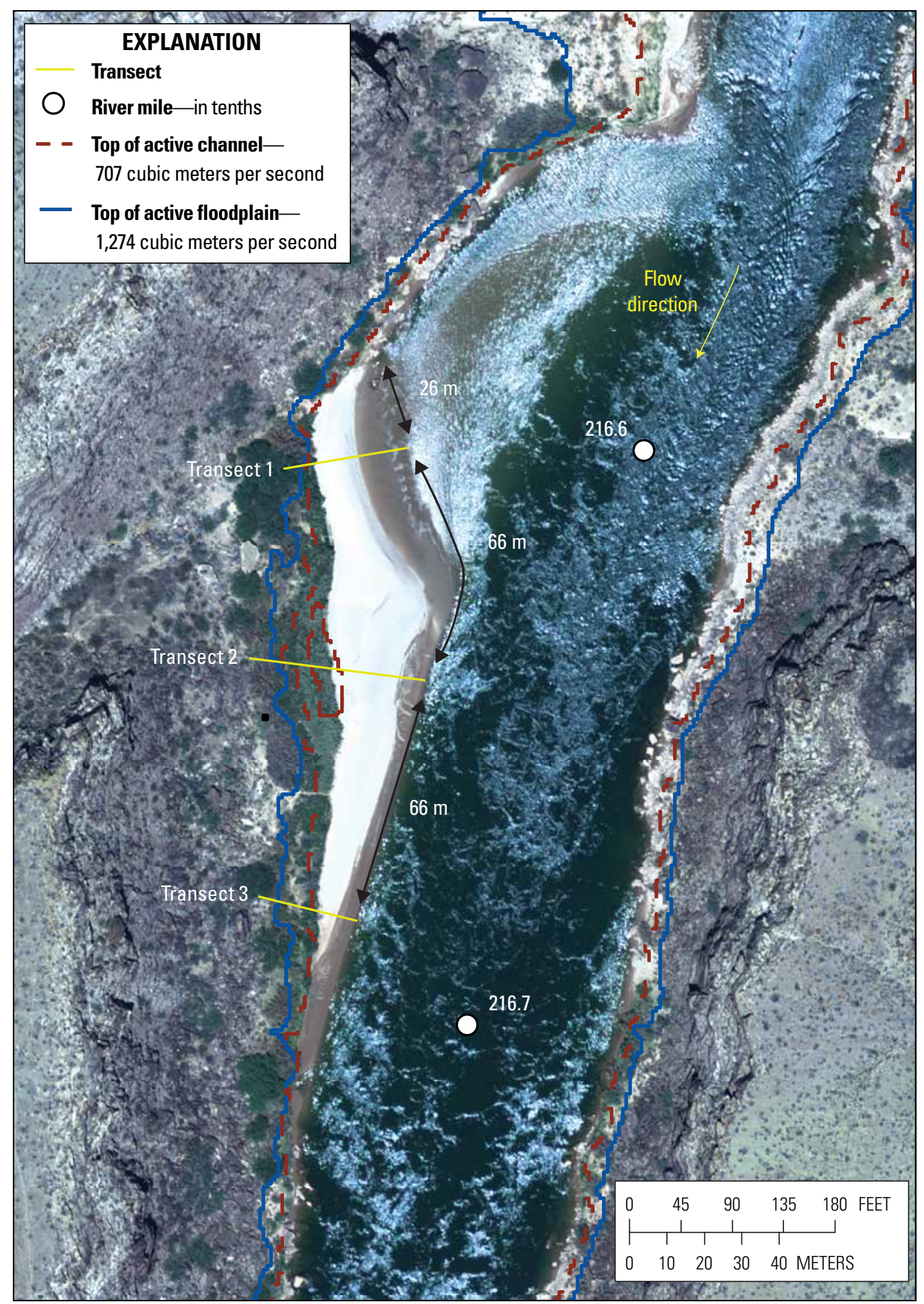

Figure S4.1. Aerial photograph showing example transect placement in a standard site setup for monitoring of vegetation composition and cover along the Colorado River in Arizona between Glen Canyon Dam and Lake Mead. Three transects are setup perpendicular to the shoreline. Each transect starts at the water's edge and runs in a straight line. Transect 1 is the furthest upstream and transect 3 is the furthest downstream. To determine the placement of transects the length of the feature is divided by 3 , a random number is selected between 0 and result of feature length divided by 3 , the random number chosen is the distance, in meters $(\mathrm{m})$, downstream to transect 1 (random number in this example is 16). The 20 - $\mathrm{m}$ distance between transects shown is not a fixed distance, but is variable by site and is based on the length of the feature. In all cases, the interval between transects is equidistant. Active channel (AC), active floodplain (AF), inactive floodplain (IF), cubic meters per second $\left(\mathrm{m}^{3} / \mathrm{s}\right)$. 


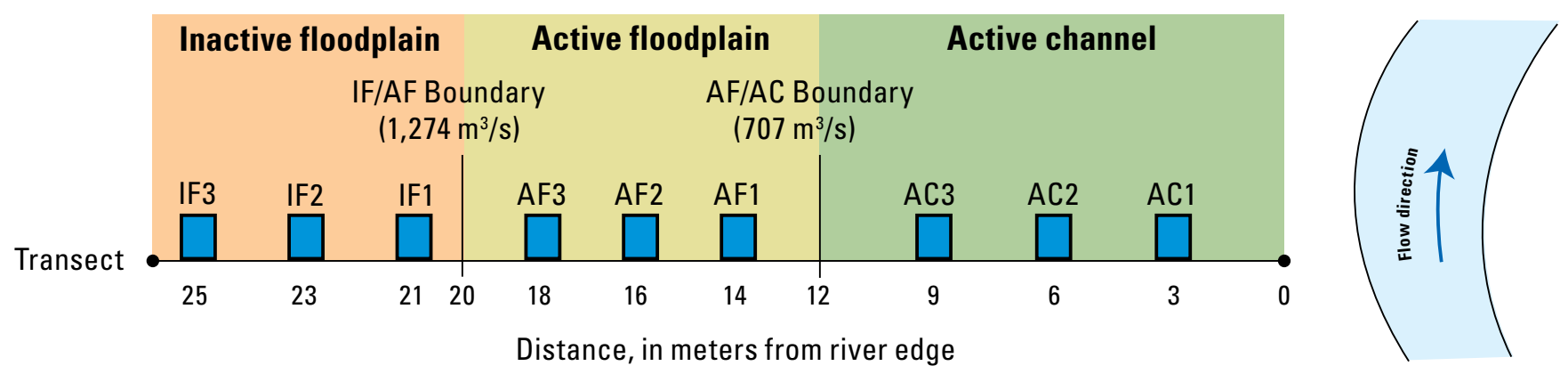

Figure S4.2. Diagram showing quadrat placement in a standard site, where all hydrologic zones are wider than 5 meters $(\mathrm{m})$, for monitoring of vegetation composition and cover along the Colorado River in Arizona between Glen Canyon Dam and Lake Mead. Each transect has nine quadrats placed on the downstream side. Three quadrats are evenly placed in each hydrologic zone. Active channel (AC) and active floodplain (AF) quadrats are evenly spaced depending on the width of the zone, while inactive floodplain (IF) quadrats are placed 2 meters $(\mathrm{m})$ apart and $1 \mathrm{~m}$ from the active floodplain/ inactive floodplain boundary. $\mathrm{m}^{3} / \mathrm{s}$, cubic meters per second.
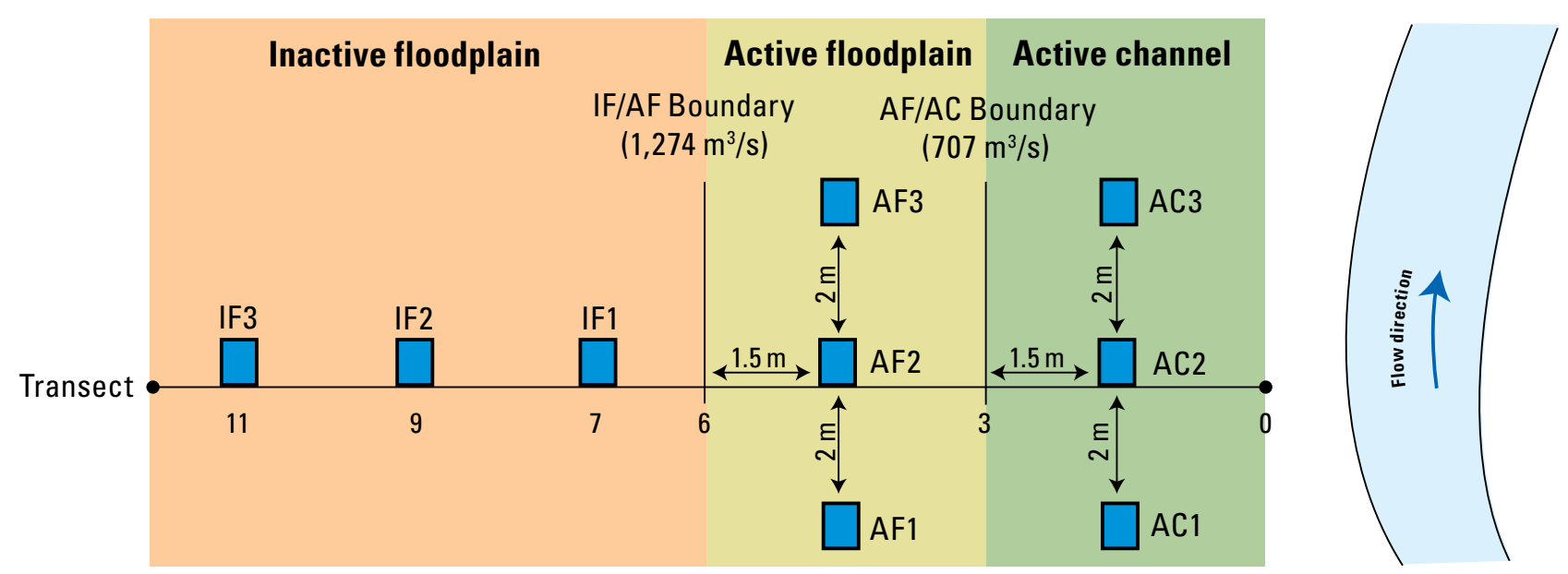

Distance, in meters from river edge

Figure S4.3. Diagram showing alternative quadrat placement in a hydrologic zone for monitoring of vegetation composition and cover that is less than 5 meters $(\mathrm{m})$ wide along the Colorado River in Arizona between Glen Canyon Dam and Lake Mead. The quadrats for that zone are placed parallel to the river, 2 meters $(\mathrm{m})$ apart, in the center of the hydrologic zone. Active channel (AC), active floodplain (AF), inactive floodplain (IF). 


\section{SOP 5-Site Photographs}

Version 1.00: Revision History Log

\begin{tabular}{|l|l|l|l|l|l|l|}
\hline $\begin{array}{c}\text { Previous version } \\
\text { number }\end{array}$ & $\begin{array}{c}\text { Revision } \\
\text { date }\end{array}$ & Author & $\begin{array}{c}\text { Changes } \\
\text { made }\end{array}$ & $\begin{array}{c}\text { Section and } \\
\text { paragraph }\end{array}$ & $\begin{array}{c}\text { Reason } \\
\text { Approved by }\end{array}$ & $\begin{array}{c}\text { New version } \\
\text { number }\end{array}$ \\
\hline & & & & & & \\
\hline & & & & & & \\
\hline & & & & & & \\
\hline
\end{tabular}

Only changes in this specific SOP will be logged here. Version numbers increase incrementally by hundredths (for example version $1.01,1.02$ ) for minor changes. Major revisions should be designated with the next whole number (for example version 2.0, 3.0).

This SOP describes the procedure for taking photographs at both random sample sites and fixed sites for riparian-vegetation monitoring along the Colorado River in Arizona between Glen Canyon Dam and Lake Mead. A digital camera that takes medium to high quality photographs (4 megapixels or higher) with a large memory card is required. Site photographs are taken to clarify discrepancies with the data at a later time or to be used in presentations and documents. These photographs are not intended to be repeated but should be taken with enough care that they could be approximately retaken if the need arises.

\section{Number of Photographs}

A total of five photographs are taken from near the water's edge at each site. One photograph each is taken facing upstream and downstream from the center transect. One photograph of each transect is taken from the river end of the transect facing up the transect. The default location for taking the upstream and downstream photographs is the river end of the center transect, but this can be altered if photographs from that spot are not informative (for example, is blocked by a large cut bank). Photos can then be taken from the river end of transect 1 or 3 and a note made on the site sheet of the adjustment.

Figure S5.1. Example of a well-taken, downstream photograph for monitoring riparian vegetation along the Colorado River in Arizona between Glen Canyon Dam and Lake Mead. The informational board is legible and does not hide any features, most of the frame contains ground, but background features can be seen, and there are no people blocking the landscape.

\section{How to Take the Photograph}

The following procedures should be followed when taking photographs for monitoring riparian vegetation along the Colorado River in Arizona between Glen Canyon Dam and Lake Mead:

- Each photograph must show a small white board with location information, the date, and the direction the photograph is taken.

- Fill out the photograph point board clearly with the river mile and side of river (for example, RM 2.3R), the date, and the direction: upstream, downstream, transect 1,2, or 3. Do not abbreviate the words "upstream," "downstream," and "transect." This ensures that the information will still be clear to other researchers in the future.

- Put the board on the ground approximately five paces away from where the photograph is being taken, such that the writing on the board can be seen in the picture, but does not block much of the picture (fig. S5.1). If a person is needed to hold the board, the person should be as inconspicuous as possible and holding the board low to the ground (fig. S5.2).

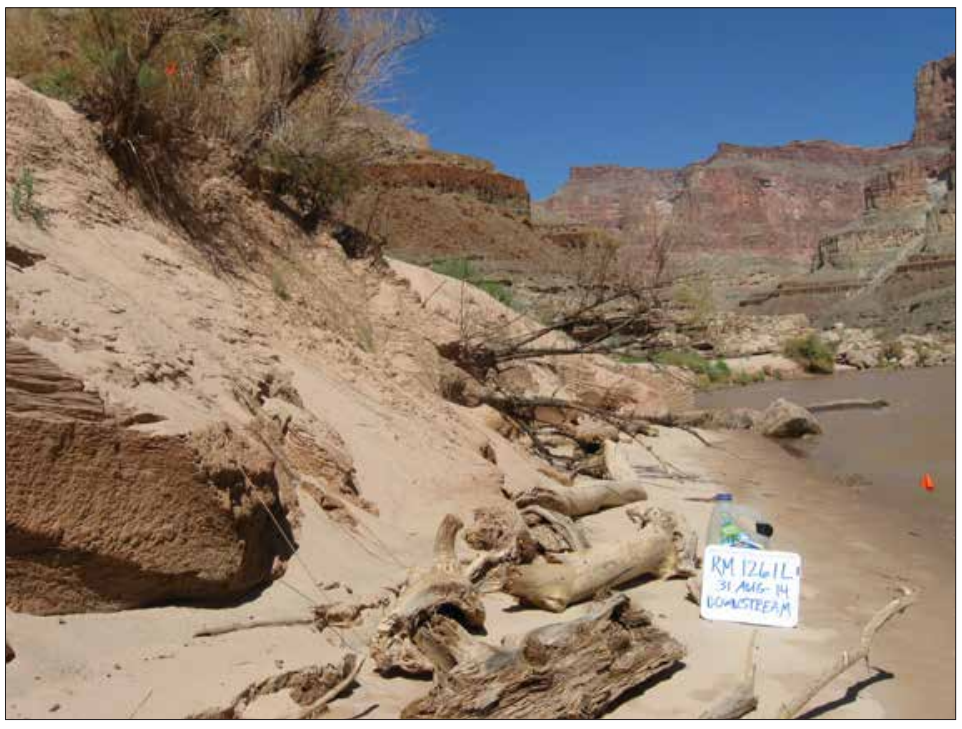


Figure S5.2. Example of a well-taken downstream photograph for monitoring riparian vegetation along the Colorado River in Arizona between Glen Canyon Dam and Lake Mead. In this case, the board needed to be held. The person is placed behind vegetation and the board held low enough to the ground to prevent it from hiding very many objects behind it.

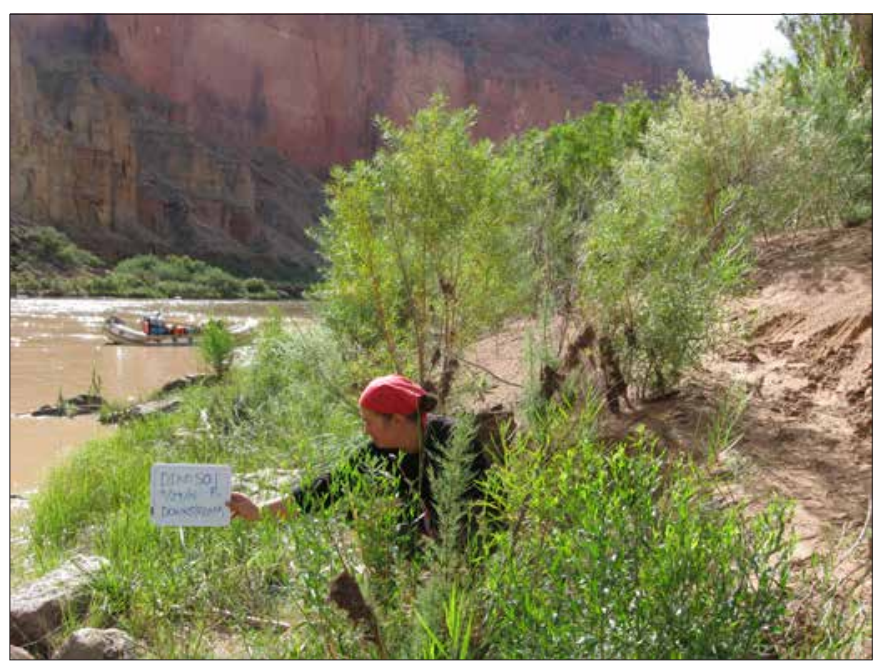

of the vegetation and geomorphology. Ask other crew members to step out of the frame if they are close to the camera or cover an important aspect of the feature.

- Make sure to include more ground than horizon, but do include background features for easy relocation later.

- Record each photograph number on the site sheet.

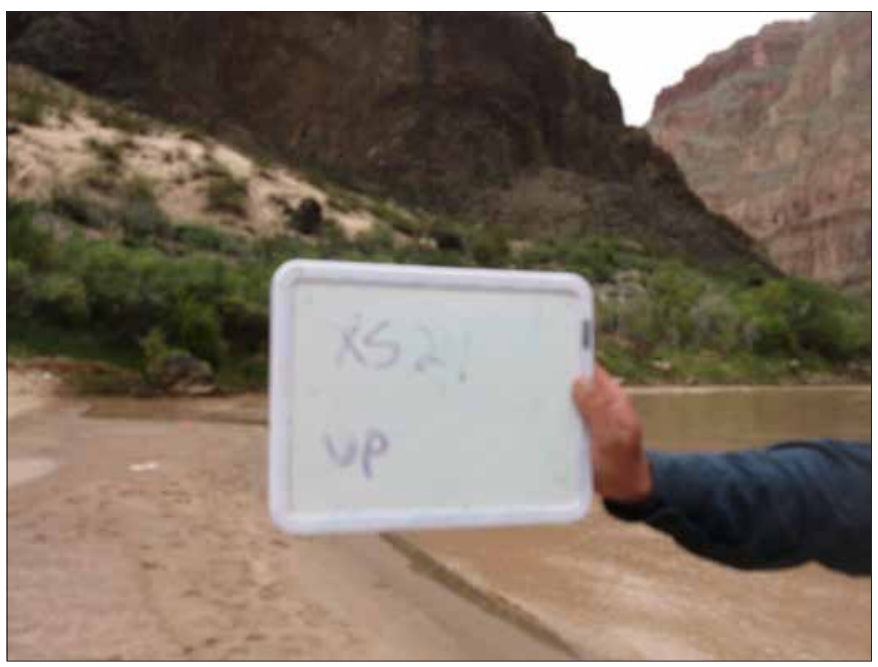

Figure S5.3. Example of a poorly taken photograph for monitoring riparian vegetation along the Colorado River in Arizona between Glen Canyon Dam and Lake Mead. This photograph contains multiple issues. The board does not contain the required information, the board takes up too much of the frame (the feature is mostly hidden), and the picture is out of focus.

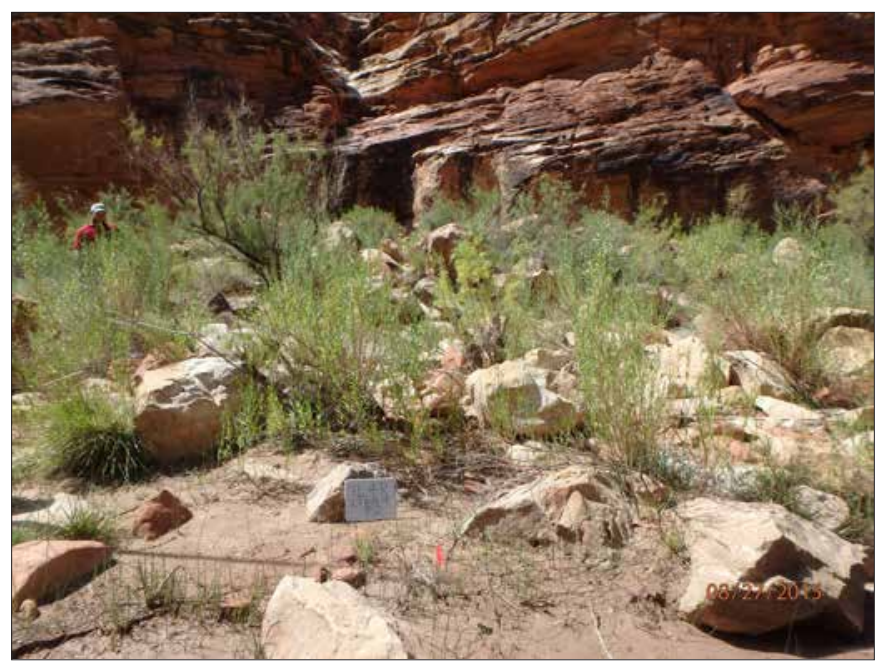

Figure S5.4. Example of a well-taken transect photograph for monitoring riparian vegetation along the Colorado River in Arizona between Glen Canyon Dam and Lake Mead. The board is legible and contains the appropriate information, but doesn't take up much space in the frame. No people are blocking vegetation or geomorphic features. The word "transect" should be written out rather than abbreviated. 

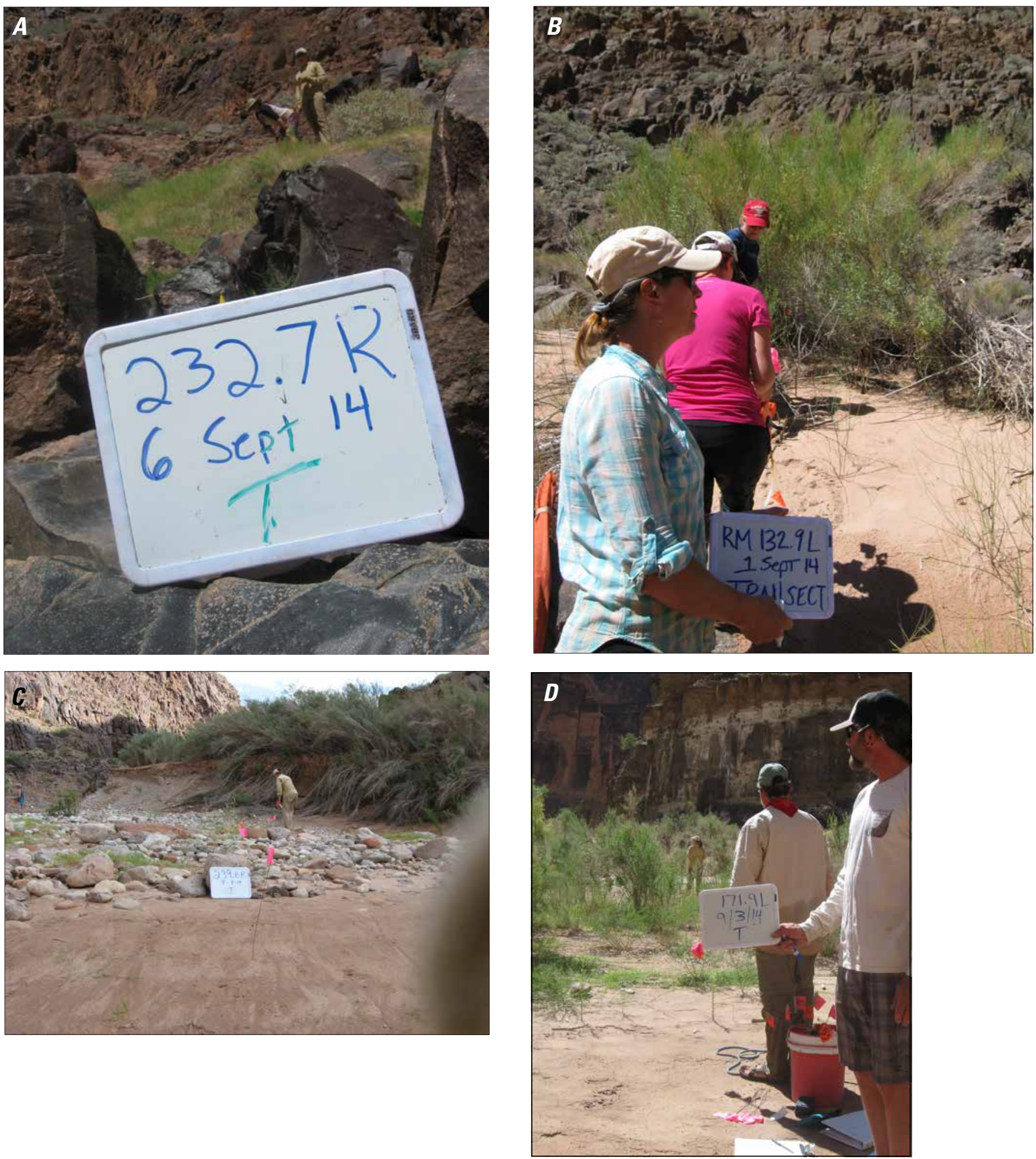

Figure S5.5. A series of problematic photographs for monitoring riparian vegetation along the Colorado River in Arizona between Glen Canyon Dam and Lake Mead. $A$, The board takes up too much of the frame, so very little information about what the site looks like is recorded, and "transect" is abbreviated. $B$, Three people are close to the person taking the photograph, which hides a lot of the frame and the transect, and the board is partially covered. $C$, This photograph would have been good, except the information on the board is abbreviated and there is a finger in the frame. $D$, The two people and field gear in the photograph take up too much of the frame, hiding the vegetation and landform. The board, although legible, contains abbreviated writing and is too high in the frame. 


\section{SOP 6-Vegetation and Ground-Cover Sampling}

Version 1.00: Revision History Log

\begin{tabular}{|l|l|l|l|l|l|l|l|}
\hline $\begin{array}{c}\text { Previous version } \\
\text { number }\end{array}$ & $\begin{array}{c}\text { Revision } \\
\text { date }\end{array}$ & Author & $\begin{array}{c}\text { Changes } \\
\text { made }\end{array}$ & $\begin{array}{c}\text { Section and } \\
\text { paragraph }\end{array}$ & Reason & $\begin{array}{c}\text { Approved by } \\
\begin{array}{c}\text { New version } \\
\text { number }\end{array}\end{array}$ \\
\hline & & & & & & & \\
\hline & & & & & & & \\
\hline & & & & & & \\
\hline
\end{tabular}

Only changes in this specific SOP will be logged here. Version numbers increase incrementally by hundredths (for example version $1.01,1.02$ ) for minor changes. Major revisions should be designated with the next whole number (for example version 2.0, 3.0).

This SOP describes the methods used for estimating and recording foliar and ground cover for riparian-vegetation monitoring along the Colorado River in Arizona between Glen Canyon Dam and Lake Mead. Estimates are conducted on each $1-\mathrm{m}^{2}$ quadrat at all sites. Sampling can be conducted individually by the botanist or in a two-person team of the botanist observing and a recorder writing down data. For both ground cover and foliar cover, only the vertical projection of cover is estimated, which means how much space the species or ground cover takes up when looking down on the quadrat from directly over the top (not at an oblique angle from the side). This can be visualized as the shade that would be projected by the plant if the sun were directly over the quadrat.

If there are no species present in a quadrat, a notation that there were no species in that quadrat is made. When finished with each transect, the data form should be reviewed by the recorder to make sure all necessary spaces have been filled in and no information has been missed.

All botanists should calibrate their estimations at the beginning of each field season and occasionally throughout each sampling trip. Initial quadrat assessments are done as a group and how estimations are made are discussed. Observers should work together through as many quadrats as needed to be sufficiently accurate and precise. Observers are considered calibrated when independent estimates of species within the same quadrat are consistently no more than 5 percent different. Observers will also have ready access to cover reference cards showing what different levels of cover look like, as well as a small card showing the amount of 1 percent cover for a $1-\mathrm{m}^{2}$ frame.

Botanists should pay attention to the species present while setting up transects and discuss any unknown species seen. This increases sampling efficiency and decreases misidentifications.

\section{Estimating Foliar Cover}

The following procedures should be followed when estimating foliar cover along the Colorado River in Arizona between Glen Canyon Dam and Lake Mead:

- Estimate the total live foliar cover of the quadrat. This should not be more than 100 percent and represents the actual amount of foliage covering the ground. This ignores any species delineations and is intended to represent how much of the quadrat is covered by living plants.

- Identify each species that is rooted inside of or overhanging the quadrat frame. Species that are rooted inside the quadrat are recorded and estimated separately from those rooted outside the quadrat. Rooted-cover estimates only include the cover that is rooted inside the frame. Estimates of overhanging cover are made and recorded separately. Thus, two independent cover values are recorded for a species that has individuals rooted inside and outside the quadrat that have cover over the quadrat. Additionally, overhanging cover is only recorded if the plant is rooted at the same elevation (within $20 \mathrm{~cm}$ ) as the quadrat. This prevents cover that is associated with different inundation frequencies from being associated with the elevation of that quadrat. If, for example, a Tamarix sp. was overhanging the quadrat, but it was rooted on a sediment bench $2 \mathrm{~m}$ above the quadrat, it would not be recorded. Two cover categories are therefore possible for each species - rooted inside or rooted outside the quadrat (table S6.1). For example, if an individual of Baccharis salicifolia is rooted in the quadrat and a separate individual is overhanging the quadrat and rooted on a substrate at the same elevation as the frame, a "rooted" value and an "overhanging" value are both recorded (table S6.1).

- Estimate only live cover for the species values. Dead branches or dead individuals do not count toward the species cover value. "Live" cover is any plant that was living during the current growing season. Senesced annual species are counted as "live" if they are from that growing season.

- For individual species covers, estimate the total cover for each species, regardless of whether or not it is under another plant. Each species receives its own value for how much of the quadrat it covers. For example, if a patch of Muhlenbergia asperifolia is growing entirely underneath a dense patch of $B$. salicifolia, the cover of $M$. asperifolia is estimated without regard to the $B$. salicifolia. The sum of the total cover values for each quadrat can be greater than 100 percent. 
- Only the vertical cover of the species is included in the estimates; spaces within the plant canopy do not count as cover (fig. S6.1). In other words, do not simply estimate how much space the perimeter of the plant takes up in the quadrat; estimate the actual amount of area the leaves and stems cover up. If a drop of rain can pass through a space without touching a plant, that space is uncovered. Figure S6.1A shows multiple individuals of the same species that cover an area, but there is a lot of space among the leaves. This would receive a lower canopy cover value than if no ground could be seen between the leaves. Figure S6.1B shows a very dense shrub with a small patch of dead branches. The whole shrub can be counted as cover, except for the dead patch outlined in yellow. Thus, a densely packed canopy will have more cover than a loose, open canopy of the same size.
- Estimate cover to the nearest 5 percent (for example, 5 percent, 10 percent, 15 percent), except for cover values of less than 5 percent. Cover that is less than 1 percent is called " $\mathrm{T}$ " for trace. Covers between 1 percent and 2.5 percent are called 1 percent (table S6.2).

- A category of "standing dead" is included on the datasheet (table S6.1). "Standing dead" includes all still rooted, dead vegetation (rooted inside and outside the frame combined) and any unrooted vegetation that is not lying on the ground (flood debris caught in trees). This is estimated in the same way as live foliar cover.

- Tamarix spp. is an exception to the standing dead category, in that we record the amount of defoliated cover separately. Defoliated Tamarix spp. cover is kept separate from the Standing Dead value (table S6.1).

Table S6.1. Cover types for estimating foliar cover along the Colorado River in Arizona between Glen Canyon Dam and Lake Mead.

[Foliar cover is recorded separately for cover rooted in the quadrat, cover rooted outside the quadrat, dead, rooted vegetation, and dead Tamarix spp.]

\begin{tabular}{|c|c|c|}
\hline Cover type & Definition & Example code \\
\hline Total foliar cover & The total vertical, living plant cover. & Noted as, "total foliar" \\
\hline Species foliar cover & The total vertical, living cover rooted inside quadrat for one species. & PLUSER \\
\hline Overhanging foliar cover & $\begin{array}{l}\text { The total vertical cover for species rooted outside a quadrat, with } \\
\text { living foliar cover overhanging the quadrat. The overhanging } \\
\text { vegetation comes from an individual that is rooted at the same } \\
\text { elevation as the quadrat. }\end{array}$ & PLUSER_O \\
\hline Standing dead & $\begin{array}{l}\text { Dead vegetation that is still rooted plus any hanging flood debris (not } \\
\text { litter that is lying on the ground). The species is not recorded; all } \\
\text { dead, rooted vegetation is recorded together. Standing dead includes } \\
\text { all standing dead cover that is rooted inside and outside the quadrat. }\end{array}$ & $\begin{array}{l}\text { Included on datasheet } \\
\text { as "standing dead" }\end{array}$ \\
\hline Defoliated Tamarix spp. & $\begin{array}{l}\text { The only dead vegetation that is recorded by species. Record the } \\
\text { amount of dead or defoliated Tamarix spp. either rooted in the } \\
\text { quadrat or overhanging the quadrat following the same methods as } \\
\text { the live foliar cover. Do not include this cover in the standing dead } \\
\text { cover estimate. }\end{array}$ & $\begin{array}{l}\text { TAMAR_D } \\
\text { TAMAR_D_O }\end{array}$ \\
\hline
\end{tabular}

Table S6.2. Cover classes for riparian foliar and ground-cover estimates made along the Colorado River in Arizona between Glen Canyon Dam and Lake Mead.

[Cover estimates are rounded to the nearest 5 percent, with the exception of trace $(\mathrm{T})$ and 1 percent]

\begin{tabular}{cccccc}
\hline Cover percentage & Cover class & Cover percentage & Cover class & Cover percentage & Cover class \\
\hline$<1$ & $\mathrm{~T}$ & $32.5-37.5$ & 35 & $72.5-77.5$ & 75 \\
$1-2.5$ & 1 & $37.5-42.5$ & 40 & $77.5-82.5$ & 80 \\
$2.5-7.5$ & 5 & $42.5-47.5$ & 45 & $82.5-87.5$ & 85 \\
\hline $7.5-12.5$ & 10 & $47.5-52.5$ & 50 & $87.5-92.5$ & 90 \\
$12.5-17.5$ & 15 & $52.5-57.5$ & 55 & $92.5-97.5$ & 95 \\
$17.5-22.5$ & 20 & $57.5-62.5$ & 60 & $97.5-100$ & 100 \\
$22.5-27.5$ & 25 & $62.5-67.5$ & 65 & & \\
$27.5-32.5$ & 30 & $67.5-72.5$ & 70 & & \\
\hline
\end{tabular}



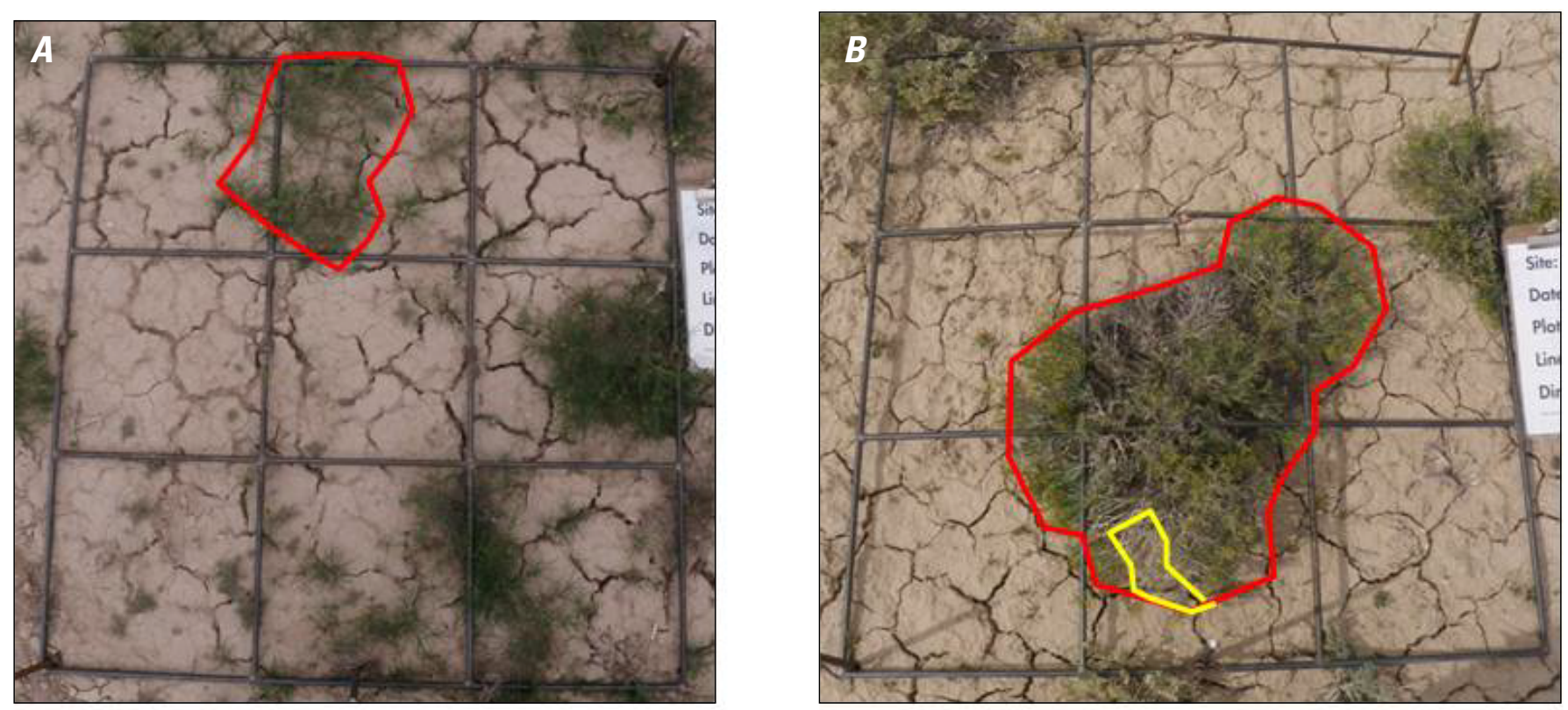

Figure S6.1. Photographs showing examples of estimating cover when plants are sparse rather than dense. $A$, Multiple individuals of the same species cover an area (red outline), but there is a lot of space among the leaves. Those spaces are not counted as cover. $B$, Very dense shrub with a small patch of dead branches (red outline). The whole shrub can be counted as cover, except for the dead patch outlined in yellow.

\section{Estimating Ground Cover}

- The following procedures should be followed when estimating ground cover along the Colorado River in Arizona between Glen Canyon Dam and Lake Mead:

- Estimate all ground-cover elements present in each quadrat - litter, biological soil crust, and soil/rock classes (table S6.3). The cover classes used for foliar cover are also used for ground cover (table S6.2). Only ground cover actually on the ground is included, so litter hanging on plants or rocks from floods is not included. Dead, rooted plant material is not included in ground-cover estimates. Both rooted, dead plant material and flood debris are included in "Standing Dead," see above.

- Ground cover values are estimated irrespective of vegetation canopy cover. Litter is estimated independently of soil, rock, and biological soil crust. Thus, there are essentially two "layers" that are estimated below all the foliar cover - litter, and mineral components (fines, sand, rocks)/biological soil crust (BSC). The values for mineral components and BSC should add up to approximately 100 percent. Plant bases (for example, the base of a bunch grass) do not take away from the ground cover total percent. For example, if the base of an individual Achnatherum hymenoides (Indian ricegrass) takes up 10 percent of the ground, the remaining 90 percent of the quadrat is the area considered for ground cover estimation and the total percent of ground cover should add up to $\sim 100$ percent.
- Dead or live branches still attached to the individual plant, but lying on the ground, are not included in the groundcover estimates. The ground underneath the branch is counted.

- Moss and lichen must be attached to the ground, not rocks, to be included. Moss or lichen on rocks is not counted.

- Biological soil crust must display some gray hues (darkening) of the surface, some surface roughening, and some hanging filaments if the crust is removed so it can be recorded as BSC. Examples of this are shown as a "level of development class 1" in Belnap and others (2008).

\section{Recording Cover Values on Paper Datasheets}

The following procedures should be followed when recording cover values on paper datasheets for monitoring riparian vegetation along the Colorado River in Arizona between Glen Canyon Dam and Lake Mead:

- If there are problems with the electronic data entry, paper datasheets can be used instead.

- All the heading information on the datasheet should be filled out at the beginning of each transect (fig. S6.2).

Double check that the correct transect number and site name are recorded.

- Ground-cover elements are already listed on each datasheet (fig. S6.2). The cover values for each one present in each quadrat are entered into the appropriate column. 
Table S6.3. Ground-cover elements and their definitions used for monitoring riparian vegetation along the Colorado River in Arizona between Glen Canyon Dam and Lake Mead.

[mm, millimeter]

\begin{tabular}{ll}
\hline \multicolumn{1}{c}{ Ground cover } & \multicolumn{1}{c}{ Definition } \\
\hline Litter & Unrooted, dead plant material, woody or herbaceous \\
Biological Soil Crust & Light gray to black cyanobacteria, moss, lichen. Must be on soil, not on rocks. \\
Fines (silts, clays) & $<0.062 \mathrm{~mm}$ diameter along median axis \\
\hline Sand & 0.062 to $2 \mathrm{~mm}$ along median axis \\
Rock & $>2 \mathrm{~mm}$ diameter along median axis \\
\hline
\end{tabular}

GCMRC Riparian Vegetation Monitoring

Site/RiverMile:__Eminence 44.5L $\_$Veg Recorder:
Veg Observer:_JDoe __

Notes:

EP092315 - 1: Brassicaceae, white flowers, silicle with minute apical notch

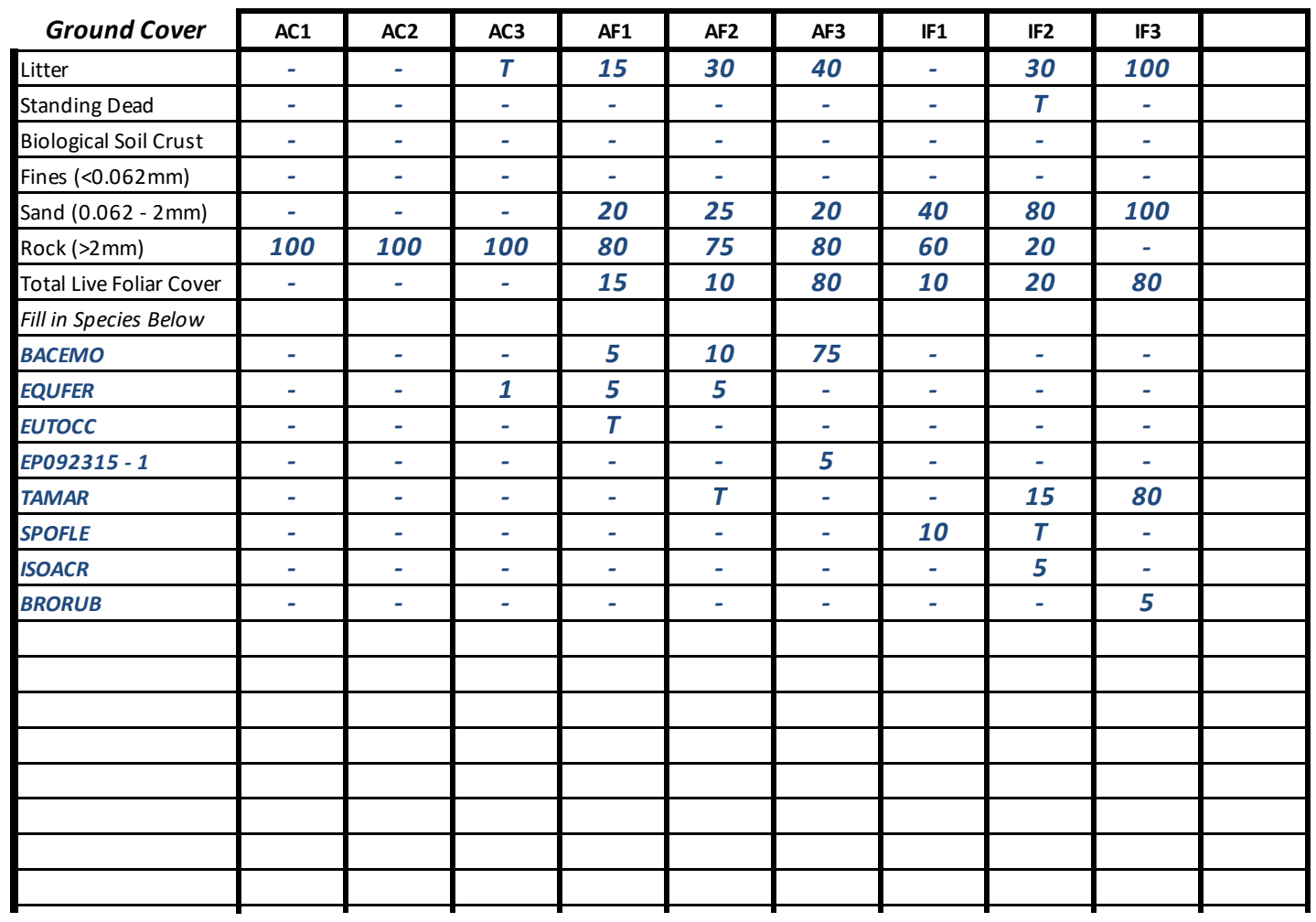

Figure S6.2. Image of the foliar and ground cover datasheet used for monitoring riparian vegetation along the Colorado River in Arizona between Glen Canyon Dam and Lake Mead. Example data are filled in. Ground-cover elements are printed on every datasheet, so only the species encountered need to be added. Species occurring in at least one quadrat on a transect are entered on the left hand side using a six-letter code. Cover values are entered into the appropriate column for each cover element. A short description of each new unknown code is written in the "notes" section of the datasheet. 
- Species are recorded on the datasheet by using a six-letter code composed of the first three letters of the genus and the first three letter of the species name. For example, Baccharis salicifolia is recorded as BACSAL and Muhlenbergia asperifolia is recorded as MUHASP. As species are encountered in quadrats along a transect, they are added to the datasheet. There is no need to add species that occur at the site but do not occur in quadrats.

- Record values for rooted and overhanging cover differently. Rooted cover is simply recorded at the code for the species (for example, BACSAL). Overhanging cover is recorded as the species code plus a modifier indicating that it is overhanging - $\mathrm{O}$, overhanging. The datasheet would then read BACSAL_O (table S6.2).

- Write the full name of species that are not encountered often in the "notes" section of the datasheet to clarify unusual six letter codes.
- If an unknown species is encountered, it is given an unknown code, which is written in place of the six-letter species code. See SOP 9 for collecting and recording unknown species.

- Place a small mark that cannot be confused with a number in each blank cover cell. This records that this cover element was not seen in that quadrat rather than just overlooked.

- If no species are encountered along a transect, write, "no species present," in the first line of the species cells.

- When a transect is completed, make sure all the header information is filled in correctly, species codes and cover values are legible, species codes are correct, and that all columns have a value in them. Quadrats with no species should still have ground cover values. 


\section{SOP 7-Slope and Aspect}

Version 1.00: Revision History Log

\begin{tabular}{|l|l|l|l|l|l|l|l|}
\hline $\begin{array}{c}\text { Previous version } \\
\text { number }\end{array}$ & $\begin{array}{c}\text { Revision } \\
\text { date }\end{array}$ & Author & $\begin{array}{c}\text { Changes } \\
\text { made }\end{array}$ & $\begin{array}{c}\text { Section and } \\
\text { paragraph }\end{array}$ & Reason & $\begin{array}{c}\text { Approved by } \\
\text { New version } \\
\text { number }\end{array}$ \\
\hline & & & & & & & \\
\hline & & & & & & & \\
\hline & & & & & & \\
\hline
\end{tabular}

Only changes in this specific SOP will be logged here. Version numbers increase incrementally by hundredths (for example version 1.01 , 1.02) for minor changes. Major revisions should be designated with the next whole number (for example version 2.0, 3.0).

This SOP provides details on how to assess the slope and aspect of a site for riparian-vegetation monitoring along the Colorado River in Arizona between Glen Canyon Dam and Lake Mead. These measurements are only taken at random sites, because accurate measures can be calculated from the survey information for fixed sites. Slope and aspect are conducted on the approximate lengthwise middle of the feature. Two people are needed for slope and aspect measurements, and they work simultaneously. One person measures the slope using a clinometer, while the other person measures the aspect using a compass.

\section{General Setup}

Before measuring the slope of the site, the person measuring slope determines where eye-level for he or she is on the person measuring aspect. For example, people with the same height should have approximately the same eye-level, whereas a shorter person's eye-level will fall below the eyes of the taller person. This needs to be assessed on a level surface.

In the approximate lengthwise middle of the feature, the person who is measuring aspect stands at the top of the feature and the person who is measuring slope stands at the bottom of the feature (fig. S7.1).

\section{Aspect}

The following procedures should be followed when measuring the aspect of a geomorphic feature when monitoring riparian vegetation along the Colorado River in Arizona between Glen Canyon Dam and Lake Mead:

- Check that the declination on the compass has been set properly.

- Hold the compass level and facing up. Do not hold anything metal near the compass while taking a reading, for example, rings, pin flags, chaining pins.

- Aim the square end or mirrored end down slope. Look at the whole feature and determine what the generalized downslope for where you are standing is.

- Wait for the arrow to stop moving. Double check that the compass is level and no magnetic or metal objects are impeding its movement.

- Turn the round dial that contains the directional numbers until the red, open-centered arrow lines up with the red painted part of the needle (fig. S7.2A). The needle fits inside the painted arrow when correctly lined up.

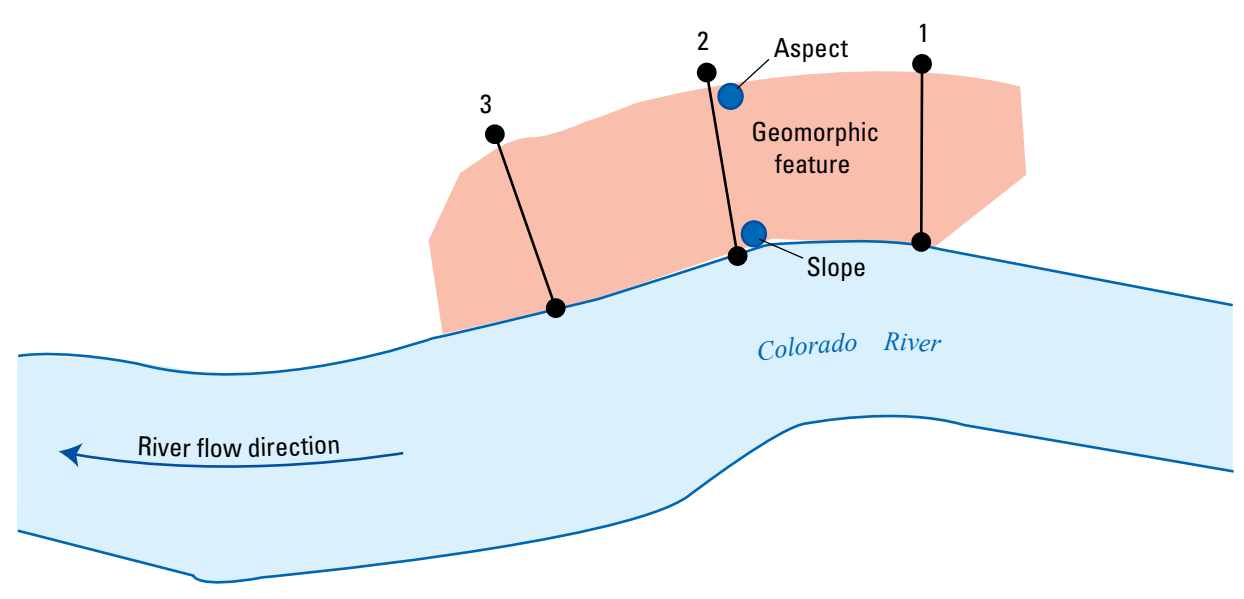

Figure S7.1. Diagram showing how slope and aspect of a geomorphic feature are measured when monitoring riparian vegetation along the Colorado River in Arizona between Glen Canyon Dam and Lake Mead. Slope and aspect are measured at the approximate lengthwise center of the geomorphic feature. The person measuring aspect stands at the top of the feature, while the person measuring slope stands at the bottom. 
- Read the direction that is indicated by the white line at the top of the dial (fig. S7.2, letter B). This line should still be pointing downslope.

- If the compass you are using only goes from 0 to $90^{\circ}$ for each quarter of the dial, be sure to add up the numbers to obtain the directional value (fig. S7.2, letter C). For example, if the value indicated on the compass is $82^{\circ}$, but the line is near the "W" symbol, the actual aspect is $90+90+82=262^{\circ}$. North is $0^{\circ}$, east is $90^{\circ}$, south is $180^{\circ}$, and west is $270^{\circ}$.

\section{Slope}

The following procedures should be followed when measuring the slope of a geomorphic feature when monitoring riparian vegetation along the Colorado River in Arizona between Glen Canyon Dam and Lake Mead:

- The default location for measuring slope is transect 2. Slope is measured from the water's edge to the end of transect 2. If vegetation or rocks obstruct the recorder's view, the recorder can adjust the location to improve visibility, but the distance from the water's edge should remain approximately the same.

- Stand facing upslope, which should also be toward the person measuring aspect. Hold a clinometer vertically in front of one eye with the lanyard on the bottom.

- To determine which side of the clinometer scale displays percent slope, tip the clinometer upwards until "\%" is displayed on one side. That side displays percent slope.

- When measuring the slope, keep both eyes open. One eye reads the scale inside the clinometer and the other sites the correct clinometer level using the upslope person.

- To place the clinometer at the correct level, align the black, horizontal band inside the clinometer with the height of the reader's eye-level on the upslope person (determined earlier). The clinometer is therefore aimed at the same height on the upslope side of the feature as it is located on the downslope side, giving the slope of the feature.

- The value that is at the same level as the horizontal line inside the clinometer is the estimated slope (fig. S7.3). In figure S7.3, the slope is 6 percent, because the slope reading is on the right-hand side.

- If there are two distinct slopes on the feature, for example, a cut-bank near the river and a gentle slope from the top of the cut-bank to the back of the feature, record two slope readings. Record each value separately and record the average of the two. Measure the length of each slope and record those values with the associated slope value.

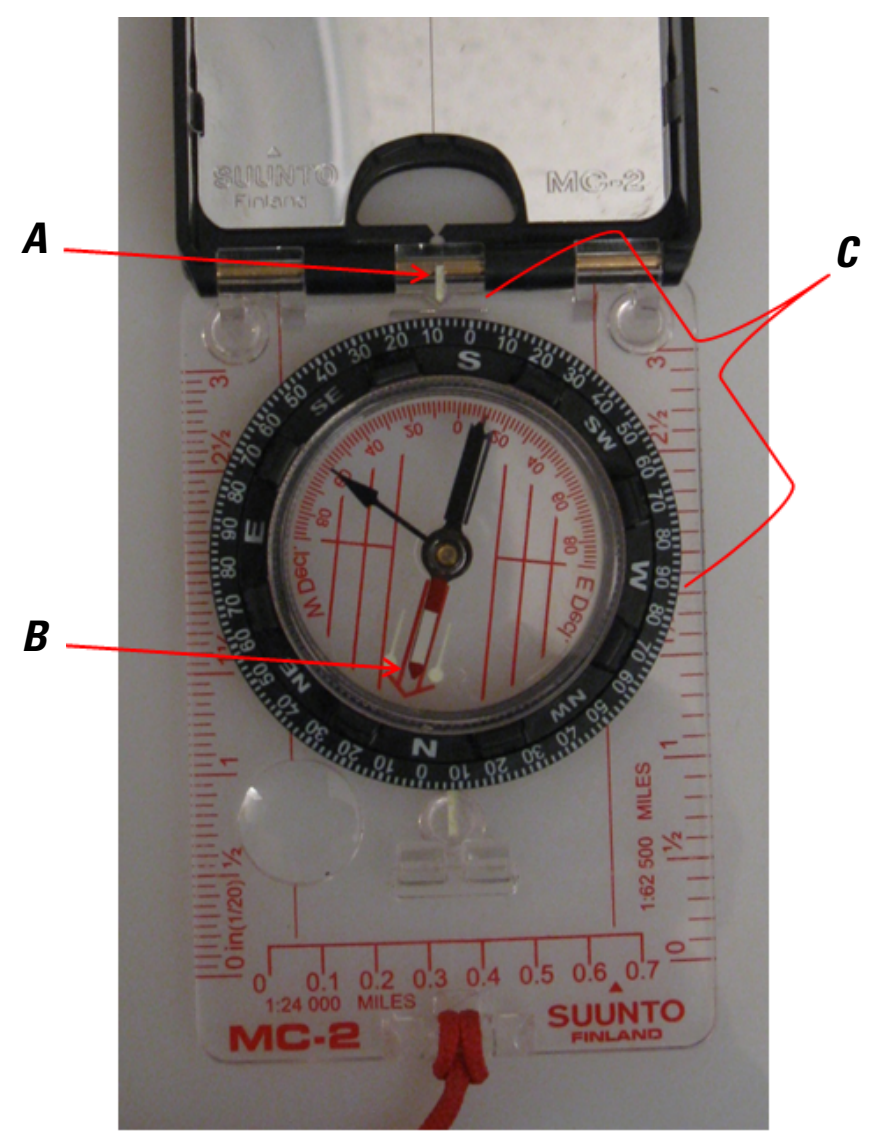

Figure S7.2. Photograph showing an orienteering compass of the type used when monitoring riparian vegetation along the Colorado River in Arizona between Glen Canyon Dam and Lake Mead. The red needle fits inside the red, open-centered arrow on the dial when properly aligned. $A$, Read the value indicated by the white line that points downslope. $B$, Numbers only range from 0 to $90^{\circ}$ between cardinal directions. $C$, Add or subtract appropriately to obtain the aspect. In this example, the aspect is $172^{\circ}$ because $180^{\circ}$ (south) minus 8 (the number indicated by the white line) equals 172 .

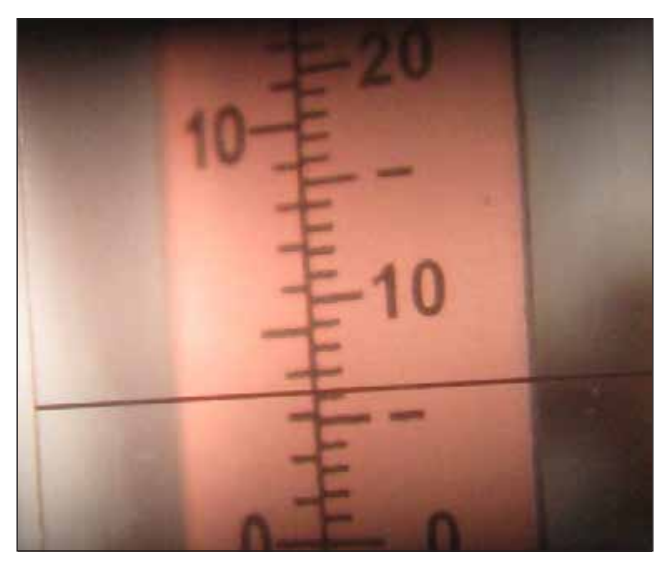

Figure S7.3. Photograph showing the view through the eye piece of a clinometer when measuring the slope of a geomorphic feature when monitoring riparian vegetation along the Colorado River in Arizona between Glen Canyon Dam and Lake Mead. 


\section{SOP 8-Measuring Quadrat Elevations}

Version 1.00: Revision History Log

\begin{tabular}{|l|l|l|l|l|l|l|l|}
\hline $\begin{array}{c}\text { Previous version } \\
\text { number }\end{array}$ & $\begin{array}{c}\text { Revision } \\
\text { date }\end{array}$ & Author & $\begin{array}{c}\text { Changes } \\
\text { made }\end{array}$ & $\begin{array}{c}\text { Section and } \\
\text { paragraph }\end{array}$ & Reason & $\begin{array}{c}\text { Approved by } \\
\text { New version } \\
\text { number }\end{array}$ \\
\hline & & & & & & \\
\hline & & & & & & \\
\hline
\end{tabular}

Only changes in this specific SOP will be logged here. Version numbers increase incrementally by hundredths (for example version 1.01 , 1.02) for minor changes. Major revisions should be designated with the next whole number (for example version 2.0, 3.0).

This SOP describes the methodology for measuring the height of each quadrat above the waterline for riparianvegetation monitoring along the Colorado River in Arizona between Glen Canyon Dam and Lake Mead. The elevation above the current waterline is measured for each quadrat at each random site, as well as the hydrologic zone boundaries on each transect. Two people are needed for this task; one holds the survey rod at the water's edge and the other takes elevation readings with the hand level. This is only conducted on the random sites, because the NAU Sandbar Team surveys the fixed site quadrats.

\section{Measuring Elevations}

The following procedures should be followed when measuring elevations for monitoring riparian vegetation along the Colorado River in Arizona between Glen Canyon Dam and Lake Mead:

- The person who is making the elevation observations is measured at eye-level to the nearest decimeter, and that value is recorded on the datasheet. If the observer changes, the height of the new recorder at eye-level needs to be recorded and connected to the quadrats that person measured. The height above water of each quadrat is calculated after the field season using these two measurements (height recorded minus height of observer at eye-level equals height above the water).

- One person stands at the end of a transect with the survey rod at the water's edge (fig. S8.1). The rod needs to be held vertically and as still as possible. The scale on the rod needs to face the transect and the person observing the elevations.

- The person measuring elevation stands on the upstream side of the pin flag that marks the placement of a quadrat (fig. S8.1). This person should not stand in the square where vegetation and ground cover assessments are conducted to avoid damaging the vegetation and altering the ground cover.
- The observer with the level reads the survey rod's height at eye-level and records that value. This is done for each quadrat and hydrologic zone boundary (AC/ $\mathrm{AF}$ and $\mathrm{AF} / \mathrm{IF}$ ) along the transect.

- At the end of the transect, both the person holding the survey rod and the elevation observer move to the next transect.

- If the observer is having difficulty reading the values on the survey rod, the rod can be moved to another, closer pin flag along the same transect. The location of the survey rod needs to be noted on the datasheet if it is not at the water's edge (fig. S8.2).

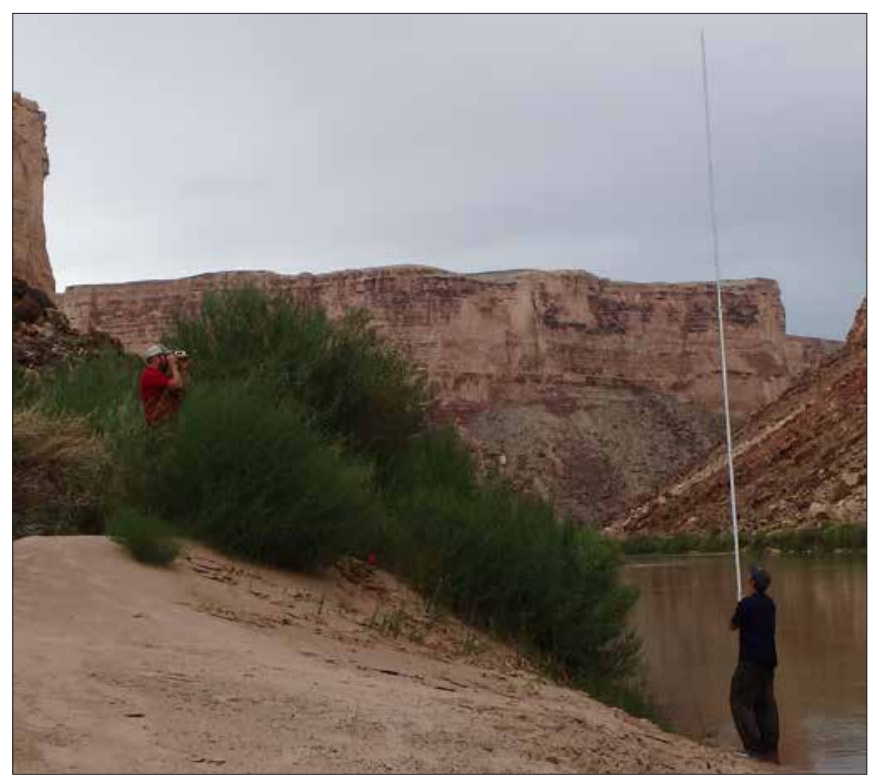

Figure S8.1. Photograph of crewmembers measuring the height of a quadrat above the water's edge while monitoring riparian vegetation along the Colorado River in Arizona between Glen Canyon Dam and Lake Mead. The survey rod is held vertically at the water's edge, while the elevation is measured by a second person standing at the quadrat upslope of the survey rod. 


\section{Recording Elevations}

The following procedures should be followed when recording elevations for monitoring riparian vegetation along the Colorado River in Arizona between Glen Canyon Dam and Lake Mead:

- The date and time that elevations were measured are especially important for this protocol and are recorded on the datasheet (fig. S8.2). Because water levels fluctuate, real elevations for the quadrats will be estimated using the water elevation for that date and time.

- Any changes in recorder need to be clearly noted and the height at eye-level of that person linked to the appropriate quadrats (fig. S8.2). Generally, it is easiest and cleanest to have the same person observing heights for a whole site.

- Any changes to the placement of the survey rod need to be clearly noted (fig. S8.2). If the rod is not at the water's edge for any measurements, the location of the rod needs to be written for each measurement, so that there is no confusion when data is being entered.

- The recorder also needs to pay attention to whether or not the values being recorded make sense. Generally, the elevations of quadrats increase with distance from the water. If a different pattern is recorded on the datasheet, the values need to be checked.

\section{Elevation Above Water - Heights in meters \\ If Stadia rod is not placed at water's edge, record placement (i.e. top of AC or top of AF)}

Time:

\section{Transect 1}

Observer:

Observ. Hght (m):

AC1: 2.4

AC2: 2.8

AC3: 3.0

Top of AC: $\quad 3.3$

AF1: 4.5

AF2: 4.7

AF3: 5.3

Top of AF: 5.9

IF1:

IF2:

IF3:

F3: 6.5
Transect 2

Observer: Elalmquist

Observ. Hght (m): 1.6

AC1: 2 .

AC2: 2.5

AC3: 30

Top of AC: $\quad 3.2$

AF1: 3.7

AF2: 39

AF3: 3,2

Top of AF:

IF1: 4.2

IF2: 4.2

IF3: 4.8
Transect 3

Observer: IDoe

Observ. Hght (m): 1.7

AC1: 2.5

AC2: 3.2

AC3: 2.8

Top of AC: $\quad 3,5$

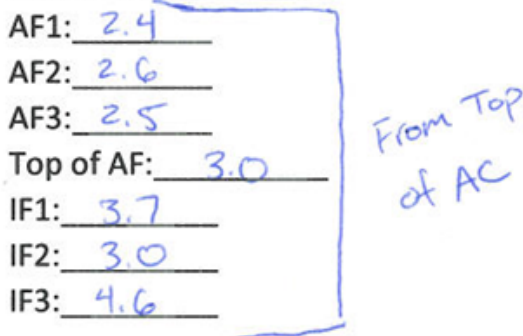

Figure S8.2. Image of part of the site sheet datasheet on which the elevations are recorded while monitoring riparian vegetation along the Colorado River in Arizona between Glen Canyon Dam and Lake Mead. The date is recorded elsewhere on the datasheet, but is also important. Changes to the location of the survey rod or the observer height should be noted next to each measurement. 


\section{SOP 9—Collecting and Pressing Unknown Plant Species}

Version 1.00: Revision History Log

\begin{tabular}{|l|l|l|l|l|l|l|l|}
\hline $\begin{array}{c}\text { Previous version } \\
\text { number }\end{array}$ & $\begin{array}{c}\text { Revision } \\
\text { date }\end{array}$ & Author & $\begin{array}{c}\text { Changes } \\
\text { made }\end{array}$ & $\begin{array}{c}\text { Section and } \\
\text { paragraph }\end{array}$ & $\begin{array}{c}\text { Reason } \\
\text { Approved by }\end{array} \begin{array}{c}\text { New version } \\
\text { number }\end{array}$ \\
\hline & & & & & & & \\
\hline & & & & & & & \\
\hline & & & & & & & \\
\hline
\end{tabular}

Only changes in this specific SOP will be logged here. Version numbers increase incrementally by hundredths (for example version $1.01,1.02$ ) for minor changes. Major revisions should be designated with the next whole number (for example version 2.0, 3.0).

This SOP describes the procedures for recording, collecting, and pressing unknown plant species for riparian-vegetation monitoring along the Colorado River in Arizona between Glen Canyon Dam and Lake Mead. Before collecting an unknown species a botanist should check with the other botanist working on the site to see if it is a known species. If neither botanist knows the species, the species is given an unknown code and is collected. It is very important to clearly link the collection with the quadrat and cover value it is associated with. A clear and consistent record should be kept in three places - the newspaper it is stored in, the datasheet, and the collection notebook.

\section{Standard Collection Process}

The following procedures should be followed when collecting unknown plant species for monitoring riparian vegetation along the Colorado River in Arizona between Glen Canyon Dam and Lake Mead:

- Give the unknown species a unique code. The unknown code is written on the datasheet anytime that species is encountered; on the newspaper it is collected in, and in the collection notebook. This unknown code needs to be unique to this collection. It is easiest to start a pattern for naming and continue with it for the entire sampling trip. For example, using your initials, the date, and a collection number for the day will produce a unique codeEP092315-1.

- Write the code and short physical description of the unknown in the "notes" section of the datasheet. The unknown code is used instead of a species code on the datasheet (associated with cover value).

- Only collect what you need to be able to identify the species. A general rule of thumb is to collect one individual of herbaceous species for every 10 individuals in the area. For example, if you see 10 individuals, you can collect one individual; if you see $\sim 50$ individuals, you can collect up to 5 individuals.
- Collect as many parts of the plants as possible, including flowers, fruit, roots (not for trees and shrubs), and leaves. The more parts that are collected, the more likely it will be correctly identified.

- Press the collection inside its own sheet of newspaper. Label the newspaper with the unknown code, the date, and the site-for example, "EP092315-1, 9/23/15, 125.6R." One sheet of newspaper should contain one species from one location and should be associated with one unknown code. Multiple plants from the same site and collected for the same unknown code can be put in one sheet. Do not put more than one species within a newspaper or individuals from more than one location in the same newspaper.

- When pressing the plants, arrange the leaves and flowers so that the front and back of each can be seen. Clean off excess dirt, mud, and litter so that only the plant is in the newspaper.

- If you see the same species at other sites, it is acceptable to use the same unknown code on the datasheets and not make a new collection. Be sure to use the correct unknown code.

- If you are not sure if a plant is the same species as a previous collection, make a new collection with a new unknown code. Do not combine different species under the same code (species code or unknown code) unless you are confident they are the same.

- Record the following information in the collection notebook:

- Date.

- Site.

- Unknown code with short description of its physical characteristics (red stemmed, ball of white flowers only at the top, very short, annual). 
- Associated species.

- Your name.

- If there are multiple unknown species at one site, you can fill out the date/location/associated species/ collector information once and follow it with a list of unknown codes found at that time and place.

\section{If a Collection Cannot Be Made}

The following procedures should be followed if a plant collection cannot be made for monitoring riparian vegetation along the Colorado River in Arizona between Glen Canyon Dam and Lake Mead:

- If there are not enough plants to make a collection or if the unknown species is a cactus or agave, a set of photographs may be taken instead.

- The unknown species is still given a unique, unknown code following the procedure above.

- Take several photographs of the plant that show the entire plant, the habitat, a close up of the flower, a close up of the fruit, and a close up of the leaves. After taking the photographs, look at them to make sure they are clear and show the elements you intended to show. Use the "macro" setting on the camera for all close ups.

- On the datasheet, the camera number and photograph numbers are recorded next to the unknown code in the "Notes" section.

- The collection notebook should still be filled out according the process described above, however, the camera number and photograph numbers are added into the list of information recorded.

\section{Collection Management in the Field}

The plant presses need to be kept dry while boating, but need to be aired out at night. Large dry bags are suitable for keeping the presses dry during the day, but will lead to specimen molding if they are not removed at night. Presses also need to be kept out of the rain. Sun and heat are good for the presses, because it will help the collections dry more quickly.

Collections made in the field press need to be moved to the standard, wooden press at the end of the day. This will keep the field press open for more collections and the wooden press protects the collections better. 


\section{SOP 10-After Each Field Trip}

Version 1.00: Revision History Log

\begin{tabular}{|l|l|l|l|l|l|l|l|}
\hline $\begin{array}{c}\text { Previous version } \\
\text { number }\end{array}$ & $\begin{array}{c}\text { Revision } \\
\text { date }\end{array}$ & Author & $\begin{array}{c}\text { Changes } \\
\text { made }\end{array}$ & $\begin{array}{c}\text { Section and } \\
\text { paragraph }\end{array}$ & Reason & Approved by & $\begin{array}{c}\text { New version } \\
\text { number }\end{array}$ \\
\hline & & & & & & & \\
\hline & & & & & & & \\
\hline & & & & & & & \\
\hline & & & & & & & \\
\hline
\end{tabular}

Only changes in this specific SOP will be logged here. Version numbers increase incrementally by hundredths (for example version $1.01,1.02$ ) for minor changes. Major revisions should be designated with the next whole number (for example version 2.0, 3.0).

This SOP describes the procedures of data management and gear management following a data-collecting trip for riparian-vegetation monitoring along the Colorado River in Arizona between Glen Canyon Dam and Lake Mead.

\section{Data Management}

The following procedures should be followed for data management after a trip for monitoring riparian vegetation along the Colorado River in Arizona between Glen Canyon Dam and Lake Mead:

- Organize and file datasheets for data entry at the end of the field season.

- If data was collected on tablets, download the data and merge with the master database.

- Download photographs from all cameras and put in proper folder. Label photographs with site number and direction it was taken—for example, RM121_5R_upstream for a photograph taken at river mile 121.5 on the right taken facing upstream.

- Remove plant collections from both presses and store in a safe location for later identification.

\section{Equipment Management}

The following procedures should be followed for equipment management after a trip for monitoring riparian vegetation along the Colorado River in Arizona between Glen Canyon Dam and Lake Mead:

- Charge camera batteries after each trip, except for the last trip.

- Inspect all field gear and make a list of gear that needs to be repaired or replaced. If gear can be repaired, do so as soon as possible. Order gear when necessary and replace it as soon as possible.

- Restock newspaper, pin flags, datasheets, writing utensils, batteries, and other temporary gear.

- Retrieve all equipment borrowed by field volunteers and clean as necessary. Return this gear to the logistics and permitting coordinator.

- Repack field boxes with the appropriate gear for the next field trip.

- Charge tablet computers, if they are being used.

\section{Travel Paperwork and Timesheet}

The following procedures should be followed for completing travel paperwork and timesheets after a trip for monitoring riparian vegetation along the Colorado River in Arizona between Glen Canyon Dam and Lake Mead:

- Coordinate with administrative personnel to submit travel vouchers for all employees and volunteers.

- Complete and fill out timesheets before the due date. 


\section{SOP 11-After the Field Season}

Version 1.00: Revision History Log

\begin{tabular}{|c|c|c|c|c|c|c|c|}
\hline $\begin{array}{c}\text { Previous version } \\
\text { number }\end{array}$ & $\begin{array}{c}\text { Revision } \\
\text { date }\end{array}$ & Author & $\begin{array}{c}\text { Changes } \\
\text { made }\end{array}$ & $\begin{array}{l}\text { Section and } \\
\text { paragraph }\end{array}$ & Reason & Approved by & $\begin{array}{c}\text { New version } \\
\text { number }\end{array}$ \\
\hline & & & & & & & \\
\hline & & & & & & & \\
\hline & & & & & & & \\
\hline & & & & & & & \\
\hline
\end{tabular}

Only changes in this specific SOP will be logged here. Version numbers increase incrementally by hundredths (for example version 1.01, 1.02) for minor changes. Major revisions should be designated with the next whole number (for example version 2.0, 3.0).

This SOP explains procedures that are carried out at the end of the field season for riparian-vegetation monitoring along the Colorado River in Arizona between Glen Canyon Dam and Lake Mead.

\section{Field Equipment}

The following procedures should be followed for assessing field equipment after the field season for monitoring riparian vegetation along the Colorado River in Arizona between Glen Canyon Dam and Lake Mead:

- All field equipment is assessed for its ability to perform and cleanliness. All equipment is cleaned. Broken equipment is either repaired or replaced, depending on its degree of disrepair. Do not store broken equipment.

- Make a list of all purchases, repairs, and resupplies needed for the next year's sampling and provide to the research ecologist as soon as feasible.

- Field equipment is returned to winter storage once cleaned and repaired.

- Clean and return any borrowed field equipment.

\section{Organizing Data}

The following procedures should be followed for organizing data after the field season for monitoring riparian vegetation along the Colorado River in Arizona between Glen Canyon Dam and Lake Mead:

- Organize and file all datasheets. This should be done after each field trip, but organizations of datasheets should be checked at the end of the field season. Make sure all datasheets are accounted for and in a logical place.
- Scan and electronically file all datasheets. Files should be labeled with the site name and date - for example, DS_121_5R_092315.pdf(datasheet, 121.5R, 9/23/15).

- Check and finish photograph labels and organization. See SOP 10 for labeling conventions.

- Data on paper datasheets is entered and error checked. Specific procedures are detailed in SOP 12.

- Data collected using tablet computers is downloaded and merged with the database. Carefully check the database to make sure that all data were transferred correctly and no data were lost.

\section{Unknown Plant Collections}

The following procedures should be followed for assessing unknown plant collections after the field season for monitoring riparian vegetation along the Colorado River in Arizona between Glen Canyon Dam and Lake Mead:

- Unknown plant collections are identified to species or the lowest taxonomic level possible.

- Identifications are noted in an identification notebook, along with collection information from the collection notebooks. The identification is also written on the newspaper of the collection.

- Unknown codes in the dataset can be updated with correct species name once data entry and error checking has been completed.

- Any high-quality collections that were not destroyed during identification are given to the GLCA, GRCA, or Hualapai Tribe herbarium, as appropriate, along with collection information. 


\section{Reports}

Three reports are due on an annual basis, and one report is due every 5 years on monitoring riparian vegetation along the Colorado River in Arizona between Glen Canyon Dam and Lake Mead: These are listed below(SOP 14 describes the contents and analyses required for these reports in greater detail):

- An administrative river-trip report is submitted to the logistics and permitting coordinator for each river trip. This contains a summary of the people who were on the trip, the actual campsites used, and comments about results of, observations during, and problems on the trip.

- Investigator annual reports are brief reports that are submitted to both GRCA and GLCA detailing the accomplishments of the field season and any collections made.

- Each year a brief report summarizing the species recorded, frequencies, richness estimates, and estimated covers is produced as a part of the larger GCMRC annual report to stakeholders.

- A report analyzing the status and trends of the riparian vegetation is created and published as a USGS Open-File Report every 5 years. Topics such as shifts in functional groups, any newly recorded species, any declines in species, responses of vegetation to hydrologic changes, and other factors are addressed in this report. 


\section{SOP 12-Data Entry and Error Checking}

Version 1.00: Revision History Log

\begin{tabular}{|l|l|l|l|l|l|l|l|}
\hline $\begin{array}{c}\text { Previous version } \\
\text { number }\end{array}$ & $\begin{array}{c}\text { Revision } \\
\text { date }\end{array}$ & Author & $\begin{array}{c}\text { Changes } \\
\text { made }\end{array}$ & $\begin{array}{c}\text { Section and } \\
\text { paragraph }\end{array}$ & Reason & Approved by & $\begin{array}{c}\text { New version } \\
\text { number }\end{array}$ \\
\hline & & & & & & & \\
\hline & & & & & & & \\
\hline & & & & & & & \\
\hline
\end{tabular}

Only changes in this specific SOP will be logged here. Version numbers increase incrementally by hundredths (for example version 1.01, 1.02) for minor changes. Major revisions should be designated with the next whole number (for example version 2.0, 3.0).

This SOP details the methods for entering and error checking data from paper datasheets for riparian-vegetation monitoring along the Colorado River in Arizona between Glen Canyon Dam and Lake Mead. The goal of data entry is to transfer the data from paper into the database without error; therefore, error checking is conducted to minimize the number of data entry mistakes. Data should be entered as soon as possible after collection. Ideally, data should be entered by the people who collected it or, at least, someone who is familiar with the data.

\section{Entering Data from Paper Datasheets}

Data recorded on paper datasheets must be entered by hand into the vegetation database. Care should be taken while entering data to try to make a few mistakes as possible. Save the database regularly while entering data. When a datasheet has been completely entered into the database, initial and date the top of the datasheet. This keeps track of which datasheets have already been entered and which ones still need to be done.

\section{Verifying Data Entered from Paper Datasheets}

After entering all the data on paper datasheets into the database, entered data is verified by comparing each datasheet against the entered data. Any errors are corrected as they are found. Initial and date each datasheet again as it is finished.

\section{Photographs}

Site photographs, unknown plant photographs, and photographs of field crews at work are saved to appropriate server locations. File names of site photographs are changed to the appropriate format (see SOP 10) so they can be easily identified.

\section{Unknown Plants}

Collections of unknown species are properly stored and identified. The scientific name of each identified collection is recorded in the identification notebook and on the newspaper of the collection. Once all data has been entered and verified, unknown codes in the data can be changed to the correct scientific name. Collections that are not destroyed in the identification process and are of herbarium quality are given to the GLCA, GRCA, or Hualapai herbarium, depending on where it was collected, along with the required collection information. 


\section{SOP 13-Data Management}

Version 1.00: Revision History Log

\begin{tabular}{|l|l|l|l|l|l|l|l|}
\hline $\begin{array}{c}\text { Previous version } \\
\text { number }\end{array}$ & $\begin{array}{c}\text { Revision } \\
\text { date }\end{array}$ & Author & $\begin{array}{c}\text { Changes } \\
\text { made }\end{array}$ & $\begin{array}{c}\text { Section and } \\
\text { paragraph }\end{array}$ & $\begin{array}{c}\text { Reason } \\
\text { Approved by }\end{array}$ & $\begin{array}{c}\text { New version } \\
\text { number }\end{array}$ \\
\hline & & & & & & \\
\hline & & & & & & & \\
\hline & & & & & & & \\
\hline
\end{tabular}

Only changes in this specific SOP will be logged here. Version numbers increase incrementally by hundredths (for example version $1.01,1.02$ ) for minor changes. Major revisions should be designated with the next whole number (for example version 2.0, 3.0).

This SOP describes the standards and protocols for data management in the field and in the office for riparian-vegetation monitoring along the Colorado River in Arizona between Glen Canyon Dam and Lake Mead. Data management procedures are detailed for cover data, elevation data, and photographs. Further information regarding general data management practices can be found in the GCMRC Riparian Vegetation Monitoring Data Management Plan, available at https://dmptool.org.

\section{Cover and Elevation Data}

\section{Paper Datasheets}

Cover data collected on paper datasheets or on field tablets is checked for completeness, legibility, and correct species codes after each transect, at the completion of each site, and at the end of each day. All spaces in which data are recorded should have some mark in them, either a value or an indication that there was nothing to record. Any handwritten items need to be legible. Species codes need to be correct and consistent. The recorder checks the data form at the end of each transect, including double checking that the transect number written on the datasheet is correct. The field crew leader checks the data forms and organizes them at the end of each site. The monitoring ecologist sorts, checks, and files all datasheets at the end of each workday. Completed paper datasheets are stored in the "library" box with the empty datasheets, floras, and extra field gear, which is securely stowed on one of the boats.

\section{Electronically Entered Data}

Data collected electronically will be entered into the vegetation database directly. The data entry forms will contain quality assurance/quality control measures to prevent recording mistakes in the field, but the recorder will still check to make sure that data was entered properly at the end of each transect. At the end of each day, any tablets that were used to collect data will be backed up on flash drives, one for each boat.

\section{Photographs}

Photograph management is mostly done in the office. On returning from the field, photographs are downloaded from all of the cameras that were used. All the photographs should be put in the proper folder on the shared drive, following the labeling pattern already present. Photograph files are labeled with site number and direction it was taken - for example, RM121_5R upstream for a photograph taken at river mile 121.5 on the right taken facing upstream. Redundant photographs and photographs that are not useful (for example, blurry photographs) should be deleted. 


\section{SOP 14-Data Analysis and Reporting}

Version 1.00: Revision History Log
\begin{tabular}{|c|c|c|c|c|c|c|c|}
\hline $\begin{array}{c}\text { Previous version } \\
\text { number }\end{array}$ & $\begin{array}{c}\text { Revision } \\
\text { date }\end{array}$ & Author & $\begin{array}{c}\text { Changes } \\
\text { made }\end{array}$ & $\begin{array}{c}\text { Section and } \\
\text { paragraph }\end{array}$ & Reason & Approved by & $\begin{array}{c}\text { New version } \\
\text { number }\end{array}$ \\
\hline & & & & & & & \\
\hline & & & & & & & \\
\hline & & & & & & & \\
\hline & & & & & & & \\
\hline
\end{tabular}

Only changes in this specific SOP will be logged here. Version numbers increase incrementally by hundredths (for example version $1.01,1.02$ ) for minor changes. Major revisions should be designated with the next whole number (for example version 2.0, 3.0).

This SOP provides guidelines for the preparation of basic reports on riparian-vegetation monitoring along the Colorado River in Arizona between Glen Canyon Dam and Lake Mead. The guidelines specify the minimum summary statistics and reporting requirements conducted on 1-year and 5-year cycles. These basic reporting standards do not preclude more novel or adaptive analyses, which may be undertaken if needs or capacities change. Beyond what is described here, other analyses and reports or publications may be needed at different times, but can be addressed by the riparian vegetation team as they arise. The required reports, their time frames, and the position responsible for each report are presented in table S14.1.

\section{River-Trip Report}

An administrative river-trip report is submitted to the logistics and permitting coordinator of GCMRC after each river trip. The purpose of this report is to provide the logistics and permitting coordinator and GRCA with a summary of how the trip went and provide any useful comments on personnel, gear, equipment, or procedures. This contains a list of the people who were on the trip and their roles and the actual campsites used. Any relevant comments about observations during and problems on the trip are included here, particularly evaluations of hired river guides and issues during exchanges. No statistical analyses are required for this report.

\section{Investigator Annual Report}

The investigator annual report (IAR) is a brief report that is submitted to both GLCA and GRCA detailing the accomplishments of the field season and any collections made. This report is written using the IAR online application and submitted through NPS Research Permit and Reporting System (RPRS, https://irma.nps.gov/rprs/Home). The purpose of this report is to inform the National Parks about what was accomplished that year. Information in the report includes the permit number and title of the project, the purpose, any findings, any collections that were made, and the source of project funding.
At a minimum, the number of sites studied in each river reach during each river trip and the number of species recorded should be included. Data summaries of diversity and cover are recommended.

\section{GCMRC Annual Report}

In November of the year following field work (for example, Nov. 2015 for field work conducted in fall of 2014), an annual report on vegetation monitoring is added to the program wide GCMRC annual report (table S14.1). Although the GCMRC annual report is due in December, it is necessary to provide the vegetation component of that report to the GCMRC communications and outreach coordinator in November. This report summarizes annual data, provides an update of ongoing monitoring activities (for example, publications), and briefly discusses the sampling activities of the current year. The minimum analyses required for the annual report are outlined in table S14.2, and include metrics such as richness, percent cover of total foliar and woody species, and measures of exotic species prevalence. The metrics listed in table S14.2 will be provided for each river segment-Glen Canyon, Marble Canyon, and eastern and western Grand Canyon.

Additionally, a list of species recorded during that year's data collecting will be made available at the annual reporting meeting and included as an appendix to the annual report. This should highlight any newly recorded species or other notable collections.

\section{5-year Status and Trend Reports}

Every 5 years a status and trends report will be prepared. It will assess changes in the monitored parameters, but may also involve syntheses with allied research - for example, the remotely sensed riparian monitoring program (project 11.2 in the GCMRC fiscal year 2015-2017 work plan). The status and trend report is intended to provide a rigorous estimate and interpretation of the change in the Colorado River riparian ecosystem and will be published as a USGS Open-File Report (table S14.1). The purpose of this report is to assess the status and trends of the riparian vegetation, particularly in response to hydrologic changes. 
Table S14.1. Time frames and responsibilities for required reports on riparian-vegetation monitoring along the Colorado River in Arizona between Glen Canyon Dam and Lake Mead.

[GCMRC, Grand Canyon Monitoring and Research Center; NPS, National Park Service]

\begin{tabular}{ccccc}
\hline \multicolumn{1}{c}{ Report } & Frequency & Submitted to & Due & Position responsible \\
\hline River-trip report & $\begin{array}{c}\text { Yearly for each } \\
\text { trip }\end{array}$ & Logistics and permitting coordinator & $\begin{array}{c}\text { As soon as possible after } \\
\text { each river trip }\end{array}$ & $\begin{array}{c}\text { Monitoring ecologist/ bio- } \\
\text { logical science technician }\end{array}$ \\
$\begin{array}{c}\text { Investigator annual } \\
\text { report }\end{array}$ & $\begin{array}{c}\text { Yearly for each } \\
\text { permit }\end{array}$ & $\begin{array}{c}\text { NPS Research Permit and Reporting } \\
\text { System website }\end{array}$ & January & Monitoring ecologist \\
$\begin{array}{c}\text { GCMRC annual } \\
\text { report }\end{array}$ & Yearly & $\begin{array}{c}\text { As a part of the GCMRC annual report } \\
\text { to the Adaptive Management Program }\end{array}$ & $\begin{array}{c}\text { November of the next } \\
\text { year }\end{array}$ & $\begin{array}{c}\text { Research ecologist/ } \\
\text { Monitoring ecologist }\end{array}$ \\
$\begin{array}{c}\text { 5-year status and } \\
\text { trends }\end{array}$ & Every 5 years & Open-File Report & $\begin{array}{c}\text { Draft June; final Decem- } \\
\text { ber of the next year }\end{array}$ & Research ecologist \\
\hline
\end{tabular}

Table S14.2. Minimum summaries included in each Grand Canyon Monitoring and Research Center annual report on riparianvegetation monitoring along the Colorado River in Arizona between Glen Canyon Dam and Lake Mead.

[Data summarized is from the previous year (for example, the 2015 annual report summarizes data collected in the fall of 2014]

\begin{tabular}{ll}
\hline \multicolumn{1}{c}{ Metric } & \multicolumn{1}{c}{ Variables } \\
\hline Percent cover & For each river segment- total percentage of foliar, woody species, and exotic species cover \\
Richness & Total species, exotic species \\
Frequency & For the ten most frequency species in each hydrologic zone and in each river segment \\
Species List & Includes all species recorded that year. Highlights newly recorded species and notable collections. \\
\hline
\end{tabular}

At a minimum, the status and trends report needs to address changes in vegetation parameters as related to hydrologic changes and include the basic analyses outlined in table S14.2. Other relevant analyses should be included as well, depending on the data available and informational needs. Because both information needs and statistical procedures may change over time, specific analyses are not outlined here. Beyond the minimum analyses stated above, the content of the 5-year summary will be determined by the riparian vegetation team.

\section{Allied Research}

In addition to the formal analysis and reporting needs specified above that form the core of the monitoring program, this Techniques and Methods protocol is intended to support applied research exploring the fundamental and applied ecology of the riparian vegetation in Grand Canyon and to interface with ongoing efforts by hydrologists, geomorphologists, fisheries biologists, and wildlife ecologists conducting research in the river corridor. It is also intended to provide predictable and high quality data to support regional analysis and synthesis by GCMRC, NPS, and outside researchers. The research ecologist and monitoring ecologist are charged with identifying opportunities to leverage the core monitoring efforts to support and stimulate allied research that, in turn, amplifies and informs the monitoring efforts. Examples include preparation of riparian vegetation flow response guilds (following Merritt and others, 2010) for the Grand Canyon and larger Colorado Basin, research linking riparian vegetation with terrestrial wildlife, and contributions to regional knowledge of plant traits. Allied research will be both specified in GCMRC work plans and occur opportunistically in response to the availability of outside funding or collaborations. 


\section{SOP 15-Revising the Protocol}

Version 1.00: Revision History Log

\begin{tabular}{|l|l|l|l|l|l|l|l|}
\hline $\begin{array}{c}\text { Previous version } \\
\text { number }\end{array}$ & $\begin{array}{c}\text { Revision } \\
\text { date }\end{array}$ & Author & $\begin{array}{c}\text { Changes } \\
\text { made }\end{array}$ & $\begin{array}{c}\text { Section and } \\
\text { paragraph }\end{array}$ & Reason & $\begin{array}{c}\text { Approved by } \\
\text { New version } \\
\text { number }\end{array}$ \\
\hline & & & & & & & \\
\hline & & & & & & & \\
\hline & & & & & & \\
\hline
\end{tabular}

Only changes in this specific SOP will be logged here. Version numbers increase incrementally by hundredths (for example version $1.01,1.02$ ) for minor changes. Major revisions should be designated with the next whole number (for example version 2.0, 3.0).

This SOP explains how to document and track changes to the Grand Canyon Monitoring and Research Center Riparian Vegetation Monitoring protocol, both the narrative and the associated SOPs. The narrative and all SOPs may be revised independently, because a change in one does not necessarily require a change elsewhere.

\section{Reviews}

Minor modifications to the current protocol, such as edits to formatting, wording, clarifications, task schedules, and such, are reviewed within the GCMRC Riparian Monitoring group. Major changes to data collection techniques, such as sampling design, or analysis techniques, may require outside reviews.

\section{Revision History and Versions}

Changes to the protocol other than formatting and punctuation must be documented in the revision history logs at the start of the affected section. A new version of the protocol is then used, rather than overwriting the previous version. New versions will be approved following USGS Fundamental Science Policies (https://internal.usgs.gov/fsp/) and Science
Publishing Network Practices (https://www2.usgs.gov/ publishing/policies.html).

Version numbers reflect the degree to which a section was altered; minor changes result in version number increasing by the hundredths (for example, version 1.01, 1.02), whereas major changes result in a whole number increase (for example, version $1.0,2.0)$.

Older versions of the protocol should be retained to document the full history of data collection for future analyses. These versions can be stored electronically with sufficient back up procedures.

\section{Dissemination}

Copies of the protocol are available to collaborators for download through the USGS Publications Warehouse (https:// pubs.er.usgs.gov/publication/tm2A14). As SOPs are added or modified and versions are approved following USGS Fundamental Science Policies (www2.usgs.gov/fsp/default. asp) and Science Publishing Network Practices (https://www2. usgs.gov/publishing/policies.html) these versions will be made available through the USGS publications warehouse. Version changes will identify changes made to the document. 


\section{Appendix 2-Fixed Sites}

Table A2.1 lists fixed site eddy sandbars sampled annually for vegetation cover and ground cover for riparian-vegetation monitoring along the Colorado River in Arizona between Glen
Canyon Dam and Lake Mead. Northern Arizona University (NAU) surveys these eddy sandbars annually to monitor geomorphic change. River miles follow U.S. Geological Survey (2002). 
Table A2.1. Table of fixed site eddy sandbars sampled annually for riparian-vegetation monitoring along the Colorado River in Arizona between Glen Canyon Dam and Lake Mead.

[River side when facing downstream—R, right side; L, left side; No. tran., number of transects; No. quads, number of quadrats; IF, inactive flood zone; random no., range of possible numbers for the random start point; transect spacing, the distance between the transects; $\mathrm{m}$, meter]

\begin{tabular}{|c|c|c|c|c|c|c|c|c|}
\hline Site name & River mile & River side & No. tran. & No. quads & IF sampled & $\begin{array}{l}\text { Approximate } \\
\text { length }(\mathbf{m})\end{array}$ & $\begin{array}{c}\text { Random } \\
\text { no. }\end{array}$ & $\begin{array}{l}\text { Transect } \\
\text { spacing } \\
\text { (m) }\end{array}$ \\
\hline-6 mile & -6.6 & $\mathrm{R}$ & 4 & 36 & Yes & 180 & $0-45$ & 45 \\
\hline Cathedral & 2.5 & $\mathrm{~L}$ & 3 & 27 & Yes & 65 & $0-22$ & 22 \\
\hline Jackass & 8.1 & $\mathrm{~L}$ & 3 & 27 & Yes & 95 & $0-32$ & 32 \\
\hline 9 Mile & 8.9 & $\mathrm{~L}$ & 4 & 24 & Yes & 100 & $0-25$ & 25 \\
\hline $\mathrm{Hot} \mathrm{Na} \mathrm{Na}$ & 16.6 & $\mathrm{~L}$ & 3 & 27 & Yes & 75 & $0-25$ & 25 \\
\hline 22 Mile & 22.0 & $\mathrm{R}$ & 3 & 27 & Yes & 90 & $0-30$ & 30 \\
\hline Harry McDonald & 23.5 & $\mathrm{~L}$ & 3 & 27 & Yes & 90 & $0-30$ & 30 \\
\hline Silver Grotto & 29.5 & $\mathrm{~L}$ & 3 & 27 & Yes & 115 & $0-38$ & 38 \\
\hline 30 Mile/Sand Pile & 30.7 & $\mathrm{R}$ & 3 & 27 & Yes & 95 & $0-31$ & 31 \\
\hline South Canyon & 31.9 & $\mathrm{R}$ & 4 & 24 & No & 130 & $0-32$ & 32 \\
\hline Nautiloid & 35.1 & $\mathrm{~L}$ & 3 & 27 & Yes & 100 & $0-33$ & 33 \\
\hline Buckfarm upper & 41.2 & $\mathrm{R}$ & 4 & 36 & Yes & 165 & $0-41$ & 41 \\
\hline Buckfarm lower & 41.4 & $\mathrm{R}$ & 4 & 24 & No & 155 & $0-38$ & 38 \\
\hline Anasazi Bridge & 43.4 & $\mathrm{~L}$ & 4 & 36 & Yes & 115 & $0-28$ & 28 \\
\hline Eminence & 44.5 & $\mathrm{~L}$ & 4 & 36 & Yes & 175 & $0-43$ & 43 \\
\hline Willie Taylor & 45.0 & $\mathrm{~L}$ & 3 & 27 & Yes & 90 & $0-30$ & 30 \\
\hline Saddle Canyon & 47.7 & $\mathrm{R}$ & 4 & 36 & Yes & 130 & $0-32$ & 32 \\
\hline Dino Camp & 50.1 & $\mathrm{R}$ & 3 & 27 & Yes & 90 & $0-30$ & 30 \\
\hline 51 Mile & 51.5 & $\mathrm{~L}$ & 4 & 36 & Yes & 230 & $0-57$ & 57 \\
\hline Kwagunt Marsh & 55.9 & $\mathrm{R}$ & 4 & 36 & Yes & 155 & $0-38$ & 38 \\
\hline Kwagunt Beach & 56.6 & $\mathrm{R}$ & 4 & 36 & Yes & 155 & $0-38$ & 38 \\
\hline Crash Canyon & 63.0 & $\mathrm{R}$ & 3 & 27 & Yes & 100 & $0-33$ & 33 \\
\hline Carbon & 65.1 & $\mathrm{R}$ & 4 & 24 & Yes & 130 & $0-32$ & 32 \\
\hline Tanner & 68.7 & $\mathrm{R}$ & 4 & 36 & Yes & 175 & $0-43$ & 43 \\
\hline Basalt & 70.1 & $\mathrm{R}$ & 3 & 27 & Yes & 90 & $0-30$ & 30 \\
\hline Cremation & 87.7 & $\mathrm{~L}$ & 4 & 24 & Yes & 60 & $0-15$ & 15 \\
\hline Above Trinity & 91.7 & $\mathrm{R}$ & 3 & 27 & Yes & 45 & $0-15$ & 15 \\
\hline Granite & 93.8 & $\mathrm{~L}$ & 4 & 24 & Yes & 145 & $0-36$ & 36 \\
\hline Emerald & 104.4 & $\mathrm{R}$ & 3 & 27 & Yes & 35 & $0-11$ & 11 \\
\hline Big Dune & 119.4 & $\mathrm{R}$ & 3 & 27 & Yes & 115 & $0-38$ & 38 \\
\hline 122 Mile & 122.7 & $\mathrm{R}$ & 4 & 36 & No & 105 & $0-26$ & 26 \\
\hline Forster & 123.2 & $\mathrm{~L}$ & 3 & 27 & Yes & 140 & $0-46$ & 46 \\
\hline Football field & 137.7 & $\mathrm{~L}$ & 3 & 27 & No & 100 & $0-33$ & 33 \\
\hline Fishtail & 139.6 & $\mathrm{R}$ & 4 & 24 & Yes & 120 & $0-30$ & 30 \\
\hline Above OLO & 145.9 & $\mathrm{~L}$ & 3 & 27 & Yes & 55 & $0-18$ & 18 \\
\hline National Canyon & 167.1 & $\mathrm{~L}$ & 4 & 36 & Yes & 90 & $0-22$ & 22 \\
\hline 172 Mile & 172.6 & $\mathrm{~L}$ & 4 & 24 & No & 175 & $0-43$ & 43 \\
\hline Below Chevron & 183.3 & $\mathrm{~L}$ & 3 & 27 & Yes & 65 & $0-21$ & 21 \\
\hline Hualapai Acres & 194.6 & $\mathrm{~L}$ & 4 & 36 & Yes & 145 & $0-36$ & 36 \\
\hline 202 Mile & 202.3 & $\mathrm{R}$ & 3 & 27 & Yes & 125 & $0-41$ & 41 \\
\hline Pumpkin & 213.3 & $\mathrm{~L}$ & 3 & 27 & Yes & 90 & $0-30$ & 30 \\
\hline Middle Gorilla & 220.1 & $\mathrm{R}$ & 3 & 27 & Yes & 70 & $0-23$ & 23 \\
\hline Hell Beach & 225.5 & $\mathrm{R}$ & 3 & 27 & Yes & 100 & $0-33$ & 33 \\
\hline
\end{tabular}




\section{Appendix 3-Datasheets}

When electronic data collection is not possible, paper datasheets are used for recording data for riparian-vegetation monitoring along the Colorado River in Arizona between
Glen Canyon Dam and Lake Mead. Figures A3.1-A3.3 are examples of the datasheets used for sampling random sites and fixed sites.

\section{GCMRC Riparian Vegetation Monitoring}

Site Specifics

Site/River Mile:

Geomorphic Feature (circle one):
Sandbar Ave. Slope: Slope 2:

Slope 1: Length 1: Length 2
Date:

Debris Fan

Channel Margin

\section{Photo Numbers}

Upstream

Transect 1 : Camera used:

Downstream Transect 2

Transect 3

Disturbances

Record any disturbances other than inundation (e.g., wildfire, heavy recreation use, etc.)

\section{Elevation Above Water - Heights in meters}

If Stadia rod is not placed at water's edge, record placement (e.g., top of AC or top of AF)

Time:

Transect 1

Observer:

Observ. Hght (m)

AC1:

$A C 2:$

AC3:

Top of AC:

AF1:

AF2:

AF3:

Top of AF:

IF1:

IF2:

IF3: : -

-

.

(2)

Transect 2
Observer:
Observ. Hght (m):
AC1:
AC2:
AC3:
Top of AC:
AF1:
AF2:
AF3:
Top of AF:
IF1:
IF2:
IF3:

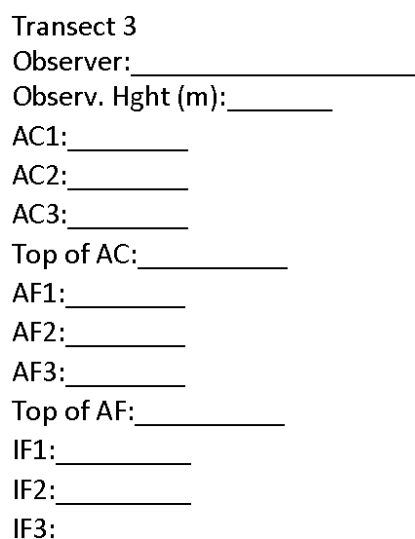

Observ. Hght (m)

AC1

$\mathrm{AC2}$

$\mathrm{AC} 3$

Top of AC

AF2

AF3:

IF1:

IF3:

Figure A3.1. Images show front (above) and back (next page) of the "site specifics" datasheet for random sites used for riparian-vegetation monitoring along the Colorado River in Arizona between Glen Canyon Dam and Lake Mead. A site species list can be made if time allows, but is not required as part of the monitoring program. 
GCMRC Riparian Vegetation Monitoring Site Specifics

SPECIES LIST

Observer (s):

Begin time:

End time:

Figure A3.1.-Continued

GCMRC Riparian Vegetation Monitoring

Site/River Mile:

Date:

Photo Numbers

Upstream:

Downstream:
Transect 1:

Transect 2:

Transect 3:

Record any disturbances other than inundation (i.e. wildfire, heavy recreation use, etc.)

\section{SPECIES LIST}

Observer (s):

Begin time:

End time:

Figure A3.2. Front image of the "site specifics" datasheet for fixed sites used for riparian-vegetation monitoring along the Colorado River in Arizona between Glen Canyon Dam and Lake Mead. Nothing is printed on the reverse side. A site species list can be made if time allows, but is not required as part of the monitoring program. 
GCMRC Riparian Vegetation Monitoring

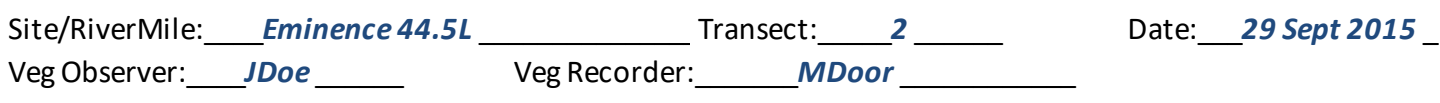

Notes:

EP092315 -1: Brassicaceae, white flowers, silicle with minute apical notch

\begin{tabular}{|c|c|c|c|c|c|c|c|c|c|c|}
\hline Ground Cover & AC1 & AC2 & AC3 & AF1 & AF2 & AF3 & IF1 & IF2 & IF3 & \\
\hline Litter & - & - & $T$ & 15 & 30 & 40 & - & 30 & 100 & \\
\hline Standing Dead & - & - & - & - & - & - & - & $T$ & - & \\
\hline Biological Soil Crust & - & - & - & - & - & - & - & - & - & \\
\hline Fines $(<0.062 \mathrm{~mm})$ & - & - & - & - & - & - & - & - & - & \\
\hline Sand $(0.062-2 \mathrm{~mm})$ & - & - & - & 20 & 25 & 20 & 40 & 80 & 100 & \\
\hline Rock $(>2 \mathrm{~mm})$ & 100 & 100 & 100 & 80 & 75 & 80 & 60 & 20 & - & \\
\hline Total Live Foliar Cover & - & - & - & 15 & 10 & 80 & 10 & 20 & 80 & \\
\hline \multicolumn{11}{|l|}{ Fill in Species Below } \\
\hline BACEMO & - & - & - & 5 & 10 & 75 & - & - & - & \\
\hline EQUFER & - & - & 1 & 5 & 5 & - & - & - & - & \\
\hline EUTOCC & - & - & - & $T$ & - & - & - & - & - & \\
\hline EP092315 - 1 & - & - & - & - & - & 5 & - & - & - & \\
\hline TAMAR & - & - & - & - & $T$ & - & - & 15 & 80 & \\
\hline SPOFLE & - & - & - & - & - & - & 10 & $T$ & - & \\
\hline ISOACR & - & - & - & - & - & - & - & 5 & - & \\
\hline BRORUB & - & - & - & - & - & - & - & - & 5 & \\
\hline & & & & & & & & & & \\
\hline & & & & & & & & & & \\
\hline & & & & & & & & & & \\
\hline & & & & & & & & & & \\
\hline & & & & & & & & & & \\
\hline & & & & & & & & & & \\
\hline & & & & & & & & & & \\
\hline & & & & & & & & & & \\
\hline & & & & & & & & & & \\
\hline & & & & & & & & & & \\
\hline & & & & & & & & & & \\
\hline & & & & & & & & & & \\
\hline & & & & & & & & & & \\
\hline & & & & & & & & & & \\
\hline & & & & & & & & & & \\
\hline & & & & & & & & & & \\
\hline & & & & & & & & & & \\
\hline & & & & & & & & & & \\
\hline & & & & & & & & & & \\
\hline
\end{tabular}

Figure A3.3. Example foliar cover and ground cover datasheet for random sites used for riparian-vegetation monitoring along the Colorado River in Arizona between Glen Canyon Dam and Lake Mead. Fixed sites cover datasheets differ only in that the header row (for example, AC1, AC2) is blank to allow the quadrat number to be filled in. Example data are filled in. Species occurring in quadrats are entered on the left hand side as a six-letter code (first three letters of the genus and species names) and their cover values entered into the appropriate columns. Each new unknown code is written in the "notes" section with a brief description of the species. 


\section{Appendix 4-Example Random Sampling Schedule}

This appendix gives examples of the schedule (table A4.1) and list of people (table A4.2) that need to be provided to the logistics and permitting coordinator before riparianvegetation monitoring along the Colorado River in Arizona between Glen Canyon Dam and Lake Mead. Fifty days before the launch date, the approximate number of people, the total number of boats, and an approximate schedule need to be submitted. The finalized personnel list and finalized schedule should be provided as soon as possible before the launch date. Actual schedules and lists of people do not have to be submitted in this format, rather these are an example of the information that is needed.

Table A4.1. Example schedule for riparian-vegetation monitoring along the Colorado River in Arizona between Glen Canyon Dam and Lake Mead.

[The schedule should contain the dates of the trip, the daily sampling goal (how many sites are expected to be sampled), an approximate camping location with river mile, and the approximate number of river miles traveled. The campsites are likely campsites, not guaranteed campsites, so can be adjusted to fit actual logistical conditions in the field. This schedule needs to be created based on the locations of the randomly generated samples, realistic sampling goals, and reasonable miles covered per day]

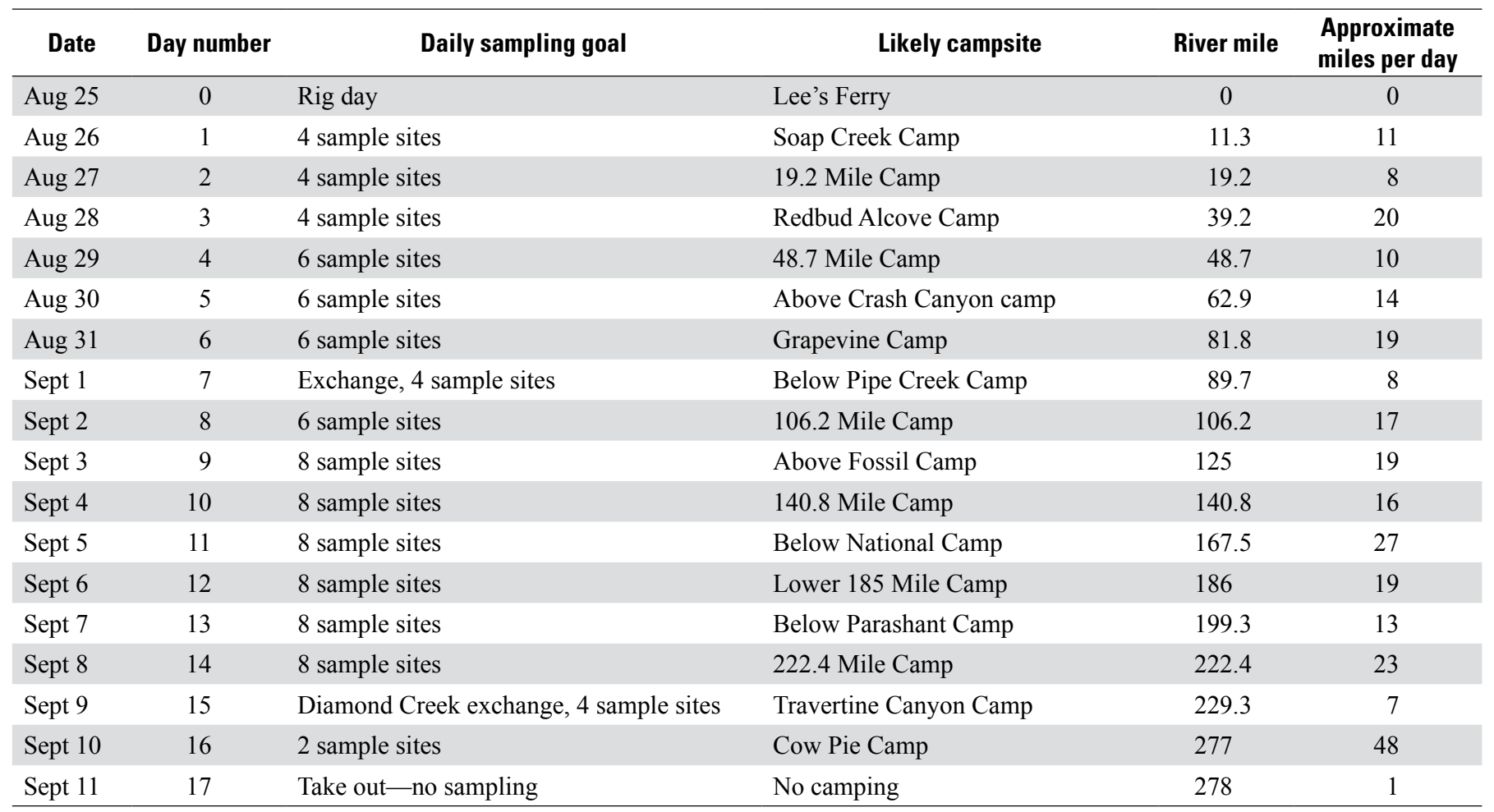


Table A4.2. Example of final participants list for riparian-vegetation monitoring along the Colorado River in Arizona between Glen Canyon Dam and Lake Mead.

[The final list of participants needs to include the first and last name of each person (except for any hired guides), what organization each person is affiliated with, any dietary restrictions, and the part of the trip each person will be on. If a volunteer has no particular affiliation, a note should be made to that effect (for example, simply, 'volunteer'). This list of participants is designed for the typical 4-boat trip; each boat contains 1 guide and 2 crewmembers. A motorboat is exchanged for the oar boats at Diamond Creek, and 5 crewmembers and 1 boat operator continue to Pearce Ferry. GCMRC, U.S. Geological Survey (USGS) Grand Canyon Monitoring and Research Center; NAU, Northern Arizona University; NCPN, Northern Colorado Plateau Network Inventory and Monitoring program]

\begin{tabular}{|c|c|c|c|}
\hline Name & Affiliation & Diet & River section \\
\hline Guide 1 & Contractor Affiliation & & Lees Ferry to Pearce Ferry \\
\hline Guide 2 & Contractor Affiliation & & Lees Ferry to Diamond Creek \\
\hline Guide 4 & Contractor Affiliation & & Lees Ferry to Diamond Creek \\
\hline Monitoring ecologist & GCMRC & & Lees Ferry to Pearce Ferry \\
\hline Vegetation cooperator & NAU & Gluten free & Lees Ferry to Pearce Ferry \\
\hline Biological technician & GCMRC & & Lees Ferry to Pearce Ferry \\
\hline NCPN technician & NCPN & & Lees Ferry to Pearce Ferry \\
\hline Volunteer 1 & GLCA & & Lees Ferry to Phantom Ranch \\
\hline Volunteer 5 & Volunteer & & Phantom Ranch to Diamond Creek \\
\hline Volunteer 6 & Volunteer & & Phantom Ranch to Diamond Creek \\
\hline \multicolumn{4}{|c|}{ Total people per monitoring-trip section } \\
\hline \multicolumn{4}{|c|}{$\begin{array}{l}\text { Lees Ferry to Phantom Ranch-12 people } \\
\text { Phantom Ranch to Diamond Creek-12 people } \\
\text { Diamond Creek to Pearce Ferry }-6 \text { people }\end{array}$} \\
\hline
\end{tabular}


Menlo Park Publishing Service Center, California

Manuscript approved for publication, February 14, 2018

Edited by Scott D. Darling

Layout and design by Cory D. Hurd 


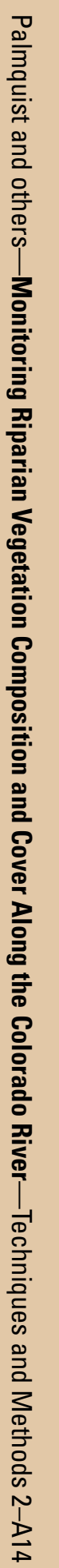

